PNL-7001

UC-607

$6 C$

\title{
Hanford Internal Dosimetry Program Manual
}
E. H. Carbaugh
M. J. Sula
D. E. Bih!
T. L. Aldridge

October 1989

Prepared for the U.S. Department of Energy under Contract DE-AC06-76RLO 1830

Pacific Northwest Laboratory Operated for the U.S. Department of Energy by Battelle Memorial Institute 


\title{
DISCLAIMER
}

This program was prepared as an account of work sponsored by an agency of the United States Government. Neither the United States Government nor any agency thereof, nor Battelle Memorial Institute, nor any or their em. ployees, makes any wamanhy, expressed or implied, or assumes any legal liability or responsibility for the accuracy, completeness, or usefulness of any information, apparatus, product, or process disclosed, or represents that its use would not infringe privately owned rights. Reference herein to any specific commercial produc, process, or service by trade name, trademark, manufacturer, or otherwise, does not necessarily constitute or imply its endorsement, recommendation, or favoring by the United States Government of any agency thereof, or Battelle Memorial Institute. The views and opinions of authors expressed herein do not necessarily state or reflect those of the United States Government or any agency thereof.

\author{
PACIFIC NORTHWEST LABORATORY \\ operated by \\ BATTELLE MEMORIAL INSTITUTE \\ for the \\ UNITED STATES DEPARTMENT OF ENERGY \\ under Contract DE-AC06-76RLO 1830
}

Printed in the United States of America

Available to DOE and DOE contractors from the

Office of Scientific and Technical Information, P.O. Box 62, Oak Ridge, TN 37831; prices available from (615) 576-8401. FTS 626-8401.

Available to the public from the National Technical Information Service,

U.S. Department of Commerce, 5285 Port Royal Rd., Springfield, VA 22161.

NTIS Price Codes, Microfiche A07

\begin{tabular}{|c|c|}
\hline \multicolumn{2}{|c|}{ Printed Copy } \\
\hline Pages & $\begin{array}{l}\text { Price } \\
\text { Codes }\end{array}$ \\
\hline $001-025$ & $\mathrm{A02}$ \\
\hline $026-050$ & $\mathrm{~A} 03$ \\
\hline $051-075$ & $\mathrm{~A} 04$ \\
\hline $076-100$ & $\mathrm{~A} 05$ \\
\hline $101-125$ & A06 \\
\hline $126-150$ & $\mathrm{~A} 07$ \\
\hline 151.175 & $A O B$ \\
\hline $176-200$ & $A 09$ \\
\hline $201-225$ & $\mathrm{~A} 10$ \\
\hline $226-250$ & A11 \\
\hline 251.275 & A 12 \\
\hline $276-300$ & A13 \\
\hline
\end{tabular}


PNL-7001

HANFORD INTERNAL DOSIMETRY PROGRAM MANUAL
E. H. Carbaugh
M. J. Sula
D. E. Bihl
T. L. Aldridge

October 1989

Prepared for the U.S. Department of Energy under Contract DE-AC06-76RLO 1830

Pacific Northwest Laboratory

Richland, Washington 99352 


\section{SUIMARY}

This document describes the Hanford Internal Dosimetry Program, as it is administered by Pacific Northwest Laboratory (PNL) in support of the U.S. Department of Energy and its Hanford contractors. Program services include administrating the bioassay monitoring program, evaluating and documenting assessments of internal exposure and dose, ensuring that analytical laboratories conform to requirements, selecting and applying appropriate models and procedures for evaluating internal radionuclide deposition and the resulting dose, and technically guiding and supporting Hanford contractors in matters regarding internal dosimetry.

Specific chapters deal with the following subjects:

- practices of the progran, including interpreting applicable DOE Orders, regulations, and guidance into criteria for assessment, documentation, and reporting of doses

- assessment of internal dose, including sumary explanations of when and how assessments are performed

- recording and reporting of practices for internal dose

- selection of workers for bioassay monitoring and establishment of type and frequency of bioassay measurements

- capability and scheduling of bioassay monitoring services

- recommended dosimetry response to potential internal exposure incidents

- quality control and quality assurance provisions of the program.

In addition, appendixes describe the bioassay measurement screening and follow-up levels used by the progran, illustrate the available on-line computerized data retrieval capability, briefly describe the analytical procedures used for measurements, and include copies of the bioassay sampling kit instructions. 
This document was originally developed as a controlled manual with distribution limited to those Hanford site personnel who routinely use the program services. The uncontrolled version of the manual was prepared for distribution to those having an interest in the services offered by the program but who do not actually use those services. The manual should not be considered applicable to facilities or circumstances other than Hanford, and reflects the operational practices only as they existed as of July 1989. There is no plan or intent to update the uncontrolled copies as changes are made in the Hanford program. 


\section{GLOSSARY}

analysis code:

annual dose:

bioassay:

can-not-out:

chest measurement:

committed dose equivalent:

contractual detection level:

dose assessment:

effective dose equivalent:

evaluation report:

(a) American National Standards Institute (ANSI). 1987. Performance Criteria for Radiobioassay. Draft ANSI Standard N13.30, New York, New York. a code for computerized scheduling of the type of analys is desired. For example, IPU denotes analysis for $238 \mathrm{Pu}$ and $239+240 \mathrm{Pu}$.

the dose received or assigned to a particular calendar year.

measurement of amount or concentration of material (usually radioactive material) in the body or in biological material excreted or removed from the body and analyzed for purposes of estimating the quantity of material in the body (according to draft American National Standards Institute [ANSI] Standard N13.30).(a)

a term denoting that the worker took the sample kit inside his/her residence but did not put it out on collection day.

direct measurement of radioactivity deposited in the chest region. Includes contributions from activity in the lung and skeleton.

the dose equivalent to an organ or tissue, or the effective dose equivalent, committed over a total 50-year period following an acute intake or onset of chronic intake of radioactivity.

a negotiated level of activity in a sample whose detection the Analytical Services Laboratory (Lab) must demonstrate at least 95\% of the time. Minimum detectable amounts as defined by draft ANSI N13.30(a) are generally equal to or less than the contractual detection level.

the evaluation and assignment of a specific dose associated with a specific intake. Documented by an evaluation report.

the sum of the products of the dose equivalent to organs and tissues of the body and the respective weighting factors as designated in DOE 5480.11 (1989). This dose is comparable to an equal dose received by total body exposure to gamma radiation.

the formal documentation of an assessment of internal dose. The evaluation report is filed by Radiological Records in the worker's occupational radiation exposure file. 
Exposure Evaluator:

Field Dosimetry:

field monitoring:

follow-up level:

head measurement:

insufficient volume:

internal dose:

Internal Dosimetry:

in vivo measurement: kit:

kit code:

lost in lab:

lost kit:

lung count: the individual responsible for assessing and documenting internal dose.

the components within a contractor organization having internal exposure radiation protection responsibilities.

monitoring performed at facilities, including air sampling, personal contamination surveys, etc.

the minimum level of a bioassay measurement result at which a follow-up investigation is started. If the measurement is confinmed, a dose assessment is made.

direct bioassay measurement of radioactive content of the head. The measurement is used to estimate total skeleton content, and to correct a chest count to give an estimate of lung content.

a urine sample less than $500 \mathrm{ml}$ that is scheduled for routine processing. This sample will not be analyzed, and another sample should be submitted.

the dose equivalent to an organ or tissue or to the effective whole body from radionuclides taken into the body. The period during which the dose is received is usually a calendar year or a 50-year period, although other time periods may be specified.

the staff within the Pacific Northwest Laboratory's (PKL's) Occupational and Environmental Protection Section assigned to the Hanford Internal Dosimetry Program.

direct measurement of radioactivity in the body.

a package containing bioassay sample containers. Usually one kit is used for each sample, but sometimes two kits are used to obtain one 24-hour total sample (work fraction and home fraction).

a code designating the type of sample to be collected. (See Appendix B, Table B.4 for a comprehensive list of kit codes.)

a sample that was lost during analysis. No results can be obtained.

a kit that was not retrievable by the Lab. A "can-notout" becomes a lost kit if it is not retrieved in 5 days.

direct bioassay measurement to determine the activity in the lung. The measurement is determined from the results of a chest count minus the activity that is contributed from the skeleton. 
minimum detectable activity:

no sample:

organ dose equivalent: processing code:

Radiological Records: the sitewide support program, operated by PNL, that maintains occupational radiation records for the Hanford Site.

reason code:

reporting level:

screening level:

sequential analyses: term that denotes more than one radiochemical analysis done on a single sample. For example, IPS is the analysis code for an IPU analys is and a $90 \mathrm{Sr}$ analysis, on the same sample.

statement of work: The technical and administrative specification of work to be performed under contract by the Analytical Services Laboratory. whole body measurement: direct bioassay measurement to determine the amount of
high-energy gamma-emitting radionuclides in the total body.

(a) American National Standards Institute (ANSI), 1987. Performance Criteria for Radiobioassay. Draft ANSI Standard N13.30, New York, New York. 


\section{ACRONYMS/ABBREVIATIONS}

ANSI

ALI

BCSR

$C L$

DAC

DAC-hours

DOE

DOE-RL

DTPA

EDF

EE

EPA

GPS

HEHF

HMS

ICRP

IDP

INTERTRAC

Lab

MDA

NAD

NCRP

NIST

O\&EP

ORE

PADI
Anerican National Standards Institute

annual limit on intake

Boeing Computer Services-Richland

contractual detection level

derived air concentration

time-integrated exposure to airborne contamination

U.S. Department of Energy

U.S. Department of Energy-Richland Operations Office

diethylenetriamine pentaacetic acid

Emergency Decontamination Facility

Exposure Evaluator

U.S. Environmental Protection Agency

Good Practices Standard

Hanford Environmental Health Foundation

Hanford Medical Scheduling

International Commission on Radiological Protection

(Hanford) Internal Dosimetry Program

Internal Dose Tracking System

Analytical Services Laboratory

minimum detectable activity/amount

Nuclear Accident Dosimeter

National Council on Radiation Protection and Measurements

National Institute of Standards and Technology

Occupational and Environmental Protection (Section)

occupational radiation exposure

pocket alarming dose integrator 
PNL

POC

QA

QC

REIRS

RPT

UDAC

WBC
Pacific Northwest Laboratory

Patrol Operations Center

quality assurance

quality control

Radiation Exposure Information Reporting System

Radiation Protection Technologist

Unified Dose Assessment Center

Whole Body Counter 


\section{ACKNOWLEDGMENTS}

The authors gratefully acknowledge the invaluable contributions of Susan Ennor as editor and Marianna Cross as word processor. 


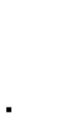




\section{CONTENTS}

SUMMARY

$\mathbf{i} i$

GLOSSARY

ACRONYMS/ABBREVIATIONS

ACKNOWLEDGMENTS

$\mathrm{ix}$

1.0 INTRODUCTION

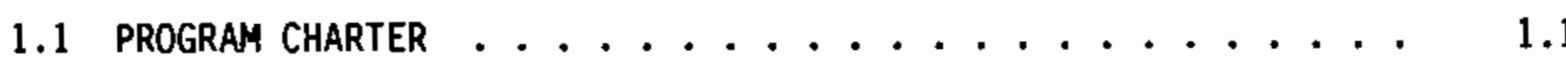

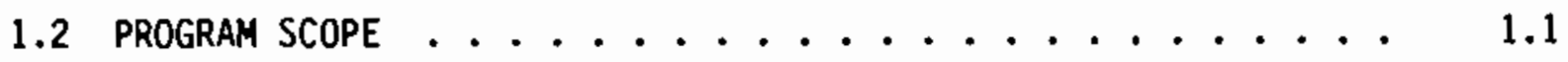

1.3 Limitations OF SERVICE . . . . . . . . . . . . . . . . 1.2

1.4 HANFORD INTERNAL DOSIMETRY PROGRAM SERVICES $\ldots \ldots \ldots$

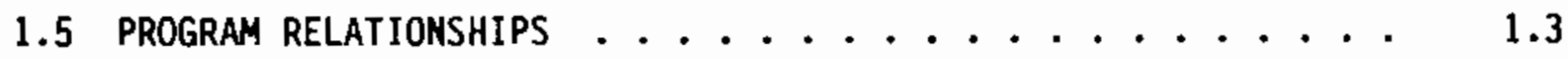

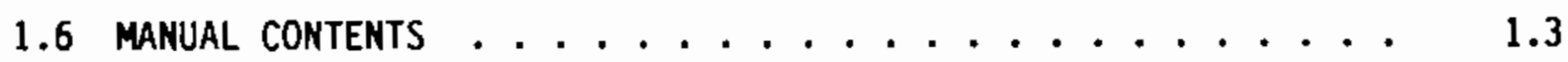

2.0 PRACTICES OF THE HANFORD INTERNAL DOSIMETRY PROGRAM . . . . . 2.1

2.1 ASSESSMENT AND DOCUMENTATION OF INTERNAL DOSE $\ldots \ldots \ldots$

2.1.1 Criteria for Assessing Internal Dose ....... 2.1

2.1.2 Dose Assessment Practices . . . . . . . . 2.2

2.1.3 Documentation of Dose Assessments ........ 2.3

2.1.4 Revisions and Updates................... 2.4

2.2 REPORTS OF INTERNAL DOSE ....................... 2.4

2.2.1 Reports Provided to Contractor Dosimetry
Organizations . . . . . . . . . . . . 2.4

2.2.2 Reports Provided to Radiological
Records . . . . . . . . . . . . . . 2.5

2.3 BIOASSAY MONITORING . . . . . . . . . . . . 2.6

2.4 PROGRAM DOCUMENTATION . . . . . . . . . . . . . . . 2.6

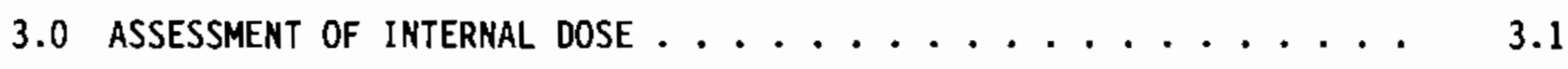

3.1 GENERAL DESCRIPTION OF AN INTERNAL EXPOSURE

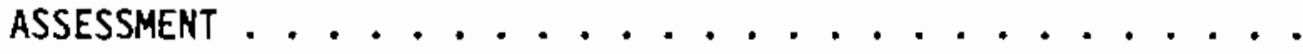


3.1.1 Criteria for Performing an Assessment . . . . . 3.1

3.1 .2 Types of Assessments ............. 3.1

3.1 .3 General Approach .............. 3.2

3.1.4 Exposure Assessment Situations ......... 3.3

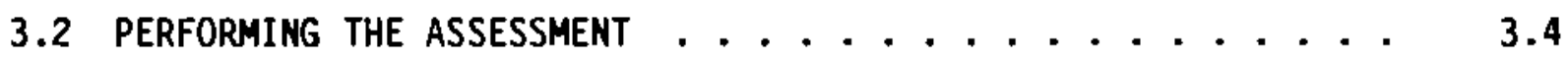

3.2 .1 Investigation ................... 3.4

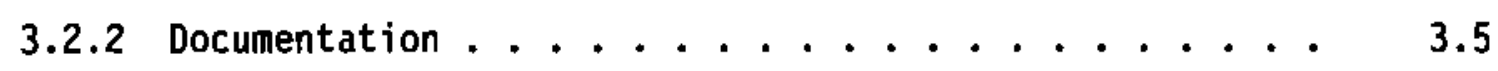

3.2 .3 Reporting ................. 3.8

3.3 DOSE ASSESSMENT METHODS . . . . . . . . . . . . 3.8

3.3.1 General Approach . . . . . . . . . . 3.9

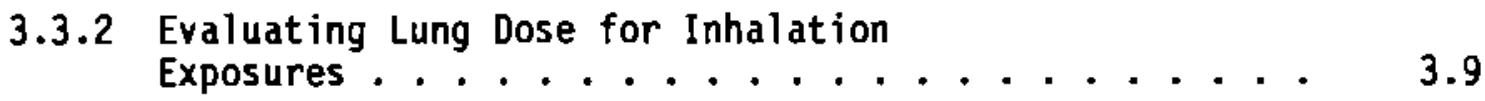

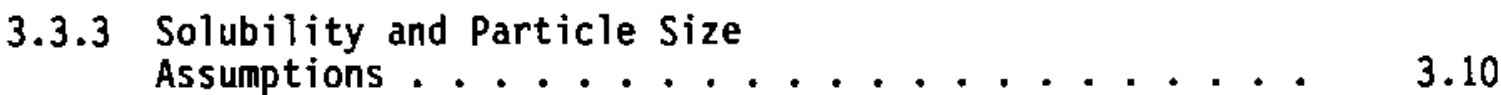

3.3.4 Radionuclides Included in the
Assessment ........................ 3.10

3.3.5 Assessment of Exposures of Localized ......... 3.10

3.3.6 Biokinetic Models ............... 3.10

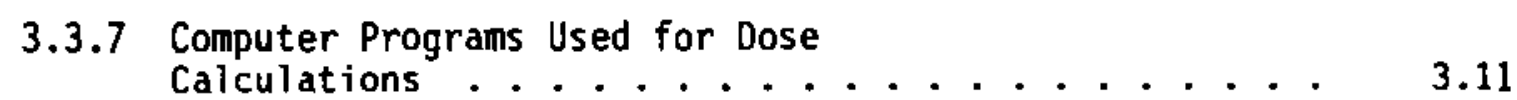

3.3.8 Simplified Dose Assessments . . . . . . . . . 3.12

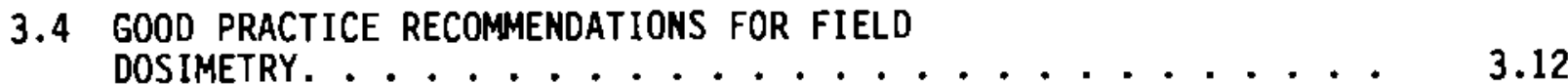

3.4.1 Identifying Routine Bioassay Monitoring
Needs . . . . . . . . . . . . 3.13

3.4.2 Identifying Potential Internal Exposures. . . . . . 3.13

3.4.3 Managing Internal Exposures............ 3.14

4.0 RECORDING AND REPORTING INTERNAL DOSES . . . . . . . . . 4.1

4.1 INTERNAL DOSE RECORDS ..................... 4.1

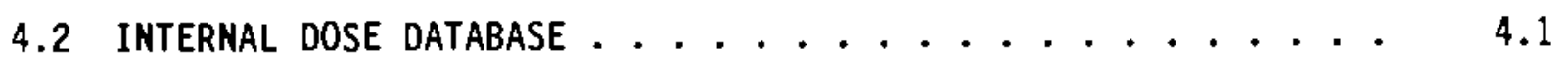


4.3 REPORTS OF INTERNAL DOSE . . . . . . . . . . . 4.2

4.4 REQUESTS FOR INTERNAL DOSIMETRY RECORDS . . . . . . . 4.3

5.0 BIOASSAY MONITORING ............................. 5.1

5.1 CONDITIONS FOR MONITORING WORKERS $\ldots \ldots \ldots . \ldots . \ldots . \ldots$

5.1 .1 Derived Air Concentration .......... 5.2

5.1 .2 Annual Limit on Intake ............ 5.4

5.1 .3 DAC-hours ................... 5.5

5.1 .4 Nature of Work ............. . 5.6

5.1.5 Long-Term Follow-Up of a Prior
Deposition ..................... 5.6

5.1.6 Beginning and Ending Work Bioassay. . . . . . . 5.6

5.1 .7 0ffsite Exposure ............. 5.7

5.1 .8 visitors ................. 5.7

5.1.9 Pregnant Women and Minors ........... 5.7

5.2 SELECTION OF NUCLIDES FOR BIOASSAY . . . . . . . . . 5.7

5.3 BIOASSAY MEASUREMENT FREQUENCY . . . . . . . . . . . 5.8

5.3.1 Typical Bioassay Frequencies .......... . 5.9

5.3.2 Frequencies for Multiple Nuclides . . . . . . . 5.9

5.3 .3 Uranium Bioassay . . . . . . . . . . . 5.9

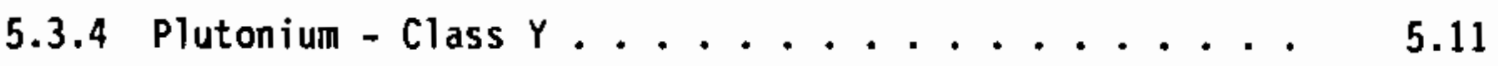

5.3.5 Special Forms of Nuclides ............. 5.11

6.0 BIOASSAY SERVICES . . . . . . . . . . . . . . . 6.1

6.1 INDIRECT BIOASSAY MEASUREMENT SERVICES . . . . . . . . 6.1

6.2 IN VIVO MEASUREMENT SERVICES . . . . . . . . . . . . 6.2

6.2 .1 Whole Body Counts . . . . . . . . . . 6.2

6.2 .2 Chest Counts .................... 6.9

6.2 .3 Special Counts .................. 6.9

6.3 SCHEDULING AND RECORD KEEPING . . . . . . . . . 6.12 
6.3.1 Contacting the Horker .............

6.3.2 Scheduling Indirect Bioassay

Measurements .............. . . 6.12

6.3.3 Reporting Results from Indirect

Measurements ............... 6.14

6.3.4 Scheduling In Vivo Bioassay

Measurements ............. 6.16

6.3.5 Reporting Results of In Vivo

Measurements ............. 6.18

6.3.6 Reporting "No Shows" . . . . . . . . . . . 6.19

6.4 FOLLOW-UP MEASUREMENTS AND REPORTS . . . . . . . . . 6.19

6.4.1 Indirect Bioassay Measurements ......... 6.19

6.4 .2 In Vivo Measurements ............. 6.20

6.5 OCCUPATIONAL RADIATION EXPOSURE DATABASE . . . . . . . 6.21

7.0 INTERNAL EXPOSURE INCIDENT RESPONSE . . . . . . . . . . 7.1

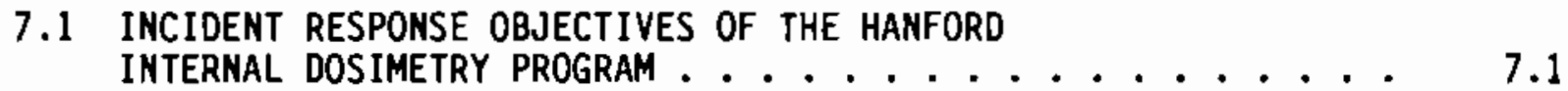

7.2 INCIDENT RESPONSE SERVICES PROVIDED BY THE

HANFORD INTERNAL DOSIMETRY PROGRAM .......... 7.1

7.3 DETERMINATION OF THE NEED FOR INTERNAL

DOSIMETRY SUPPORT . .................... 7.2

7.3.1 Notifications for Prompt Internal

Exposure Evaluation and Dose

Reduction Therapy.............. 7.3

7.3.2 Information to Provide When Notifying . . . . . . . . 7.5
the Exposure Evaluator . .

7.4 CONTACTING the EXPOSURE EVALUATOR . . . . . . . . . 7.5

7.4 .1 Preferred Method ............. 7.5

7.4 .2 Alternate Methods . . . . . . . . 7.5

7.5 EXPOSURE EVALUATOR RESPONSE TO INCIDENTS . . . . . . 7.6

7.5.1 Receiving Incident Notification . . . . . . . 7.6 
7.5.2 Scheduling and Performing Bioassay

Measurements ............... 7.7

7.5 .3 Dose Assessment Capability . . . . . . . . 7.9

7.6 GUIDANCE FOR EXPOSURE EVALUATOR RESPONSE

TO INCIDENTS ........................... 7.10

7.6.1 Managing Externally Contaninated .................... 7.10

7.6.2 Managing Externally Contaminated
Injured Workers . . . . . . . . . . . 7.11

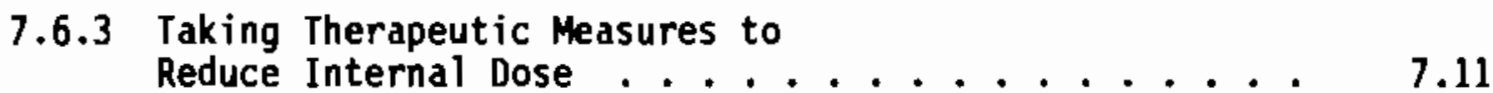

7.6.4 Releasing Horkers Following an Incident ....... 7.12

7.6.5 Assisting in External Radiation Exposure

Situations ................. 7.12

7.6.6 Requesting Region 8 Radiological

Assistance Program Teams ........... 7.12

7.6.7 Requesting Activation of the Unified

Dose Assessment Center ............ 7.12

7.6.8 Requesting Offsite Assistance . . . . . . . . 7.13

8.0 QualitY ASSURANCE . . . . . . . . . . . . . 8.1

8.1 QUALITY ASSURANCE AND QUALITY CONTROL

FOR BIDASSAY ANALYSES ............... 8.1

8.1.1 Analytical Services Laboratory. . . . . . . . 8.1

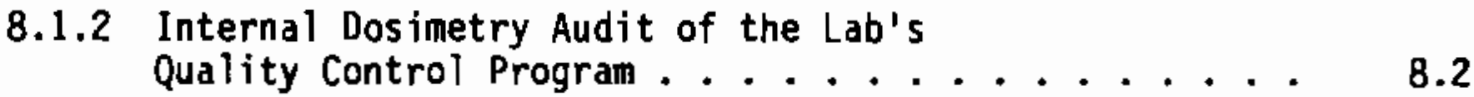

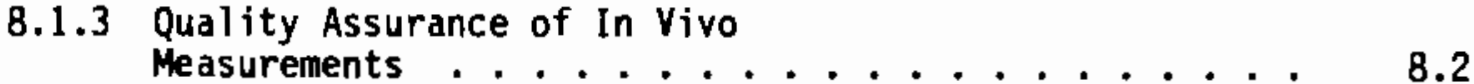

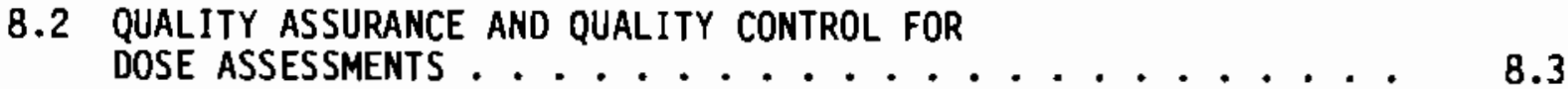

8.3 INTERNAL DOSIMETRY PROGRAM RECDRDS . . . . . . . . 8.3

9.0 DOCUMENTS AND RECORDS . . . . . . . . . . . . . . . 9.1

9.1 PROgRamatic documentation . . . . . . . . . . . . 9.1

9.2 TECHNICAL ASSESSMENT DOCUMENTATION . . . . . . . . . 9.2 
9.3 DOCUMENTATION OF ChANGES . . . . . . . . . . . 9.2

9.3.1 Program Change Record . . . . . . . . . . . . 9.7

9.3.2 Revision/Update of Documents and Manuals . . . . . 9.7

9.3.3 Revision of Technical Assessments . . . . . . . 9.8

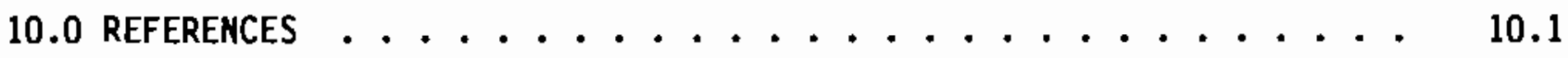

APPENDIX A - REPORTING, SCREENING, AND FOLLOH-UP LEVELS

FOR ROUTIME BIOASSAY MEASUREMENTS ........... A.1

APPENDIX B - COMPUTER REPORT SCREENS AND CODES OF THE

OCCUPATIONAL RADIATION EXPOSURE DATABASE ........

APPENDIX C - ANALYTICAL PROCEDURES . . . . . . . . . . c. c.

APPENDIX D - SAMPLE KIT INSTRUCTIONS .............. D. . .

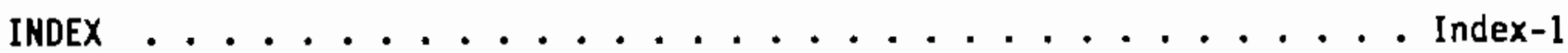




\section{FIGURES}

3.1 Internal Dose Assessment Process Flow Chart . . . . . . . . 3.5

9.1 Hanford IDP Programmatic Documentation ........... 9.2

B.1 ORE Master Menu ................... B.2

B.2 Available Records - Submenu ............... B.3

B.3 Data Retrieval - Submenu . . . . . . . . . . . . B.4

B.4 Available Records - Bioassay Results Screen............ B.5

B.5 Available Records - In Vivo Records Screen . . . . . . . B. B.6

B.6 Available Records - Dosimeter Results Screen . . . . . . . B B.7

B.7 Available Records - Incident Records Screen . . . . . . . . B B.8

B.8 Available Records - Schedules Screen ............ B.9

B.9 Data Retrieval - Emergency Search Screen . . . . . . . . . B.10

B.10 Data Retrieval - Bioassay Display Screen . . . . . . . . B.11

B.11 Data Retrieval - In Vivo Display Screen . . . . . . . . B. B.12

B.12 Data Retrieval - Incident Display Screen . . . . . . . . B.13

B.13 Emergency Search - Bioassay Results Screen ........... B.14

B.14 Emergency Search - In Vivo Disptay Screen . . . . . . . . . B.15 


\section{TABLES}

3.1 Dose Assessment Situations . . . . . . . . . . . . 3.3

3.2 Information Supporting the Internal Dose Assessment . . . . . 3.6

3.3 Excretion Functions ................. 3.11

3.4 Computer Programs Used for Dose Calculations . . . . . . . . 3.12

5.1 Derived Air Concentrations and Annual Limits on
Intake for Comanon Radionuclide Mixtures . . . . . . . . 5.3

5.2 Potential Intake Fractions as a Function of Containment Type and Physical Form ........... 5.5

5.3 Potentially Undetected Effective Dose Equivalent for Bioassay Measurements for Single Radionuclides . . . . . . 5.10

5.4 Example Bioassay Programs for Some Typical Radionuclide Combinations .................

6.1 Analytical and Reporting Requirements for Routine

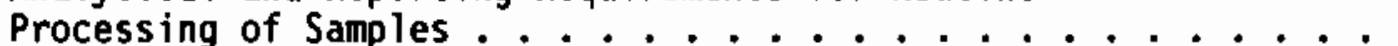

6.2 Analytical and Reporting Requirements for Priority Processing of Samples.................. 6.4

6.3 Analytical and Reporting Requirements for Expedite Processing of Samples ................

6.4 Analytical and Reporting Requirements for Emergency Processing of Samples ................ 6.6

6.5 Contractual Detection Levels for Routine, Priority, and Expedite Processed Gama Spectroscopy Analyses. . . . . . . . 6.7

6.6 Contractual Detection Levels for Emergency Processing of Gamtna Spectroscopy Analyses . . . . . . . . 6.8

6.7 Accuracy and Sensitivity for Whole Body Counts

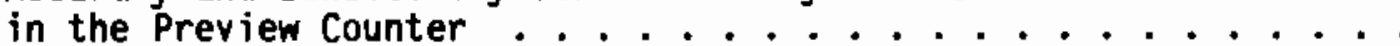

6.8 Accuracy and Sensitivity for In Vivo Measurements of Comon Radionuclides Using Various Numbers of Germanium Planar Detectors .............. 6.11

6.9 Reason Codes for Indirect Bioassay Measurement . . . . . . . 6.13

6.10 Reason Codes for In Vivo Bioassay Counting . . . . . . . . 6.17

7.1 Contamination Levels for Notification of the Hanford Environmental Health Foundation . . . . . . . . 7.4 
7.2 Contamination Levels for Internal Dosimetry . . . . . . . . 7.4

7.3 Typical Incident Response Bioassay Measurements and Their Purposes ...................... 7.8

7.4 Example Protocols for Incident Bioassay Measurements . . . . . 7.9

9.1 Summary of Programatic Documents for the Hanford Internal Dosimetry Progran .............. 9.3

9.2 Summary of Technical Assessment Documents for the Hanford Internal Dosimetry Program ............ 9.5

A.1 Routine Bioassay Measurement Results Indicative of a Potential Internal Exposure of $10 \mathrm{mrem}$ First-Year Effective Dose Equivalent

A.2 Screening and Follow-Up Levels for Possible Chemical Toxicity ...................

B.1 Company Codes ................... B.16

B.2 Sample type Codes . . . . . . . . . . . . . B.19

B.3 Sample Reason Codes for Excreta . . . . . . . . . . B.20

B.4 Sample Kit Codes . . . . . . . . . . . . . B.22

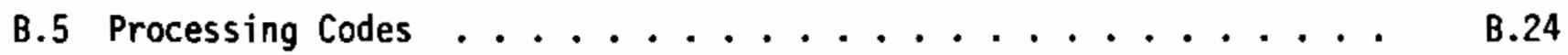

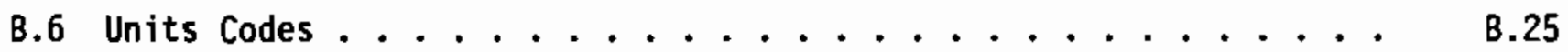

B.7 Multiple Results Codes . . . . . . . . . . . . . B. B.26

B.8 Bioassay Frequency Codes . . . . . . . . . . . . B. B. . B

B.9 Reason Codes for In Vivo Measurements . . . . . . . . B.28

B.10 Body Location Codes for In Vivo Measurements . . . . . . . B B.30

B.11 In Vivo Detector Codes . . . . . . . . . . . B.31

B.12 Mode of Intake Codes . . . . . . . . . . . . . B.33

B.13 Contacts and Special Analysis Requests ............ B.34

B.14 ORE Isotope Codes ................... B. . . . . . .

B.15 Codes for in vivo Schedule Types ............. B. . B

B.16 In Vitro No-Result Codes . . . . . . . . . . . . B.37 


\section{EXHIBITS}

3.1 Internal Dose Evaluation Report Form . . . . . . . . 3.15

6.1 Employee and Dosimetry Changes Form . . . . . . . . . . . 6.22

6.2 Field Dosimetry Bioassay Request Form . . . . . . . . . . 6.23

6.3 Sample Form - Bioassay Urine Sample Results . . . . . . . . 6.24

6.4 Sample Letter - Preliminary Analysis of

In Vivo Examination ................... 6.25

6.5 Sample Letter - In Vivo Measurements Results . . . . . . . . 6.26

7.1 Check List for Incident Data . . . . . . . . . . . . 7.14

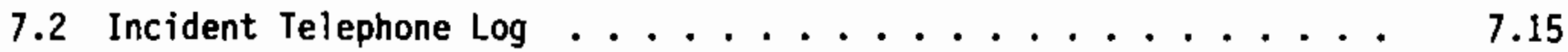

9.1 Program Change Record . . . . . . . . . . . . . . 9.9

D.1 Instructions for Kit Code $1 \ldots \ldots \ldots . \ldots . \ldots . \ldots . \ldots . \ldots$

D.2 Instructions for Kit Code $2 \ldots \ldots \ldots$. . . . . . . .

D.3 Instructions for Kit Code $\ldots \ldots \ldots$. . . . . . . .

D.4 Instructions for Kit Code $\ldots \ldots \ldots$. . . . . . . . . .

0.5 Instructions for Kit Code $\ldots \ldots \ldots$ D.7

D.6 Instructions for Kit Code $6 \ldots \ldots$. . . . . . . . . . .

D.7 Instructions for Kit Code $7 \ldots \ldots$. . . . . . . . . . . . .

D.8 Instructions for Kit Code $8 \ldots \ldots$. . . . . . . . . . .

D.9 Instructions for Kit Code $9 \ldots \ldots$. . . . . . . . . . . 


\section{CHAPTER 1.0}

INTRODUCTION 


\subsection{INTRODUCTION}

The Hanford Internal Dosimetry Progran (IDP) was initiated in late 1944. By 1946, a routine progran had been established at Hanford to assess and document occupational doses to employees from intakes of radionuclides.

\subsection{PROGRAM CHARTER}

The current IDP is a sitewide service program operated by the Pacific Northwest Laboratory (PNL) for all Hanford U.S. Department of Energy (DOE) and DOE-contractor personnel. It is funded by the DOE-Richland Operations office (DOE-RL), and is administered and staffed by the PNL Occupational and Environmental Protection (O\&EP) Section. The Hanford Site Services Handbook (RL 1983) assigns by charter the following responsibilities to PHL:

- Assess and document occupational doses from intakes of radionuclides.

- Determine compliance with applicable internal dose standards.

- Administer the routine bioassay monitoring program required by site contractors.

- Provide technical guidance to contractors on internal dosimetry matters.

- Establish models for evaluating internal radionuclide deposition.

\subsection{PROGRAM SCOPE}

The scope of the IDP is limited to the support of Hanford contractor radiation protection efforts to the extent specified in the charter statement above. It is assumed that site contractors protect their workers from internal exposures to radioactivity and determine the extent to which the IDP is applied. This includes identifying needs for bioassay monitoring and determining when potential internal exposures have occurred.

Air sampling, contamination surveys, and other field monitoring techniques provide the primary means of identifying evidence of internal exposures at Hanford facilities. Routine bioassay monitoring is considered a secondary means of identifying internal exposures. 


\subsection{PROGRAM SCOPE (contd)}

It is assumed that each contractor communicates to the workers the need for bioassay measurements and the need to address questions regarding measurements. The IDP staff discuss measurement results with workers on an individual basis if so requested by the contractor, and also deal with specific questions if contacted directly by workers. It is the intent of the IDP that the contractor dosimetry organization be the focal point for all communication with workers regarding dosimetry needs and concerns.

\subsection{LIMITATIONS OF SERVICE}

The IDP capabilities are limited by the degree to which contractors use the available services. The IDP provides consultation and advisory services to contractors for developing and establishing bioassay programs. However, it is assumed that the contractor bears the direct responsibility for determining that workers receive adequate and appropriate bioassay monitoring.

The IDP provides bioassay services that, if properly used, should be capable of identifying and evaluating an intake resulting in a first-year effective dose equivalent of 100 mrem. However, the capability for such sensitivity depends, in some cases, on early identification of potential intakes by the contractor using regular workplace monitoring and personal survey techniques. Because the routine bioassay monitoring program uses only periodic measurements, it does not necessarily provide adequate sensitivity to detect intakes resulting in first-year effective dose equivalents of $100 \mathrm{mrem}$.

\subsection{HAMFORD INTERNAL DOSIMETRY PROGRAM SERVICES}

The Hanford IDP is administered as specified by the Hanford contractors and, for the benefit of all site employees, provides services to

- administer the routine bioassay monitoring program for internally deposited radionuclides

- investigate and document evaluations of potential internal exposures for exposure record files and contractor staff

- ensure that the Analytical Services Laboratory conforms to the requirements of the analytical services contract 


\subsection{HANFORO INTERNAL DOSIMETRY PROGRAM SERVICES (contd)}

- select and apply appropriate mode1s, procedures, and practices for evaluating internal radionuclide deposition and the resulting dose

- technically guide and support Hanford contractors in matters regarding internal dosimetry.

The IDP is comitted to quality service that meets or exceeds DOE regulations and guidance, uses methods and practices recommended by appropriate national and international organizations, and actively explores needed improvements in technology and techniques.

\subsection{PROGRAM RELATIONSHIPS}

The IDP works closely with Hanford contractor dosimetry organizations to provide a comprehensive internal dosimetry service. However, the IDP has no direct responsibility to ensure protection of workers, to monitor or conduct surveillance of work environments, to operate facilities, or to assure worker cooperation with bioassay measurement requests. Such items are considered to be the responsibilities of the contractor.

The IDP also interfaces with other sitewide service programs operated by PNL, including Radiological Records, Whole Body Counting, External Dosimetry, Analytical Support Services, and the Emergency Preparedness Project.

\subsection{MANUAL CONTENTS}

This Hanford Internal Dosimetry Program Manual is one of three programmatic documents of the IDP. The other two programatic documents are the Technical Basis for Internal Dosimetry at Hanford (Sula, Carbaugh, and Bihl 1989) (hereafter referred to as the Technical Basis) and an internal manual documenting internal dosimetry procedures at Hanford. Chapter 9.0 discusses the purpose, scope, and interrelationship of these three documents.

This manual contains the following:

- the policies upon which the design and operation of the IOP are based (Chapter 2.0) 


\section{I.6 MANUAL CONTENTS (contd)}

- a description of the internal exposure assessment methods and process and good practice recommendations for Hanford contractors to implement IDP policies in their radiation protection prograns (Chapter 3.0)

- internal dose recording and reporting practices (Chapter 4.0)

- recomendations for participation in a bioassay monitoring program, including measurement types and frequencies (Chapter 5.0)

- a description of the available bioassay services and explanations of how to obtain them (Chapter 6.0)

- IDP response to potential internal exposure incidents (Chapter 7.0)

- the quality assurance and quality control features of the IOP (Chapter 8.0 )

- a brief summary of the programatic and technical assessment documents and use of Program Change Records to document any program changes (Chapter 9.0).

In addition, Appendix $A$ lists screening and follow-up levels for routine bioassay measurements. Appendix B contains complementary figures of computer report screens and tables of data field codes. Appendix $C$ describes the analytical procedures used by the Analytical Services Laboratory to analyze samples, and Appendix D contains copies of the instructions for each type of sample bioassay kit. 
CHAPTER 2.0

\section{PRACTICES OF THE HANFORD INTERNAL DOSIMETRY PAOGRAM}




\subsection{PRACTICES OF THE HANFORD INTERNAL DOSIMETRY PROGRAM}

It is IDP policy to comply with DOE Orders. Similarly, it is IDP practice to follow the guidance and good practice recommendations issued through the International Commission on Radiological Protection (ICRP), National Council on Radiation Protection and Measurements (NCRP), U.S. Environmental Protection Agency (EPA), DOE, and Anerican National Standards Institute (ANSI) to the extent practical.

The following subsections describe the conduct of the internal dosimetry program and provide for interpretation of applicable regulations and guidance for application at Hanford.

\subsection{ASSESSMENT AND DOCUMENTATION OF INTERNAL DOSE}

This section contains criteria for assessment, documentation, and revision of internal doses at Hanford.

\subsubsection{Criteria for Assessing Internal Oose}

Assessment of potential internal exposure is conducted for

- any potential occupational intake reported to Internal Dosimetry by site radiation protection organizations

- any bioassay measurement that indicates a potential occupational internal exposure, not previously evaluated, resulting in an annual internal effective dose equivalent greater than 10 mrem

- any "new hire" or "beginning work" bioassay measurement that indicates any detectable intake not previously evaluated

- any employee, hired by DOE-RL or a DOE contractor, who has incurred an occupational internal exposure.

The initial assessment generally should include confirmatory bioassay measurements. To the extent practicable, confirmatory bioassay measurements should consist of the following:

- a minimum of one bioassay measurement following a workplace indication of an intake, or

- a minimum of two bioassay measurements following a bioassay indication of an intake. 


\subsubsection{Criteria for Assessing Internal Dose (contd)}

A potential intake is considered to be confirmed if

- follow-up bioassay measurements show detectable levels of internal radioactivity not associated with background or previously identified intakes, or if

- follow-up bioassay measurements were not performed according to the criteria for confirmatory bioassay measurements ( 1 isted above) and there is no overriding evidence that an occupational intake did not occur.

\subsubsection{Dose Assessment Practices}

Where appropriate bioassay data are available, they constitute the primary basis for assessment of internal dose. Horkplace monjtoring data (such as air samples) or other means may be used to assess dose in cases where appropriate bioassay data are not available.

If the available evidence suggests that the annual effective dose equivalent from an intake does not exceed 100 mren, generalized (default) models and assumptions may be used, where specific information is not readily available, to assess the dose. These general assumptions are as follows:

- The intake is assumed to occur by inhalation.

- The intake is acute.

- If the actual intake date(s) is unknown, the intake occurs at the midpoint of the potential exposure period for acute intakes or throughout the potential exposure period for chronic intakes.

- For monitored workers, the potential exposure period extends back one monitoring period unless known to be otherwise.

- The radionuclides that were observed in bioassay measurements or were otherwise known to be present are included in the assessment.

- The physiological characteristics of Reference Man (ICRP 1974) are assumed.

- The biokinetic models and parameters described in the Technical Basis are used for radionuclides included in the document; otherwise models and parameters endorsed or prescribed by the NCRP or ICRP are used. 


\subsubsection{Dose Assessment Practices (contd)}

At projected annual effective dose equivalents above 100 mrem, actions are taken as follows:

- Bioassay and exposure characterization data are obtained to enable adjustments to be made to the default assumptions and models, as appropriate.

- All radionuclides potentially involved in the exposure are considered, including those not specifically identified in the initial bioassay measurements but expected to be present.

At projected annual effective dose equivalents above 1500 mrem, consideration is given to individual-specific physiological characteristics.

Dose equivalents are recorded as calculated for each assessment, with the following special provisions:

- Quantified doses of less than 10 mrem are rounded to the nearest whole number, and doses of 10 mrem or greater may be rounded to two significant figures.

- Organ dose equivalents are recorded for any organ contributing more than $10 \%$ to an annual effective dose equivalent exceeding $100 \mathrm{mrem} / \mathrm{yr}$ or for any organ receiving more than $1 \mathrm{rem} / \mathrm{yr}$.

- If a conmitted effective dose equivalent for an intake is less than 100 mrem, then the entire committed effective dose equivalent is assigned to the year of intake. Once recorded, comitted doses are not reassigned to actual calendar years for purposes of dose control.

\subsubsection{Documentation of Dose Assessments}

Assessments of occupational internal exposures are documented.

The documentation includes or references the methods, assumptions, and data used to make the assessment and provides a summary of the assessed dose equivalents.

A copy of the documented assessment is provided to Radiological Records for placement in the individual worker's occupational radiation exposure (ORE) file.

For each assessment, a letter, sumarizing the conclusion of the assessment and updating the worker's current internal exposure status, is sent to the worker's radiation dosimetry organization. 


\subsubsection{Documentation of Dose Assessments (contd)}

Assessments are documented within 3 months of obtaining all the necessary data. A preliminary assessment is issued by February 1 for all internal exposure cases originating the preceding year for which final assessments have not been completed. These preliminary assessments include the estimated internal dose equivalent received during the prior calendar year and the projected internal dose equivalent for the current calendar year.

Chronic internal exposures are assessed within 4 months of termination of the chronic exposure and on a calendaryear basis for continuing exposures.

\subsubsection{Revisions and Updates}

Assessments for active workers are revised when information demonstrates a change in the currently assessed annual internal effective dose equivalent of $10 \%$ of either the DOE standard or the previously assigned dose, whichever is higher.

When the revision involves a specific exposure case, the contractor dosimetry representative is notified, in advance, of the need to issue a revised assessment.

When the revision results from general changes in dosimetry techniques, assumptions, or regulations, and a number of exposure cases are affected, then Internal Dosimetry presents a discussion of the impacts of the change to the Hanford Dosimetry Advisory Comittee.

Internal dose assessments for specific intakes by active workers are reviewed and updated every 5 years as long as the worker's annual effective dose equivalent from the intake is greater than 1 rem.

\subsection{REPORTS OF INTERNAL DOSE}

Internal Dosinetry provides reports of internal dose to contractor dosimetry organizations and to Radiological Records as described in the following subsections.

\subsubsection{Reports Provided to Contractor Dosimetry Drqanizations}

Final exposure evaluation reports and annual summary reports are provided to contractor dosinetry organizations as follows: 


\subsubsection{Reports Provided to Contractor Dosimetry Organizations (contd)}

- Final report of evaluated internal exposure--Final reports are provided upon completion of internal exposure evaluations. Preliminary reports (verbal or written) are provided upon request. The reports contain the projected 50-year committed and the assigned first and maximum calendar-year effective dose equivalent for the assessed exposure.

- Summary of annual, committed, and cumulative (through age 75) internal dose equivalents--A summary report of doses for all assessed internal exposures to active workers is provided by December 15 of each year.

\subsubsection{Reports Provided to Radiological Records}

The following four reports on annual effective dose equivalent are provided to Radiological Records:

- Annual effective dose equivalent, all intakes-Reports of annual effective dose equivalents are prepared for active workers and visitors during the prior calendar year by February 1 of each year. (The reports are used to prepare annual dose reports for workers.)

- Annual effective dose equivalent, each evaluated intake--Reports of the annual effective dose equivaTent received by active workers and visitors during the prior calendar year are provided by February 15 of each year and include separate doses for each evaluated internal exposure. (This information is used to prepare reports required by DOE 5484.1 [1981].)

- Annual effective dose equivalent, terminating workers--Reports of annual effective dose equivalent from internally deposited radionuclides are provided for terminating workers within 90 days of their termination.

- Annual effective dose equivalent, next calendar year--Reports of the annual effective dose equivaTent for the subsequent calendar year from internally deposited radionuclides are provided by December 15 for all evaluated internal exposures.

(Radiologica) Records provides this information to contractors via the ORE system for use in occupational exposure management.) 


\subsection{BIOASSAY MONITORING}

Internal Dosimetry provides, to the extent that Hanford Site contractors and DOE-RL will support and that technical capabilities will allow, a bioassay monitoring program capable of detecting an intake potentially resulting in an annual effective internal dose equivalent of 100 mrem.

The bioassay monitoring progran is developed in consideration of facility-specific radionuclide mixtures and characteristics.

Bioassay capabilities are optimized considering sensitivity requirements and cost.

\subsection{PROGRAM DOCUMENTATION}

The practices and general recommendations of the IDP are documented in this controlled distribution manual. Copies of the manual and updates to the manual are maintained in the Hanford Radiation Protection Historical Files. The manual is updated within 12 months of any changes in practice or recommendations.

Temporary or interim practices and recommendations are documented in a letter, with a copy maintained in the Hanford Radiation Protection Historical Files.

The following are also documented or referenced in the Hanford Radiation Protection Historical Files:

- operating procedures

- technical bases

- biokinetic models

- computer codes. 
CHAPTER 3.0

ASSESSMENT OF INTERNAL DOSE 


\subsection{ASSESSMENT OF IRTERNAL DOSE}

The internal dose assessment process involves collecting and analyzing information concerning a potential internal exposure and developing a conclusion regarding the magnitude of the exposure in terms that can be related to radiation protection standards. In a broad sense, the dose assessment process consists of three parts:

- identification of a potential exposure

- collection of exposure information

- evaluation and documentation of dose equivalent.

The accomplishment of a successful internal exposure assessment effort at Hanford relies on both the contractor dosimetry organization (Field Dosimetry) and IDP support. Field Dosimetry has the primary responsibility for identifying potential internal exposures for assessment. Internal Dosimetry supports this effort by providing guidelines and recomendations for establishing routine bioassay monitoring programs and for identifying situations that warrant assessment of internal exposure (see Chapters 5.0,6.0, and 7.0). The performance of bioassay measurements and the collection of other data and information used in the assessment require the combined efforts and cooperation of Field Dosimetry and Internal Dosimetry.

The evaluation of the data, the assessment of internal dose, and the documentation of the assessment are primarily the responsibility of Internal Dosimetry. as discussed in this chapter.

\subsection{GENERAL DESCRIPTION OF AN INTERMAL EXPOSURE ASSESSMENT}

Determining when and what kind of an assessment of internal exposure is necessary and how the assessment is conducted for various exposure situations are key to the assessment process.

\subsubsection{Criteria for Performing an Assessment}

Program practice statements in Chapter 2.0 establish the criteria for determining when an internal exposure assessment is needed and provide the general guidance used in performing the assessment.

\subsubsection{Types of Assessments}

Assessments of potential internal exposures generally fall into one of three categories: 


\subsubsection{Types of Assessments (contd) \\ - preliminary evaluation \\ - final evaluation \\ - re-evaluation.}

Preliminary

Evaluation

Final Evoluation

Re-evoluation
A preliminary evaluation may be performed before completing the follow-up investigation. Its purpose is to provide a prompt or interim assessment of the potential seriousness of an intake prior to obtaining the data required for a final evaluation. Because the preliminary evaluation is performed before completing the investigation, the assessment of the magnitude of exposure is based on relatively conservative assumptions. Thus, preliminary evaluations tend to result in a higher assessed dose than do final evaluations.

In cases where the significance of the potential exposure is obviously small, the conclusions of the preliminary evaluation are reported verbally. For cases with greater significance, Field Dosimetry may request a written preliminary evaluation. The written preliminary evaluation is usually issued within a week of the request. A preliminary evaluation will also be issued within 3 months of the identified need for dose assessment, if a final evaluation cannot be issued within that time.

A final evaluation represents the conclusion of the internal dose assessment process based on the follow-up investigation. As stated in Section 2.1.3, a report on the final evaluation is issued within 3 months of the receipt of the necessary data. Generally, the time period between identifying an intake and issuing a final internal dose evaluation report ranges from 1 month, for simple cases, to 1 year for complex cases where long-tern bioassay data are needed. Final evaluations may be revised by issuing a re-evaluation report if additional evidence is obtained affecting the conclusion of the previous final evaluation.

A re-evaluation is an updated final evaluation report. The criteria for determining when a re-evaluation should be performed are provided in Section 2.1.4.

\subsubsection{General Approach}

Assessments of internal dose are conducted by investigating the nature of the exposure and by analyzing bioassay measurement results and other pertinent data. Bioassay measurement data provide information on the deposition and retention of radionuclides in the involved individwal(s) and, therefore, provide the best bas is for assessing internal dose. However, in cases where bioassay data are not available, an internal dose assessment can be 


\subsubsection{General Approach (contd)}

made using other available information, such as air sample data, source terms, contamination surveys, and other relevant sources.

\subsubsection{Exposure Assessment Situations}

Various situations necessitate an assessment of internal dose. Table 3.1 lists possible situations for which an assessment may be needed and the criteria used to determine if an assessment is needed.

\section{TABLE 3.1. Dose Assessment Situations}

\section{Situation}

Field Dosimetry identifies a potential internal exposure incident.

Specially-requested (nonroutine) bioassay measurement shows detectable activity.

Routine bioassay measurement shows activity.

Bioassay result for a worker with a known internal deposition shows an unanticipated increase.

Bioassay data collected subsequent to an evaluated intake suggest that the assigned dose may be incorrect.

Field Dosimetry requests a special internal dose assessment.

Prior work history or beginning work bioassay measurement for a newly hired employee indicates a previously incurred occupational exposure.
Criteria for Initiating an Internal Dose Assessment

Field measurement data meet contractor criteria for potential exposure. Recomnendations for these criteria are provided in Chapter 7.0.

Measurement result indicates internally deposited radionuclides.

Measurement result exceeds the routine bioassay monitoring program follow-up level.

Recent and previous known bioassay measurements are compared and it is determined that the recent result exceeds nomally expected fluctuations.

Evidence suggests that the assigned dose may be in error by $10 \%$ of an annual dose limit or $10 \%$ of the previously assigned dose, whichever is greater.

Request by Field Dosimetry.

Bioassay or other information indicates internally deposited radioactivity at the time of employment. 


\subsection{PERFORMING THE ASSESSMENT}

When one of the situations in Table 3.1 occurs and the dose assessment criteria are met, an assessment of internal exposure is performed. The assessment process includes investigation, documentation, and reporting of conclusions. Figure 3.1 depicts the steps that comprise the complete assessment process.

\subsubsection{Investigation}

The investigation phase of the exposure assessment process involves the perfomance of follow-up bioassay measurements and the collection of other pertinent data.

Follow-up bioassay measurements have three purposes:

1. identifying (confinming) that an intake occurred

2. establishing the material's distribution in and clearance from organs in the body

3. assessing dose equivalent.

Recommendations for follow-up bioassay measurements are made by Internal Dosimetry on a case-by-case basis consistent with stated practices in Chapter 2.0 and other guidance provided in Chapters 6.0 and 7.0, and with the concurrence of Field Dosimetry. The type and extent of the follow-up measurements depend on the significance and complexity of the exposure case.

Follow-up measurements for assessing dose are based on the need to establish the magnitude of the internal deposition and its clearance rate from the body. Generally, the frequency for performing follow-up bioassay measurements can be decreased with time post-intake, until, for long-retained nuclides, the follow-up measurements can be continued on an annual monitoring frequency. It is recommended that follow-up bioassay measurements continue until the measurement results are consistently less than detectable or below the follow-up level established for routine bioassay monitoring.

Other information of primary importance to the assessment that should be obtained during the follow-up investigation is listed in Table 3.2.

The investigation determines that either an intake did or did not occur. If the conclusion is that an intake did occur, the magnitude of the resulting exposure in terms of annual and committed dose equivalent is determined. 


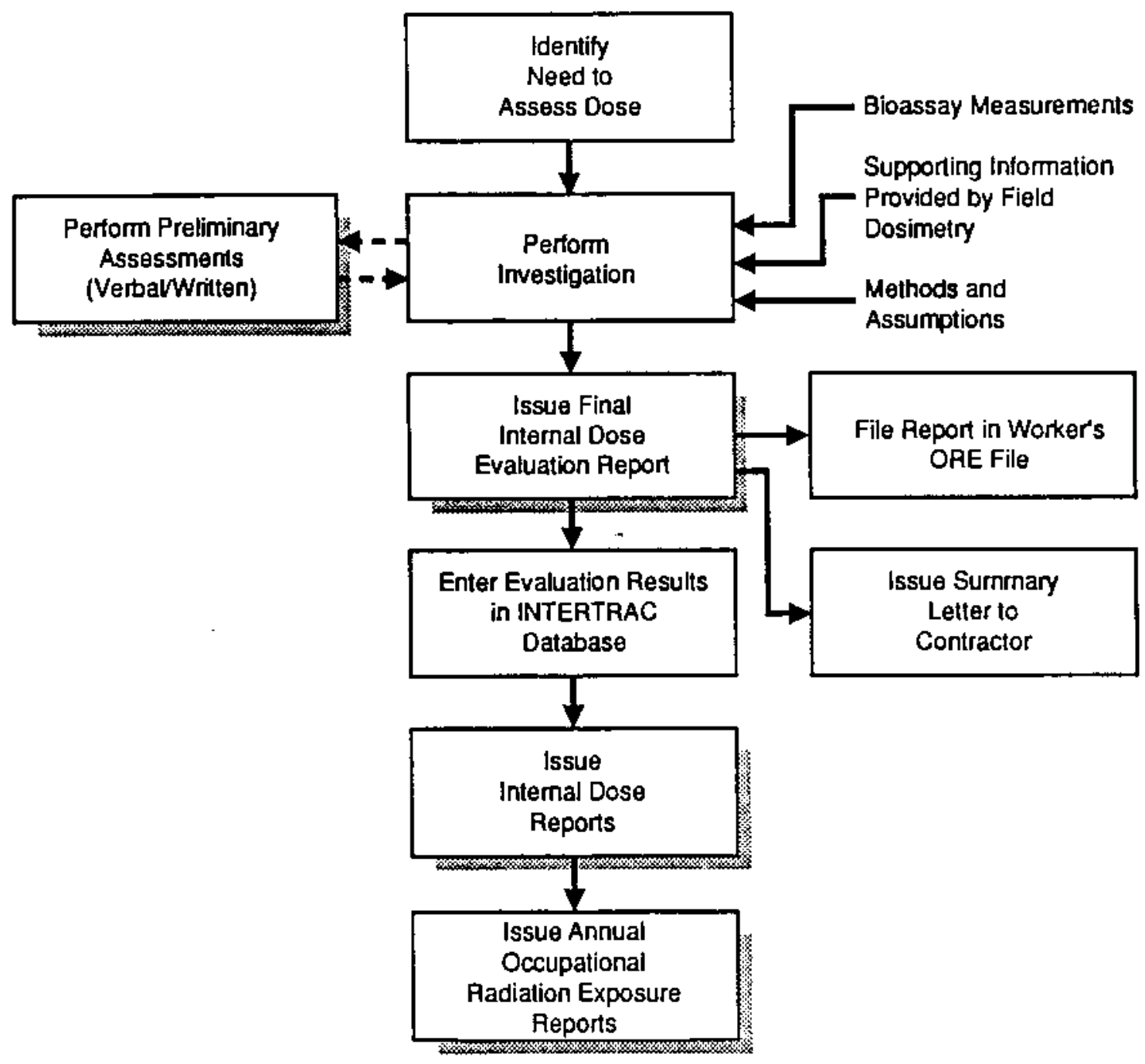

FIGURE 3.1. Internal Dose Assessment Process Flow Chart

\subsubsection{Documentation}

Internal Dose

Evaluation Report
Occupational internal exposures to radionuclides are assessed and formally documented via the Internal Dose Evaluation Report. The Internal Dose Evaluation Report provides the methods, assumptions, data, and conclusions of the assessment. All subsequent detailed or summary accounts of internal dose from a particular exposure event are derived from the Internal Dose Evaluation Report.

Internal Dose Evaluation Reports are prepared by Internal Dosimetry using methods and assumptions described in this manual, in the Technical Basis, and in other resources as appropriate. Before any report is issued, it is reviewed internally by a peer. 
TABLE 3.2. Information Supporting the Internal Dose Assessment

General Information

Inhalation Intake Information

Absorption/Wound Information

Materials for Potential Analysis
Location where exposure occurred

Description of the exposure event, including time, suspected mode of intake, duration of intake, and other individuals involved

Personnel contamination survey results and decontamination actions

Radionuclide(s) involved, including relative abundance in mixtures

Physical and chemical characteristics of contamination and host matrix

Airborne radionuclide concentrations

Respiratory protection used

observed facial, nasal, and/or hand contamination

Breathing habits (mouth/nose breather)

Location of wound(s)

Cause and description of wound

Wound contamination survey results

Characteristics of contamination in and around the wound site

Medical and health physics actions

Analysis of the following materials can also provide useful information, and it is recomended that, to the extent practical, these materials be identified and retained for a period of 1 month:

- air sample media (filters, canisters)

- contamination smear survey pads

- nasal swab and irrigation fluid

- respirator filters

- wound debris (blood, tissue, foreign matter) 
Exhibit 3.1 shows the evaluation report form that is used to document internal dose evaluations. This form is used to identify the assessment, organize the content of the report, summarize the conclusions, and show who prepared and reviewed the report. When an assessment is complex, special attachments, containing the details of the assessment, are attached to the evaluation report form.

Each internal dose evaluation is identified by a unique identification number. Prior to 1987, numbers were assigned sequentially. Beginning on January 1, 1987, the numbering systen was revised to include a five-digit event number followed by a two-digit person designator and a one-digit evaluation revision designator. The first two digits of the event number represent the calendar year during which the evaluation is originally initiated, and the last three digits are assigned sequentially to each event during that year. The sequence character after the two-digit individual worker number indicates that the evaluation report is either the original ("A") or a revision ("B,C,D---"). For example, the evaluation number, "87005-02A," identifies the evaluation as the original version issued for individual number 2 who was involved in the fifth potential internal exposure event of 1987.

Evaluation numbers are assigned by the Internal Dosimetry clerk upon notification that an assessment will be performed.

The following information is provided in the evaluation report:

- evaluation number

- worker's name, payroll number, and social security number

- date or period of exposure, actual or assumed

- area and building where exposure occurred, if known

- summary of exposure scenario, if known

- mode(s) of intake, actual or assumed

- radionuclides addressed by the assessment

- summary of data used in the assessment

- description of assessment methods and assumptions 


\subsubsection{Documentation (contd)}

- calendar-year and conaitted effective dose equivalents

- calendar-year dose to organs meeting the criteria in Section 2.1.2

- references, as required

- author's name and signature and date prepared

- peer reviewer's signature.

\subsubsection{Reporting}

Sumnory Letter

A letter sumarizing the conclusions of the evaluation (preliminary or final) is sent to the designated dosimetry office of the involved worker's employer, and a copy of the sumary letter along with the evaluation report, is sent to Radiological Records for inclusion in the worker's ORE file.

The summary letter contains the following information:

- worker's name and payroll number

- date or period of the exposure

- area and building where the exposure occurred

- assigned effective dose equivalent for the year of intake

- maximum annual effective dose equivalent and the assigned year

- projected committed effective dose equivalent

- recommendations for further follow-up sampling.

\subsection{DOSE ASSESSMENT METHODS}

Program practices, discussed in Chapter 2.0, provide general statements regarding the operation of the IDP. Technical considerations for the internal dose assessment process are covered in the Technical Basis. The methods and approaches used for investigating, assessing, and reporting internal dose assessments are summarized in the following subsections. They are "default" methods used unless available information points to a more appropriate 


\subsection{DOSE ASSESSMENT METHODS (contd)}

method or assumption. If a method and technique other than those discussed here are used, they are documented in the evaluation report.

\subsubsection{General Approach}

Internal exposures are preferably assessed based on bioassay measurement results. However, if bioassay data are unobtainable, the assessment is performed using whatever information is available.

Direct (in vivo) measurements of internal burdens and retention patterns are preferred to indirect (excreta) methods that require the use of excretion functions and biokinetic models.

Assumptions used in the dose assessment process should be conservative but realistic. Assumptions should not be made when actual data or information are available.

When the actual intake time or period is not known, it is necessary to attempt to identify the probable intake date(s). This may be done by considering available evidence, such as air monitoring results, contamination surveys, operating periods, previous bioassay measurement results, and any other pertinent information. After narrowing the intake time to a probable time period, it is assumed that an acute intake occurred at the midpoint of that period. If the evidence suggests that a chronic exposure is more reasonable, it is assumed that the chronic exposure occurred uniformly throughout the duration of the probable exposure period.

If the mode of intake is not known, it is assumed that the intake was by inhalation.

\subsubsection{Evaluating Lung Dose for Inhalation Exposures}

Potential lung doses from inhalation exposures must be considered even if direct in vivo measurements do not identify the nuclide in the lung. In such cases, assessments of the lung burden and dose should be performed using alternative techniques such as excreta measurements, air samples, or other available information; but the assessed activity in the lung should not exceed the reported minimum detectable activity (MDA) level of the chest measurement. 


\subsubsection{Solubility and Particle Size Assumptions}

Input terms for biokinetic models should be based on field data and on bioassay measurements that are specific to the exposure event being evaluated. If model input requires information that cannot be reasonably obtained, then appropriate conservative assumptions should be used. For particle size input to the respiratory tract biokinetic model, the default particle size input is $1.0 \mathrm{~mm}$ AMAD (activity median aerodynamic diameter), assuming that the particles are lognormally distributed with a geometric standard deviation of $2.7 \mathrm{~mm}$. For transportability class input to the model, the transportability characteristics should be determined based on the known or probable chemical and physical makeup of the material. The evaluation should include appropriate discussion of the rationale for choosing these parameters.

\subsubsection{Radionuclides Included in the Assessment}

The internal dose assessment should consider all radionuclides identified by in vivo or field measurements, as well as additional radionuclides that are reported by Field Dosimetry as being present or that are known to be present from previous experience. If field measurements indicate gross radioactivity levels only (gross $\beta$. gross a), then appropriate radionuclide representations of these levels should be used based on a conservative evaluation of radionuclides potentially present. Reference radionuclide mixtures developed in the Technical Basis can be considered applicable in this situation.

\subsubsection{Assessment of Exposures of Localized Tissue}

For radionuclide depositions in localized tissues, such as in regional lymph nodes or at wound sites, the quantity of the radionuclide deposited in the tissue and its projected half-life are assessed and documented. This assessment becomes part of an individual's ORE record, but is not used for determining compliance with either stochastic or nonstochastic annual dose equivalent limits in DOE 5480.11 (1989). This approach is analogous to the approach required by DOE 5480.11 (1989) for irradiation of limited areas of the skin. Additional discussion is provided in Appendix $B$ of the Technical Basis.

\subsubsection{Biokinetic Models}

Biokinetic models for specific applications are discussed in the Technical Basis. The standardized models summarized below are used for initial evaluation of internal exposure and are applied to final evaluations unless a more appropriate model is determined to apply to the specific exposure situation. 


\subsubsection{Biokinetic Models (contd)}

Respiratory

Tract Model

Gostrointestinal

Tract Model

Systemic Retention Models

Systemic Excretion Models
The general model for the respiratory tract presented in ICRP 30 (1979) is used for evaluation of retention and elimination of inhaled particulates by the respiratory system.

The model for the gastrointestinal (GI) tract presented in ICRP 30 (1979) is used to evaluate retention and absorption of materials by the stomach and small and large intestines.

The systemic retention models used are those described in ICRP 30 (1979), except for the updated recommendations on uptake fractions and retention for transuranic radionuclides contained in ICRP 48 (ICRP 1986). Retention models are most useful when organ uptake and retention cannot be determined using in vivo measurenents.

The systemic excretion functions in Table 3.3 are applied to excreta data unless a more appropriate model applies to a specific situation. The models are discussed further in the Technical Basis.

\section{TABLE 3.3. Excretion Functions}

Element

Plutonium

Strontium

Uranium

Tritium
Systemic Excretion Model

Jones function (Jones 1985)

Alkaline earth model, as implemented by the GENMOD computer code (Johnson and Myers 1981)

ICRP 30 (1979) retention model

ICRP 30 (1979) retention model

\subsubsection{Computer Programs Used for Dose Calculations}

The computer program codes 1 isted in Table 3.4 are consistent with the retention and/or excretion models discussed previously and are used in the assessment process unless another approach is determined to be more appropriate for the specific situation. Each of the computer programs is documented in the Hanford Radiation Protection Historical Files. 
TABLE 3.4. Computer Programs Used for Dose Calculations

\author{
Computer \\ Program \\ Code Name
}

GENMOD

PUCALC

PLUDO

GENDOS
Purpose

A general purpose retention, excretion, and dose-calculation program that is compatible with ICRP 30 (1979) and ICRP 48 (1986)

A set of programs for estimating systemic uptake of plutonium from urine data

Adaptations of GEMMO for calculating calendar-year dose equivalents from plutonium intakes

\subsubsection{Simpiified Dose Assessments}

The simplified dose assessment procedure is a standardized approach for assessing internal doses. The procedure is generally employed for calculations used in prospective program design, initial retrospective assessments when available bioassay and other data regarding the exposure are minimal, and final assessments for which the dose equivalent is relatively low. Generally, the simplified dose assessment procedure is used for final assessment of intakes resulting in annual effective dose equivalents of less than 100 mrem.

The simplified dose assessment procedure employs the standardized excretion and retention functions and assumptions discussed previously in this section and other specific assumptions and methods described in the Technical Basis.

If the assessed dose, using the simplified dose assessment procedure, exceeds the 100-mrem/yr effective dose equivalent, then models, methods, and assumptions are reviewed to detemine their applicability.

\subsection{GOOD PRACTICE RECOMMENDATIONS FOR FIELD DOSIMETRY}

Monitoring and assessing internal occupational exposures at Hanford are accomplished through the mutual effort and cooperation of the Hanford Internal Dosimetry Program and Field Dosimetry. These activities are complementary, that is, both the contractor and Internal Dosimetry responsibilities must be fulfilled. The recommendations provided below are suggested by Internal Dosimetry as 


\subsection{GOOD PRACTICE RECOMMENDATIONS FOR FIELD DOSIMETRY (contd)}

general guidance for Field Dosimetry administration of monitoring programs. In addition to this general guidance, Internal Dosimetry provides specific guidance and technical support as needed.

\subsubsection{Identifying Routine Bioassay Monitoring Meeds}

The following good practice recommendations cover activities that are required for a complete internal dosimetry program:

- Identify the routine bioassay monitoring needs of individuals and arrange for a routine bioassay monitoring progran that is responsive to these needs. The bioassay monitoring program should be radionuclide-specific; that is, established by radionuclide and exposure scenario, rather than by measurement type. General guidance on bioassay monitoring progran needs is provided in Chapter 5.0 of this manual. Internal Dosimetry can recommend measurement types to ensure the inclusion of radionuclides of concern.

- Apprise Internal Dosimetry of the radiological conditions in facilities. Include identification and physical and chemical characteristics of the radionuclides and the potential internal exposure situations that exist.

- Contact Internal Dosimetry as needed for specific guidance and support in the setup and operation of the routine bioassay monitoring program.

- In cooperation with Internal Dosimetry, identify the radionuclides for which bioassay monitoring is not performed or is not adequate, and assure that appropriate monitoring of these radionuclides (using other techniques) is provided. This could apply, for example, to short-lived radionuclides that cannot be reliably detected through routine bioassay monitoring.

\subsubsection{Identifying Potential Internal Exposures}

Identify potential internal exposure events and report these promptly to Internal Dosimetry. Assessinents of internal dose are more accurate and can be performed with less expense if the intake time is known, if follow-up samples are collected shortly after intake, and if field data are available regarding the nature and characteristics of the exposure. 


\subsubsection{Managing Internal Exposures}

Good practice in managing internal exposures includes adhering to the following recomendations:

- Avoid potential internal exposures to workers until baseline bioassay measurements (e.g., beginning employment) have been performed and prior exposure history has been reviewed.

- Consider the impact of internal exposures on allowable external exposure for workers with internal doses.

- Consider a work restriction if the annual dose from internal exposure exceeds $50 \%$ of the standards.

- Consider a temporary work restriction to avoid exposure to like radionuclides if such exposures could adversely affect an ongoing investigation of a potential internal exposure.

- Provide long-term follow-up bioassay measurements for workers with current internal depositions. This tracks the retention of the radionuclide and establishes a baseline from which to evaluate possible future exposures.

- Inform the worker of the status of the follow-up investigation and dose assessment. 
Exhibit 3.1

Internal Dose Evaluation Report Form

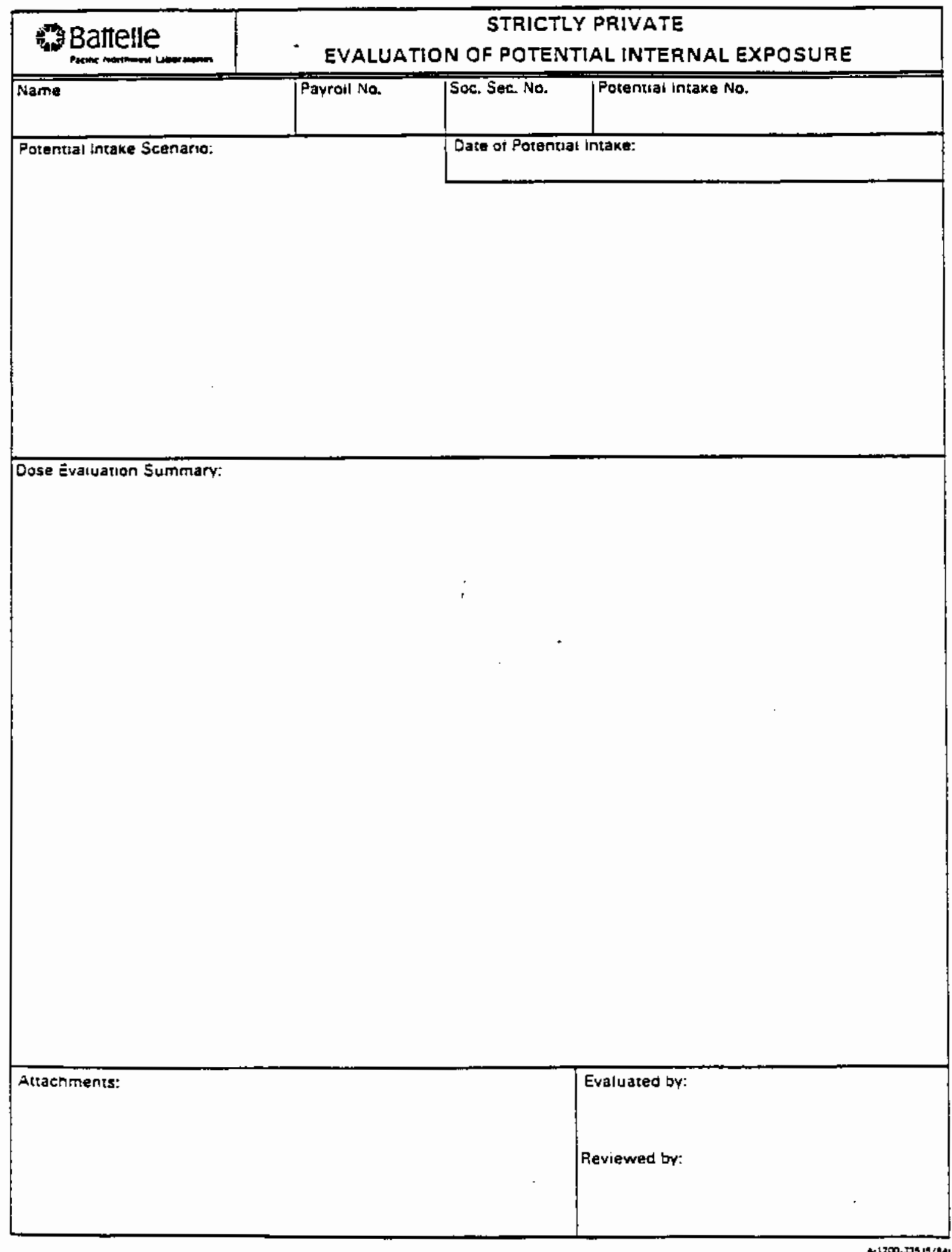



CHAPTER 4.0

\section{RECORDING AND REPORTING INTERNAL DOSES}




\subsection{RECORDING AND REPORTING INTERHAL DOSES}

Reports of occupational dose equivalent are required as specified in DOE 5480.11 (1989) and DOE 5484.1 (1981). The occupational dose equivalent is composed of the dose equivalent received from external sources of radiation and internally deposited radionuclides. This section provides information on the recording and reporting of the internal dose component as performed by the IDP. Assessed internal doses are provided to Radiological Records for compilation and preparation of occupational dose reports.

\subsection{NTERNAL DOSE RECORDS}

The official record of internal dose is the Internal Dose Evaluation Report. Section 3.2.2 describes the contents of the Internal Dose Evaluation Report. An Internal Dose Evaluation Report is issued for each assessed internal exposure. Completed reports are maintained by Radiological Records in ORE files. Summary dose information is maintained in the ORE database.

\subsection{INTERNAL DOSE DATABASE}

Dose information from Internal Dose Evaluation Reports is maintained by Internal Dosimetry in the computer database INTERTRAC (for Internal Dose Tracking System). INTERTRAC contains annual and committed organ and effective dose equivalent information from the Internal Dose Evaluation Report for each assessed intake, and this information is used to generate dose sumaries for tracking and reporting occupational doses to individuals. Reports that can be generated using INTERTRAC include the following:

- annual organ and effective dose equivalents for each evaluated intake

- annual organ and effective dose equivalents from all evaluated intakes

- cumulative organ and effective dose equivalents through a specified year or for a specified number of years

- comitted organ and effective dose equivalents for each evaluated intake and for all evaluated intakes. 


\subsection{INTERMAL DOSE DATABASE (contd)}

Additional information on the INTERTRAC system is provided in "The Hanford Internal Dose Accounting and Reporting System - IKTERTRAC (Version 1.0)." (a)

Prior to the beginning of a new calendar year, the annual effective dose equivalent from all internal exposures assessed to date is provided to Radiological Records for input into an interactive file on the ORE database. Thus, the current year effective dose equivalent is accessible to contractors. Updates to this file are made as new or revised evaluations are issued.

\subsection{REPORTS OF INTERNAL DOSE}

Letters of assessed internal dose are issued to contractor dosimetry representatives upon completion of the Internal Dose Evaluation Report as discussed in Chapter 3.0. Summary reports of employee internal dose equivalents are distributed to contractor dosimetry representatives annually. Updates to these reports are provided throughout the year, based on new or revised internal dose assessments, or to include reactivated workers with internal doses from past intakes. The current calendar-year effective dose equivalent can be accessed on the ORE system (see Appendix B, Figure B.6).

Annual occupational dose reports (report cards), reports of occupational dose for terminating employees, and reports to the DOE Radiation Exposure Information Reporting System (REIRS) are provided by the Hanford Radiological Records group. Special requests for internal dosimetry information may be made to the IDP.

Several groups of Hanford workers are considered to be chronically exposed to radionuclides during the course of their work. These groups include those individuais working with tritium and uranium of low or depleted enrichment. Bioassay samples for these workers are collected throughout the year. A final internal dose assessment is issued after yearend; however, throughout the year, the routine bioassay measurements are reviewed and the contractor is advised if there is an indication that the annual effective dose equivalent from chronic exposures could exceed $100 \mathrm{mrem}$.

(a) Sula, M. J., K. K. Johnson, and R. A. May II. 1989. "The Hanford Internal Dose Accounting and Reporting System - INTERTRAC (Version 1.0)." Internal Report dated February 1989. Copy in the Hanford Radiation Protection Historical Files, Pacific Northwest Laboratory, Richland, Washington. 


\subsection{REQUESTS FOR INTERNAL DOSIMETRY RECORDS}

Occupational radiation exposure records are controlled according to the requirements and provisions of the Privacy Act (1974) and ANSI N13.6-1966 (ANSI 1966), Practice for Occupational Radiation Exposure Records Sys tems. Access to the records is permitted as follows:

- Current employees may contact their company's radiation protection representative, who will arrange with Radiological Records to obtain the requested records.

- Individuals may request their records by contacting Radiological Records either in person or by mail. Verbal requests are not accepted.

- Employers requesting records of current or former Hanford workers should contact Radiological Records.

- Requests by the U.S. Transuranium Registry should be made by contacting Radiological Records.

- If none of the above apply or are practical, contact the DOE Privacy Act Officer, who will prepare the proper paperwork and submit the request to Radiological Records.

In the above cases, the following are required before records are released:

- An individual appearing in person must provide a driver's license or other photographic identification and sign a release form that will be provided by Radiological Records. This signed release is entered into the individual's ORE record.

- An individual requesting records by mail must provide in a notarized written request his/her name, social security number and/or payroll number, and signature. This written request must define exactly which records are needed and the address to which they should be sent. Verbal requests are not honored.

- Employer and U.S. Transuranium Registry requests must be accompanied by a signed radiation exposure release-of-information form. 

CHAPTER 5.0

\section{BIOASSAY MONITORING}




\subsection{BIOASSAY MONITORING}

This chapter discusses who should be included in a routine bioassay monitoring program, what measurements should be performed, and at what frequency.

\subsection{CONOITIONS FOR MONITORING WORKERS}

DOE 5480.11

Requirement
Participation in an internal dose evaluation and routine bioassay monitoring program is required by

Section 9.g.(2) of DOE 5480.11 (1989), which states:

"Internal Radiation. Internal dose evaluation programs (including routine bioassay programs) shall be adequate to demonstrate compliance with the radiation protection standards in paragraph 9b. Such programs are required for radiation workers exposed to surface or airborne radioactive contamination where the worker could receive 0.1 rem $(0.001$ sievert) annual effective dose equivalent from all intakes of all radionuclides from occupational sources, or if any organ or tissue dose equivalent could exceed 5 rem ( 0.05 sievert) annual dose equivalent."

Although $O O E$ 5480.11 requires only that dose evaluation and routine bioassay programs be adequate to demonstrate compliance with the annual dose equivalent standards, it is the practice of the IDP, as stated in Section 2.3, to provide bioassay monitoring capability to detect an intake potentially resulting in an annual effective dose equivalent of $100 \mathrm{mrem}$.

The achievement of an annual effective dose equivalent capability of 100 mrem for bioassay monitoring eliminates the possibility that any single organ or tissue might exceed 5 rem in a calendar year without being detected via bioassay monitoring. This is because a 100-mrem program capability, divided by the smallest weighting factor $(0.03)$ leads to an organ or tissue dose equivalent of 3.3 rem, which is well below the 5-rem criterion.

The requirement in $00 E 5480.11$ further calls for monitoring in consideration of the potential total dose from all intakes, rather than monitoring on a "per nuclide" basis. Thus, monitoring may be appropriate for workers exposed to multiple nuclides, even though any single nuclide may be only a small fraction of the criterion for an effective dose equivalent of $100 \mathrm{mrem} / \mathrm{yr}$. 


\subsection{CONDITIONS FOR MONITORING WORKERS (contd)}

General

Reconnendation

Bosed on

Comitted Dose
The IDP recomends placing workers on a routine bioassay monitoring program if the 50-year conmitted effective dose equivalent from a single intake or multiple intakes in a single calendar year may exceed 100 mrem for all radionuclides.

The 50-year comitted effective dose equivalent is recommended for establishing bioassay monitoring requirements. Its use provides some conservatism relative to the annual dose equivalent limit specified by DOE 5480.11 (1989), particularly with regard to tenaciously retained nuclides. The committed dose equivalent also allows for the convenience of correlating bioassay requirements to derived air concentrations (DACs), annual limits on intake (ALIS), and time-integrated exposure to airborne contanination (DAC-hours), which are widely used in the workplace for exposure control.

For bioassay program planning purposes, a 100-mrem committed effective dose equivalent may be considered to correspond to chronic exposure for 1 year to $2 \%$ of a DAC, an acute or chronic intake equal to $2 \%$ of an ALI, and a time-integrated exposure to airborne contamination of 40 DAC-hours. Technically, this is not completely accurate, because if the DAC or ALI is based on the nonstochastic limit for a particular organ or tissue, the corresponding compitted effective dose equivalent will be less than 100 mrem. Because of this conservatism, the use of established DAC and ALI values is an acceptable practical approach.

The DAC, ALI, and DAC-hour concepts and the nature of the work and the exposures may be used to determine who should be included in a bioassay monitoring program. The following subsections provide guidance for their application for bioassay monitoring.

\subsubsection{Derived Air Concentration}

Long-Term

Chronic Exposures
A worker should be placed on a routine bioassay program if chronic exposure to airborne radioactivity could exceed an average of $2 \%$ of the DAC. For exposures to multiple nuclides, the contribution from each significant nuclide should be considered. The DACs referred to in this manual are those contained in Attachment 1 to DOE 5480.11 (1989). The DACs for selected Hanford radionuclide mixtures are given in Table 5.1. 
IABLE 5.1. Derived Air Concentrations and Annual Limits on Intake for Common Radionuclide Mixtures

\begin{tabular}{|c|c|c|c|}
\hline $\begin{array}{l}\text { Radionuclide } \\
\text { Mixture (a) }\end{array}$ & $\begin{array}{l}\text { Inhalation } \\
\text { Class }\end{array}$ & $\operatorname{DAC}(\mu \mathrm{C} i / \mathrm{ml})$ & $A L I(\mu C i)$ \\
\hline $\begin{array}{l}\text { Uranium (natural, depleted } \\
\text { and recycled) }\end{array}$ & $\begin{array}{l}\text { D - chronic } \\
\text { D - acute }\end{array}$ & $\begin{array}{l}\text { 3.E-g(c) } \\
\text { HA (d) }\end{array}$ & $\begin{array}{l}75 \mathrm{mg}(\mathrm{b}) \\
14 \mathrm{mg}(\mathrm{b})\end{array}$ \\
\hline $\begin{array}{l}\text { Uranium (natural and } \\
\text { depleted) }\end{array}$ & $\begin{array}{l}W \\
Y\end{array}$ & $\begin{array}{l}\text { 2.E-10 } \\
\text { 2.E-11 }\end{array}$ & $\begin{array}{l}\text { 7.E-1 } \\
\text { 5.E-2 }\end{array}$ \\
\hline Uranium (recycled) & $\begin{array}{l}H \\
y\end{array}$ & $\begin{array}{l}2 . E-10 \\
2 . E-11\end{array}$ & $\begin{array}{l}6 \cdot E-1 \\
4 \cdot E-2\end{array}$ \\
\hline Plutonium (6\% Mixture)(e) & $\stackrel{W}{Y}$ & $\begin{array}{l}\text { 2.E-12 } \\
\text { 5.E-12 }\end{array}$ & $\begin{array}{l}\text { 5.E-3 } \\
1 . E-2\end{array}$ \\
\hline Plutonium (128 Mixture) (e) & $\begin{array}{l}H \\
Y\end{array}$ & $\begin{array}{l}2 . E-12 \\
4 . E-12\end{array}$ & $\begin{array}{l}5 . E-3 \\
1 . E-2\end{array}$ \\
\hline
\end{tabular}
(a) Isotopic ratios are given by Sula, Carbaugh, and Bihl (1989).
(b) The class $D$ chronic inhalation and acute inhalation values are based
(c) Units are $\mathrm{mg} / \mathrm{ml}$.
(d) Not applicable.
(e) Expressed as total alpha activity.

\subsubsection{Derived Air Concentration (contd)}

Short-Term

Chronic Exposures

Horkers exposed to short-term chronic exposures should participate in a routine bioassay monitoring program for each radionuclide to which he/she is exposed when the average air concentration exceeds that determined by the following formula:

$$
\begin{aligned}
& \text { Air Concentration } \\
& \text { Implying Bioassay }
\end{aligned}=\frac{0.02 * D A C}{f_{w}}
$$

where $D A C$ is the derived air concentration listed in DOE 5480.11 (1989), and $f w$ is the occupancy factor determined by

$$
f_{w}=\frac{\begin{array}{c}
\text { number of hours per year } \\
\text { in airborne area }
\end{array}}{2000 \text { working hours per year }}
$$

If a worker is exposed to more than one radionuclide, the result of Equation (5.1) should be divided by the number of significant radionuclides. 


\subsubsection{Derived Air Concentration (contd)}

Short-Term

Chronic Exposures

(contd)
In general, Hanford experience has shown that no more than four radionuclides or mixtures contribute significantly to internal dose in any one situation.

\subsubsection{Annual Limit on Intake}

The ALI is a useful concept for bioassay planning purposes when acute intakes are considered or exposure may be limited to readily identified quantities or sources. A routine bioassay program should be considered if an acute or chronic intake of activity corresponding to $2 \%$ of the ALI might be possible. Although ALIs are not listed in DOE 5480.11 (1989) or its attachments, they can be derived by multiplying the OOE 5480.11 DAC (units of $\mu \mathrm{Ci} / \mathrm{ml}$ ) by $2.4 \mathrm{E}+9$ (giving the ALI in units of microcuries). The ALIs for selected Hanford radionuclide mixtures are given in Table 5.1.

NOTE: Specific reference is made to DOE 5480.11 DACs as the basis for ALI calculation. It should not be assumed that ALIs calculated based on DOE 5480.11 (1989) are identical to the ALIs contained in ICRP 30 (1977).

Even if not chronically exposed to airborne radioactivity, certain workers risk incurring an intake because of an unplanned breakdown of a protection barrier. Potential conditions may be identified by the amount of materia) handled in a process, the physical form of the material, and the type of containment, or by the determination that the workers frequently need respiratory protection.

One approach to the consideration of source magnitude and containment is to use potential intake factors related to material form and containment. The potential intake factors in Table 5.2 should be considered for general guidance only. Actual facility experience should be used when possible.

For example, a worker should be included in a routine bioassay monitoring program if the activity of an unencapsulated radionuclide that is frequently handled, processed, or worked with in any way equals or exceeds the activity calculated by the following formula:

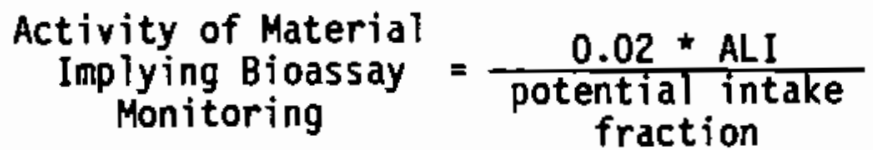


TABLE 5.2. Potential Intake Fractions(a) as a Function of Containment Type and Physical Form

\begin{tabular}{|c|c|c|c|}
\hline \multirow[b]{2}{*}{ Form } & \multicolumn{3}{|c|}{ Containment } \\
\hline & Glovebox & $\begin{array}{l}\text { Open-Faced } \\
\text { Hood } \\
\end{array}$ & Open Area \\
\hline Tritium(b) & $1.6 E-4$ & $1.6 \mathrm{E}-3$ & $1.6 \mathrm{E}-2$ \\
\hline Powders & $1 E-5$ & $1 E-4$ & $1 E-3$ \\
\hline $\begin{array}{c}\text { Volatile } 1 \text { iquids, elevated } \\
\text { temperatures, iodines }\end{array}$ & $1 E-6$ & $1 E-5$ & $1 E-4$ \\
\hline Normal liquids & $1 E-7$ & $1 E-6$ & $1 E-5$ \\
\hline $\begin{array}{l}\text { Grinding, sawing, polish- } \\
\text { ing, etc., on solids }\end{array}$ & $1 E-8$ & $1 E-7$ & $1 E-6$ \\
\hline
\end{tabular}

(a) Extrapolated from data and discussion in Watson and Fisher (1987; pp. 15-19) and from Brodsky (1980). The purpose of these potential intake fractions is to determine the need for participation in a bioassay program. The fractions should not be used to estimate actual expected releases under average conditions.

(b) Data from U.S. Nuclear Regulatory Commission Regulatory Guide 8.32 (1988).

\subsubsection{Annual Limit on Intake (contd)}

where ALI is the annual limit on intake. Potential intake fractions are listed in Table 5.2 as a function of the type of containment and physical form. The information in Table 5.2 should be considered for general guidance only. Actual facility experience should be used when possible.

If a worker is exposed to more than one radionuclide, the result of Equation (5.3) should be weighted, based on the number of significant nuclides.

\subsubsection{DAC-hours}

For specific job assignments, it is useful to consider the concept of DAC-hours in planning bioassay requirements. A worker potentially exposed to an accumulation of 40 DAC-hours in a year for all radionuclides should participate in a routine bioassay program. 


\subsubsection{Nature of Hork}

Special consideration for routine bioassay programs should be given to the following:

- Knowledge of or prior experience with the work performed or the facility involved.

- Workers who frequently wear respirators in airborne radioactivity areas.

- Workers who routinely work with transuranics in hoods or glove boxes.

- Workers who are subjected to a wide range of potential internal exposure conditions.

\subsubsection{Long-Term Follow-Up of a Prior Deposition}

A worker who has been assessed as having a long-term internal deposition of radioactivity may be recommended by Internal Dosimetry for a specialized follow-up bioassay monitoring program to verify the accuracy of the assessment and identify any potential need for revision.

This provision results from the need to update long-term body burdens and associated doses from well-retained radionuclides, and it applies regardless of present work assignment or origin of the occupational exposure.

Better understanding of the biokinetic behavior of retained material and improved estimates of dose can be obtained from long-tern follow-up bioassay measurements. For example, a small, very long-term component of material in the lung may be masked for several years by short-term components until the short-term components are removed. However, the long-term component will add significantly to dose in outyears as well as to the 50 -year dose conmitment.

Long-term follow-up monitoring is most likely to be associated with depositions of plutonium and americium, al though other nuclides may also warrant it.

\subsubsection{Beginning and Ending Hork Bioassay}

Beginning and ending work samples or measurements should be obtained for a worker whose work assignments will require or have required routine bioassay monitoring (NCRP 1987; ANSI 1978). Such samples should provide a better estimate of the time and nature of an intake, prevent the improper assignment of a prior intake to the 


\subsubsection{Beginning and Ending Work Bioassay (contd)}

present task, and provide accurate feedback on the effectiveness of radiation protection measures for specific work assignments.

Beginning and ending work measurements may be a suitable alternative to the routine bioassay monitoring associated with work assignments of limited duration. Consult with Internal Dosimetry to determine whether this option is appropriate.

\section{1 .7 Offsite Exposure}

Bioassay programs designed for monitoring internal exposures to materials and situations at Hanford may not necessarily be adequate for monitoring internal exposures to materials or facilities that may occur offsite. Internal Dosimetry should be contacted to determine the appropriate bioassay if offsite internal exposure is a possibility.

\subsubsection{Visitors}

The same criteria used for determining the need for bioassay monitoring of workers should be used for determining the bioassay monitoring requirements for visitors. Consideration may be given to the nature of the visit. facility entered, proximity to sources, duration of visit, and extent of work performed while a visitor. Application of the DAC-hour criteria or equations 5.1 and 5.3 may be helpful.

\subsubsection{Pregnant Women and Minors}

The DOE 5480.11 Radiation Protection Standards for pregnant women and minors are substantially more restrictive than those for occupational workers. Rout ine bioassay monitoring programs may not have the sensitivity required to verify compliance with the more restrictive standards. Internal Dosimetry should be consulted on a specific case bas is as the need arises.

\subsection{SELECTION OF NUCLIDES FOR BIOASSAY}

Any radionuclide or mixture of radionuclides that may contribute more than 25\% to the 100-mrem comitted effective dose equivalent criterion should be included in the bioassay monitoring program. Radionuclides do not require specific bioassay monitoring if they are adequately monitored by indicator nuclides for a reference mixture. 


\subsection{SELECTION OF NUCLIDES FOR BIOASSAY (contd)}

In some cases it is possible to use indicator radionuclides for established mixtures to optimize the number of bioassay measurenents performed. For example, mixtures containing equal parts of $137 \mathrm{Cs}$ and $90 \mathrm{Sr}$ may be sufficiently monitored by using whole body measurements of $137 \mathrm{Cs}$ as an indicator of exposure.

Once a worker is placed on a rout ine program, that program should be reviewed on a regular basis to assure that potentially significant nuclides are adequately addressed.

As a rule of thumb, it may be considered that workers are not likely to be exposed to more than four reference mixtures of radionuclides.

\subsection{BIOASSAY MEASUREMENT FREQUENCY}

The frequency of bioassay measurements is dictated by two objectives. The first is to monitor the accumulation of radioactive material in the body from low-level chronic intakes. The second is to assure that significant acute depositions are detected so that appropriate corrections can be instituted in the working conditions (NCRP 1987).

In general, significant acute intakes are discovered by first-line monitoring methods (e.g., air monitoring, and clothing and body surveys) and are investigated according to the protocol discussed in Chapter 7.0. Nevertheless, a properly chosen bioassay frequency is important both to account for undetected, acute intakes and to monitor the effectiveness of first-1ine monitoring methods.

The choice of frequency depends on the following:

- purpose of the measurement, i.e., to monitor for accumulation from chronic intakes, potential acute intakes undetected by first-line monitoring methods, or acute intakes that occur simuitaneously with a chronic background

- the need to meet the objective given in Section 2.3 (i.e., an annual effective dose equivalent of 100 mrem)

- MDAs for various radionuclides and bioassay measurements

- likelihood and ratios of combinations of radionuclides associated with an intake for a particular facility or task. 


\subsection{BIOASSAY MEASUREMENT FREQUENCY (contd)}

Longest Interval Routine bioassay measurement frequencies longer than Between Bioassays annual are not recomended (NCRP 1987; ANSI 1978). Routine bioassay measurement periods longer than five effective half-lives are also generally not recomnended.

\subsubsection{Typical Bioassay Frequencies}

Table 5.3 lists typical measurement frequencies and monitoring methods for pure radionuclides. Unless otherwise noted, the frequencies are based on detecting an acute intake occurring on the day after the last sample or measurement that could result in a first-year effective dose equivalent of $100 \mathrm{mrem}$. Also, unless noted, it is assumed that chronic intake is negligible. Trying to detect a potential acute intake above a chronic background requires greater sampling frequencies.

\subsubsection{Frequencies for Multiple Nuclides}

Many facilities and tasks deal with more than one radionuclide at a time. In such cases, the measurement frequencies in Table 5.3 may not be appropriate. Characterizing the source of potential intakes and consulting with Internal Dosimetry is advised to establish the best bioassay monitoring progran for the situation. Table 5.4 lists bioassay programs for some typical Hanford radionuclide combinations.

\subsubsection{Uranium Bioassay}

Monitoring for uranium poses special problems for the following reasons:

- Uranium presents both chemical and radiological toxicity risks, the relative importance of which depends on its transportability from the lung.

- Uranium usually exists in mixed transportability classes.

- Small recent intakes easily mask larger older intakes because nearly $50 \%$ of the uranium going to blood is cleared immediately through the urine.

- An intake of class $Y$ material potentially resulting in a committed effective dose equivalent of 100 mrem generally cannot be detected by normal routine bioassay monitoring practices. Monitoring of the workplace to document the working environment and to provide imnediate indication of an intake is essential. 
TABLE 5.3. Potentially Undetected Effective Dose Equivalent for Bioassay Measurements of Single Radionuclides(a)

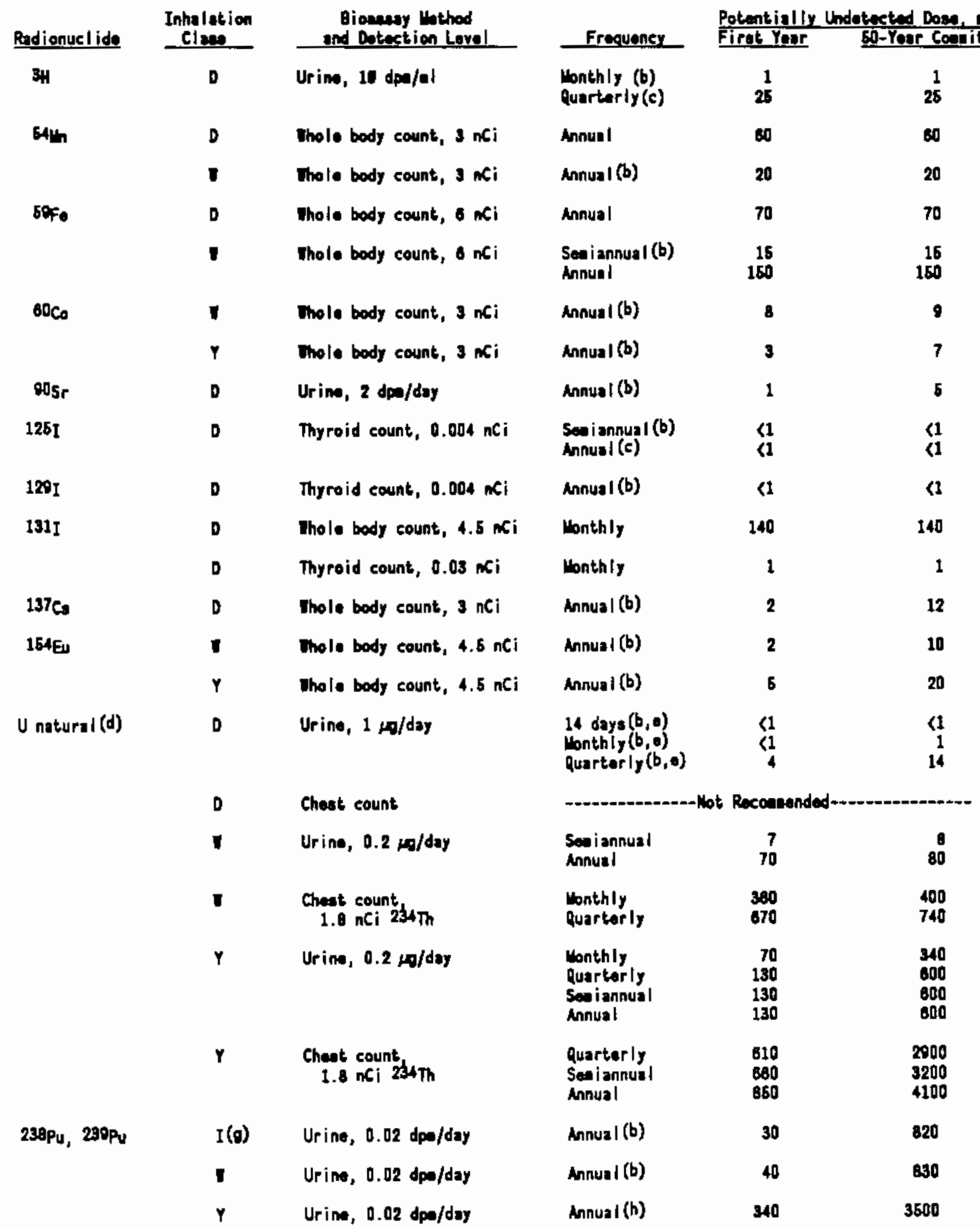


IABLE 5.3. (contd)

\begin{tabular}{|c|c|c|c|c|c|}
\hline Badionuclide & $\begin{array}{l}\text { Inholstion } \\
\text { Claes }\end{array}$ & $\begin{array}{l}\text { Biousey lethod } \\
\text { and Dotection Level }\end{array}$ & Frequency & $\begin{array}{l}\text { Potentially } \\
\text { First Year }\end{array}$ & $\begin{array}{l}\text { detected Doen, orea } \\
\text { Bo-Yoar Conitted }\end{array}$ \\
\hline \multirow[t]{3}{*}{$241 \mathrm{Am}$} & I & Urim, $0.02 \mathrm{dp} / \mathrm{day}$ & Annual (b) & 30 & 950 \\
\hline & (7 & Urine, $0.02 \mathrm{dp} / \mathrm{day}$ & Annual (b) & 360 & 850 \\
\hline & $\mathbf{Y}$ & Cheat count, $0.10 \times \mathrm{C} i$ & Annual (b) & 380 & 3000 \\
\hline
\end{tabular}

(a) Band on dato in Technical gasiz for Internal Doainetry at Hanford (Sula, Carbaugh, and Bihl 1880).

(b) Reconcended frequency.

(c) Dotectable but $75 \times$ half-lifa.

(d) For depleted uraniun, oultiply doese by 0.5 . For recycled uranius, wultiply doses by 1.5 (elaen D), 1.4 (clase 1 ), and 1.3 (claes $\eta$.

(b) Band on chesical toxicity.

(f) Conervily, both ur in anpling and chat counting are necesery for proper conitoring of clase I and Y uranius, especially if chronic intakes are paseible. Frequent urine easpling is uead to eatabliah the tim of an weute inteke or the berinning of ehronic intakes. Leas freawent cheot counting is used to quantify the lung deposition. This applies to deploted-through-1.25s-onriched uraniu, but the detactable offective does equivelenta vill vary sliphtly fros those liated for natural ureniw.

(g) Injection - repreanto readily-treneportable entarial or an intake straight to the blood.

(h) Sea iannusl or cuartarily sappling frequency does not iaprove the ability to detect.

\subsubsection{Uranium Bioassay (contd)}

- Low-level chronic intakes are common, so the bioassay program must monitor for long-term buildup as well as for potentially significant acute intakes.

- Individual and temporal variability in the environmental background of uranium complicates interpretation of urinalysis results.

Consequently, the proper bioassay monitoring program for uranium workers is best determined on a case-by-case basis in consultation with Internal Dosimetry.

\subsubsection{Plutonium - Class $Y$}

An intake of class $Y$ (or worse, i.e., less transportable) plutonium with a $239 \mathrm{Pu}{ }^{241} \mathrm{Am}$ ratio greater than about $1: 1$ cannot practically be detected at a potential annual effective dose equivalent of 100 mrem by routine bioassay monitoring. Prompt detection of an intake at the workplace is essential.

\subsubsection{Special Forms of Nuclides}

Special forms of radionuclides (e.g. tritium or $14 \mathrm{C}$ labeled materials) can behave much differently than the normal compounds for which routine bioassay programs are designed. Case-specific bioassay monitoring programs for situations such as these should be established through consultation with Internal Dosimetry. 


\section{TABLE 5.4. Example Bioassay Programs for Some Typical}

Radionuclide Combinations

Case Description

Reactor corrosion products. These typically include $60 \mathrm{Co} 58 \mathrm{Co}, 54 \mathrm{Mn}$, $59 \mathrm{Fe}$, and ${ }^{134} \mathrm{Cs}$, but ${ }^{60} \mathrm{Co}$ predominates in activity and dose impact.

Aged fission products. ${ }^{137} \mathrm{Cs}$ and $905 r$ predominate. A $1: 1$ ratio is assumed if the site-specific ratio is not known.

Europiums at $N$ Reactor. 154Eu and $155 \mathrm{Eu}$ are assumed to have a $2: 1$ ratio at intake.

Readily-transportable uranium. Considered a chemical toxicity risk only. Both chronic and potential acute intakes are considered.

Depleted-to-slightly-enriched uranium metal and various oxides resulting in a mixture of class $D$ class $Y$ material. Chemical and

radiological risks and chronic and potential acute intakes are considered.

Class $W$ plutonium mixtures containing 238 Pu, 239 pu, 240 Pu, $241 \mathrm{Pu}$, and possibly $241_{\mathrm{Am}}$ in various amounts.

Class Y plutonium mixtures.
Program Description

Annual whole body counts. If $60 \mathrm{Co}$ is detected, germanium counting is done to quantify the other corrosion products.

Annual whole body counts. If $137 \mathrm{Cs}$ is above the screening level, $905 \mathrm{r}$ urine samples are scheduled.

Annual whole body counts.

Biweekly or monthly urine samples obtained after 2-day absence from the workplace.

No program at present is adequate to detect 100 mren. A combination of frequent urine samples and less frequent chest counts is used. Urinaly-

sis results above the screening level trigger special chest counts.

Annual plutonium urine samples and annual chest counts. Chest counts monitor for possible chronic buildup or for small class $Y$ components.

No program at present is adequate to detect 100 mrem. Annual plutonium urine samples and annual chest counts are used. Chest counts quantify lung burden when $241 \mathrm{Am}$ grows in or if the intake is of aged $12 \%$ plutonium. (b)

(a) $N A=$ not applicable.

(b) $12 \%$ by weight $240 \mathrm{Pu}$ at several years after americium separation. 
CHAPTER 6.0

\section{BIOASSAY SERVICES}




\subsection{BIOASSAY SERVICES}

After a bioassay monitoring need has been identified and the appropriate types of measurements have been determined, the measurements then need to be scheduled and performed. This chapter covers normal bioassay services provided through the IDP, i.e., the available bioassay services, the scheduling of bioassay samples, and the generation, reporting, and follow-up of data. Special services not included here can be scheduled by contacting Internal Dosimetry.

Frequently used telephone numbers and mail stops for bioassay services are:

- Internal Dosimetry Dffice, 376-7245, A3-60

- Whole Body Counter Facility, 376-6102, 81-60

- Radiological Rec.ords, 376-6342, 376-8203, A3-60

- United States Testing Company, Inc., Richland, 375-3131, H2-51

\subsection{INDIRECT BIOASSAY MEASUREMENT SERVICES}

The indirect bioassay analyses are performed by the Analytical Services Laboratory (Lab). Terms applicable to Lab services are provided in the Glossary. The Lab is responsible for

- providing sample kits, including kit delivery and pickup at designated locations (usually worker residences) within a 75-mile radius of Richland. (Field Dosimetry is responsible for kit delivery and pickup outside of this range.) Delivery and pickup of routine and priority samples are usually available on business days only.

- attempting a second pickup of a "can not out" sample on a day specified by Field Dosimetry, within 5 days after the originally scheduled pickup.

- analyzing urine and fecal samples in four processing categories: routine, priority, expedite, and emergency.

- analyzing miscellaneous samples, such as blood, body tissue, cloth, air filters, etc., by rapid or priority processing. Some chemical analyses, such as that for creatinine, are also available. 


\subsection{INDIRECT BIOASSAY MEASUREMENT SERVICES (contd)}

Provisions have been made for obtaining bioassay samples from workers outside the 75-mile service area through the use of mail and private carrier. Internal Dosimetry should be contacted if this method of bioassay sampling is to be done.

The sample type and collection method are identified by the sample kit code. Kine kit codes are available. They are explained in Appendix B, Table B.4, and kit instructions are provided in Appendix $D$.

The analytical and reporting requirements for the four processing categories as of FY 1989 are detailed in Tables 6.1 through 6.6. Changes in these requirements occur from year to year. Therefore, Internal Dosimetry should be contacted when the most accurate information is needed.

Note that the detection levels listed are "contractual." Actual detection levels, as determined by statistics like those in draft ANSI N13.3D,(a) are generally equal to or lower than the contractual detection levels (CLs).

\subsection{IN VIVO MEASUREMENT SERVICES}

Rout ine in vivo measurements are performed by PNL's O\&EP Section at the 747-A Building. In vivo measurement services are summarized below and details are provided in the Whole Body Counting Manual (Palmer et al. 1987). The type of measurement performed depends on the radionuclide(s) being looked for and, for some radionuclides, the expected location of the radionuclide(s) in the body.

\subsubsection{Whole Body Counts}

Most gamma-emitting radionuclides can be easily detected by a standard whole body count. This measurement is normally scheduled as a periodic routine measurement or when an employee is newly hired, terminated, or beginning or ending a special project. No appointment is necessary for a whole body count. Annually scheduled in vivo examinations normally occur on the same day as the worker's annual physical.

The whole body measurement may consist of one or more counts using different equipment. Generally, a screening

(a) American National Standards Institute (ANSI). 1987. Performance Criteria for Radiobioassay. Draft ANSI Standard N13.30, New York, New York. 
IABLE 6.1. Analytical and Reporting Requirements for Routine Processing of Samples

\begin{tabular}{|c|c|c|c|c|c|}
\hline \multirow[b]{2}{*}{ Constituents Roported } & \multicolumn{2}{|c|}{$\begin{array}{c}\text { Contractual } \\
\text { Dotoct ion Lovel (a) }\end{array}$} & \multirow{2}{*}{$\begin{array}{l}\text { Dutoraination } \\
\text { rive (bus inoss } \\
\text { dayz folloring } \\
\text { salplo recoiph) }\end{array}$} & \multicolumn{2}{|c|}{ Reporting Tine } \\
\hline & $\begin{array}{l}\text { Idpingapl } \\
\text { Uring }\end{array}$ & Focal & & Oral & Irittion (b) \\
\hline 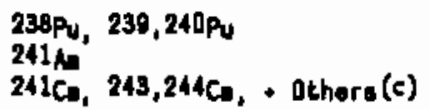 & $\begin{array}{l}0.02 \\
0.02 \\
0.02\end{array}$ & 0.2 & $\begin{array}{l}20 \\
20 \\
20\end{array}$ & By close of & \\
\hline 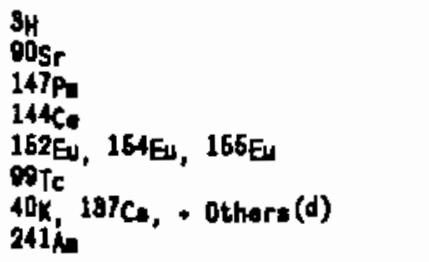 & 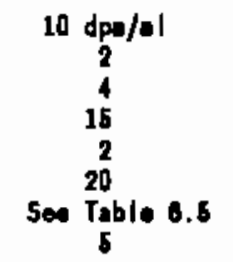 & & $\begin{array}{l}5 \\
30 \\
20 \\
20 \\
20 \\
20 \\
20 \\
20\end{array}$ & $\begin{array}{l}\text { day of dotar- } \\
\text { ination if } \\
\text { proporting } \\
\text { lovel(f) }\end{array}$ & $\begin{array}{l}\text { Within } 5 \\
\text { businos: } \\
\text { days }\end{array}$ \\
\hline $\begin{array}{l}\text { Elenontal U } \\
\text { Elonontal U }\end{array}$ & $\begin{array}{l}0.03 \text { po/sanple } \\
0.6 \mathrm{\mu g} / \mathrm{sanp} / \mathrm{e}\end{array}$ & & 20 & & \\
\hline $\begin{array}{l}\text { Same on for individual } \\
\text { analyes aboyo }\end{array}$ & $\begin{array}{l}\text { Sane as for indi } \\
\text { analysos above }\end{array}$ & duel & $\begin{array}{l}\mathbf{9 5} \\
\mathbf{2 5} \\
\mathbf{2 5} \\
\mathbf{2 5} \\
\mathbf{3 6}\end{array}$ & & \\
\hline
\end{tabular}

(a) Hininus volume for valid eaples of urine is 600 a for kit code 1 (oxcopt for 99Te for thich the eaxinu aliquot eize is 200 el) and 20 al for all other sapple types.

(b) Fime allorod folloning doteruination of sanples for recoipt of uritton resulto by Internal Dosinotry.

(d) Roport all radionuclides observed to be present at lovels oxcoeding the oppropriate controctual dotection lovel (a) in Table e.s and any othor redionucl ides dotorained to be present. If ordered by the Battollo Technical Adninietrator, report roevito for radionuclidas I istod in Table 6.5 specified with the order, ragardleas of noanured level of uctivity.

(o) Pu(a) ieotopic, 241 A and $\mathrm{Co}(\mathrm{a})$ ieotopic.

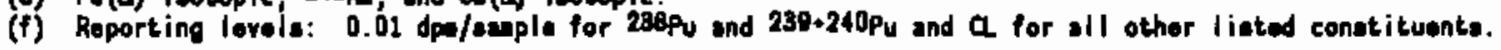


IABLE 6.2. Analytical and Reporting Requirements for Priority Processing of Samples

\begin{tabular}{|c|c|c|c|c|c|c|}
\hline \multirow[b]{2}{*}{ Ans lysie (Code) } & \multirow[b]{2}{*}{ Conetitinante Reperted } & \multicolumn{2}{|c|}{$\begin{array}{l}\text { Contructual } \\
\text { Dotection Lovel (s) } \\
\text { (dpa/agede) }\end{array}$} & \multirow{2}{*}{$\begin{array}{l}\text { Dotare instion } \\
\text { Tise (bus inose } \\
\text { daye fol louing } \\
\text { sesple receipt) }\end{array}$} & \multicolumn{2}{|c|}{ Peporting Ties } \\
\hline & & Urine & Fecal & & Oral & Iritten (b) \\
\hline 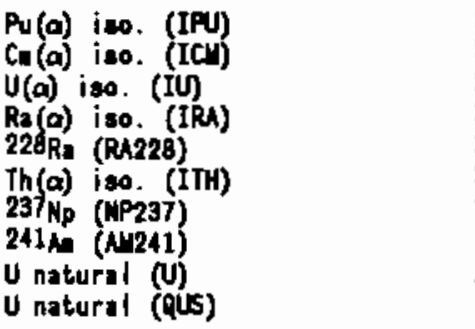 & 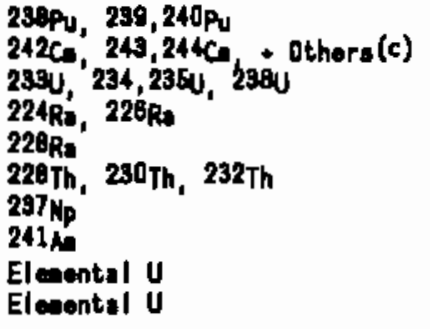 & $\begin{array}{c}0.02 \\
0.02 \\
0.02 \\
0.8 \\
0.3 \\
0.1 \\
0.02 \\
0.02 \\
0.03 \\
0.6 \text { po/sat }\end{array}$ & $\begin{array}{l}0.2 \\
0.8 \\
0.3 \\
1.5 \\
1.5 \\
1.5 \\
1 \\
0.1\end{array}$ & $\begin{array}{l}0 \\
0 \\
8 \\
8 \\
0 \\
0 \\
0 \\
0 \\
0 \\
4\end{array}$ & $\begin{array}{l}\text { By close of } \\
\text { business on } \\
\text { day of } \\
\text { deteraination }\end{array}$ & \\
\hline 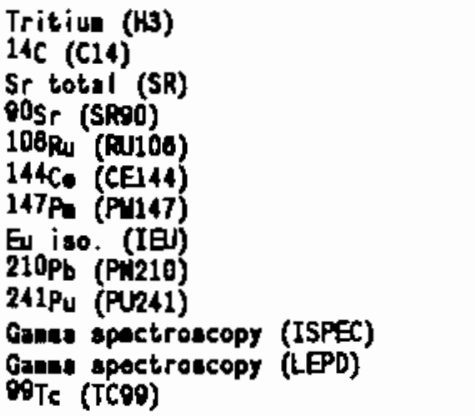 & 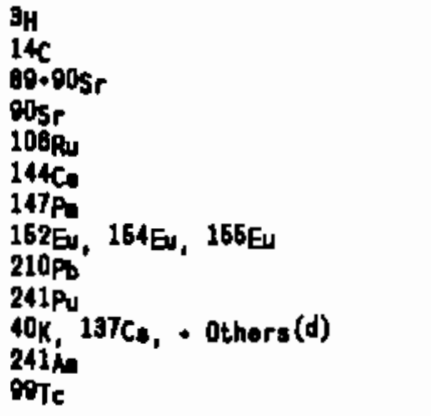 & $\begin{array}{c}10 \mathrm{dpe/ai} \\
10 \mathrm{dpe/=1} \\
2 \\
0,2 \\
10 \\
25 \\
4 \\
2 \\
2 \\
2 \\
5 \\
20\end{array}$ & $\begin{array}{l}-- \\
208 \\
19 \\
46,10 \\
25 \\
25 \\
220 \\
15 \\
20 \\
7 \\
9.5 \\
5 \\
200\end{array}$ & $\begin{array}{c}3 \\
8 \\
7 \\
15(0) \\
6 \\
6 \\
8 \\
8 \\
8 \\
9 \\
3 \\
8 \\
8\end{array}$ & & $\begin{array}{l}\text { Tithin } 5 \\
\text { businese } \\
\text { days }\end{array}$ \\
\hline 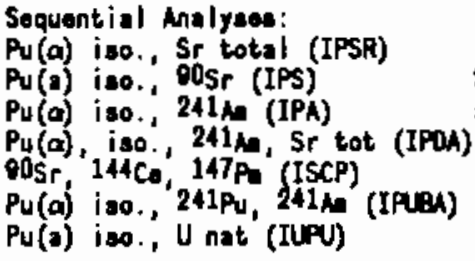 & $\begin{array}{l}\text { Sane as for indiridual } \\
\text { analyeas }\end{array}$ & $\begin{array}{l}\text { Sawe as for } \\
\text { analyses }\end{array}$ & dual & $\begin{array}{l}q \\
q(f) \\
q(f) \\
g(g) \\
q(g) \\
q(h)\end{array}$ & $\begin{array}{l}\text { By close } \\
\text { of bua inase } \\
\text { on day of } \\
\text { deteruination }\end{array}$ & $\begin{array}{l}\text { Within } 9 \\
\text { bus inese } \\
\text { dayo }\end{array}$ \\
\hline
\end{tabular}

(a) Winieus auple size is 20 a for urine and 30 grase for foces. Waxieus al iquot size for 9 Te is 200 al. The contractual detection level (Q) is stated in torns of disintegrations per ninute per 50 grase for fecsl ecaples in oxcese of 60 grans.

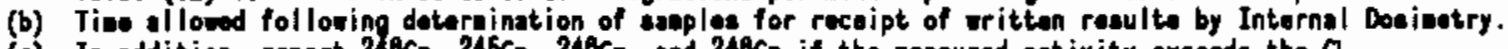

(c) In addition, report 240Ca, 246C, 246C and 248C if the eeasured activity exceode the $\mathbb{C}$.

(d) Roport all radionuclides obearved to be present at levels oxceeding the appropriate $Q$ in Tablo 8.5 and any other radionuclides dotereined to be present. If ordered by the Battelle Technical Adainistrator, report reaulte of radionuclides lieted in Table 6.6 specified with the order, ragardlese of noasured level of activity.

(o) Strontiun-80 to be detereined vithin 15 businese days. Total strontiue to be deterained vithin 7 businese daye and roported orally upon doteraination.

(f) Strantiua-\$0 to be deterained vithin 16 bueinese daye. Tatal strontiun to be dotareined vithin business daye and reported orally upon doternination.

(a) 241Pu to be deternined vithin 16 business days.

(h) U natural to be detarained vithin 12 businese days. 
TABLE 6.3. Analytical and Reporting Requirenents for Expedite Processing of Samples

\begin{tabular}{|c|c|c|c|c|c|}
\hline \multirow[b]{2}{*}{ Analreis (Code) } & \multirow[b]{2}{*}{ Constituents Reported } & \multirow{2}{*}{\multicolumn{2}{|c|}{$\begin{array}{l}\text { Contractuol } \\
\text { Dotection Lovel (o) } \\
\text { (dop/seuple) }\end{array}$}} & \multicolumn{2}{|c|}{ Reporting Tize } \\
\hline & & $\begin{array}{c}\text { (dpels } \\
\text { Urine }\end{array}$ & & Bral & Iritten(b) \\
\hline 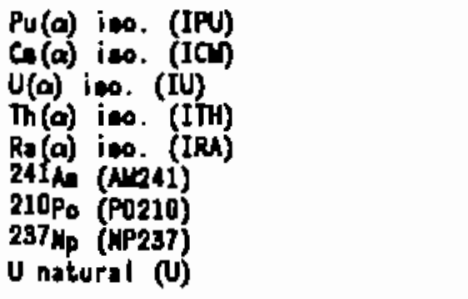 & 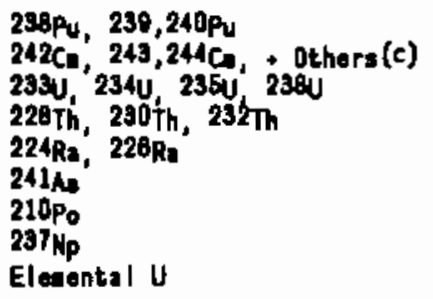 & 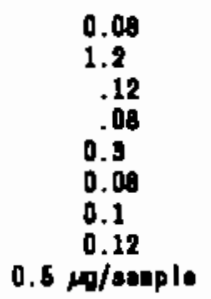 & $\begin{array}{c}3 \\
70 \\
4 \\
1 \\
3 \\
6 \\
10 \\
3 \\
5 \text { posaplo }\end{array}$ & $\begin{array}{l}\text { By } 0: 00 \text { a.a. } \\
\text { on 2nd business } \\
\text { day fol lowing } \\
\text { anplo receipt }\end{array}$ & $\begin{array}{l}\text { Within } 6 \\
\text { bus inose } \\
\text { daye }\end{array}$ \\
\hline 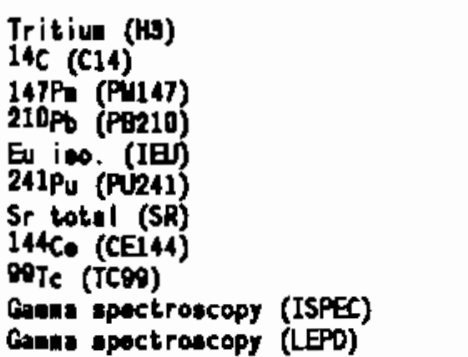 & 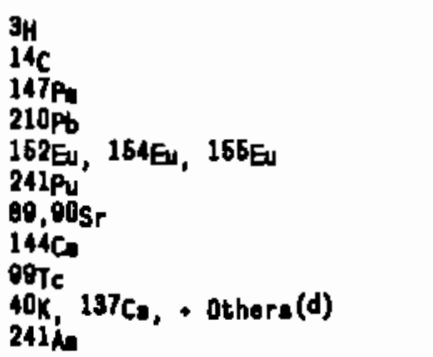 & $\begin{array}{c}100 \mathrm{dpm} / \mathrm{al} \\
20 \mathrm{dpm} / \mathrm{l} / \\
5 \\
4 \\
5 \\
3 \\
10 \\
10 \\
30 \\
5\end{array}$ & $\begin{array}{r}2000 \\
2000 \\
100 \\
180 \\
70 \\
150 \\
60 \\
2000 \\
6.6 \\
6\end{array}$ & & \\
\hline 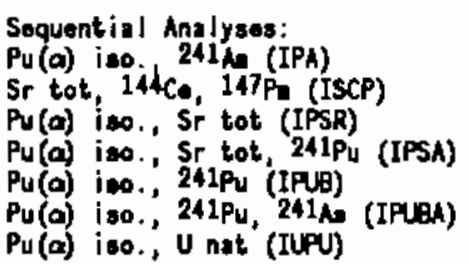 & - & $\begin{array}{l}\text { ual analyses--- } \\
\text { ual analysos--- } \\
\text { ual onalyoos--- } \\
\text { (o) }\end{array}$ & (c) & & \\
\hline
\end{tabular}

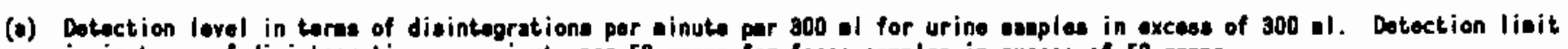
is in torns of disintegrations per ainute par 50 greas for foces sapples in excese of 50 grans.

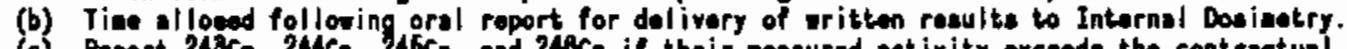

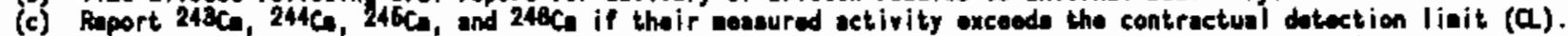

(d) Roport all radionuclides obeerved to be present at lovelo exceoding the appropriate Q listed in Table 8.5 and all other redionuclides obearved. If ordered by the Battelle Technical Adninietrator, report resulte for radionuclides in Table 6.6 apecified in the processing inatructions, regardiess of the activity measured.

(๑) Additional 2 businose days for roporting 24 pu resulta. 
TABLE 6.4. Analytical and Reporting Requirements for Energency Processing of Samples

\begin{tabular}{|c|c|c|c|c|c|}
\hline \multirow[b]{2}{*}{ Analyais (Coda) } & \multirow[b]{2}{*}{ Conatituents Reportiod } & \multicolumn{2}{|c|}{$\begin{array}{c}\text { Contractual } \\
\text { Dotection Lovel (a) } \\
\text { (dpa/susplo) }\end{array}$} & \multicolumn{2}{|c|}{$\begin{array}{l}\text { Reporting Roquircoonts } \\
\text { (howrs folloming sonplo } \\
\text { sup lo recoipt) }\end{array}$} \\
\hline & & Urine & Focen & Urine/Foces & Iritten (b) \\
\hline 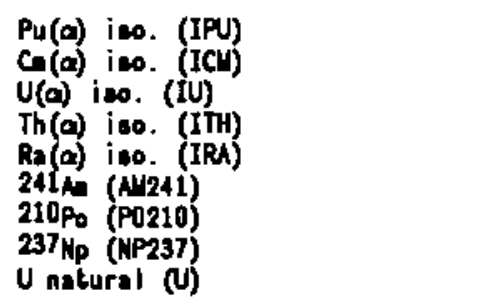 & 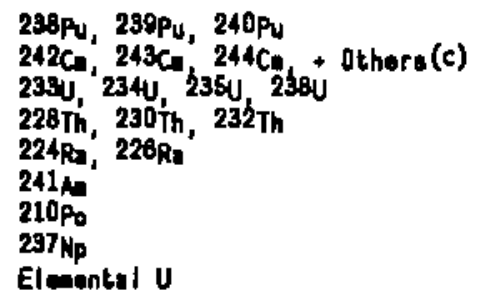 & $\begin{array}{c}0.5 \\
10 \\
1 \\
0.5 \\
2.0 \\
1 \\
0.0 \\
1 \\
7 \text { polsaplo }\end{array}$ & $\begin{array}{r}240 \\
12 \\
2 \\
10 \\
20 \\
340 \\
10 \\
90 / \text { sappl. }\end{array}$ & $\begin{array}{l}5 / 8 \\
6 / 8 \\
5 / 8 \\
5 / 8 \\
8 / 8 \\
5 / 9 \\
4 / 9 \\
6 / 8 \\
1 / 8\end{array}$ & $\begin{array}{l}\text { Vithin } \\
24 \text { hours } \\
\text { and det: } \\
\text { circuit } \\
\text { input } \\
\text { eithin } 5\end{array}$ \\
\hline 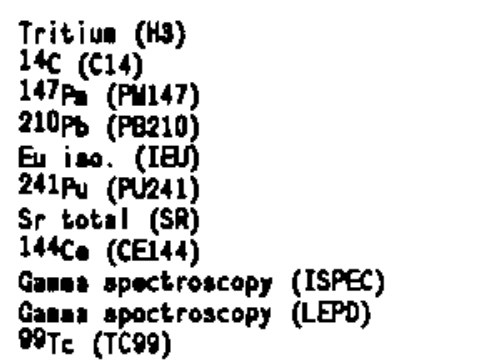 & 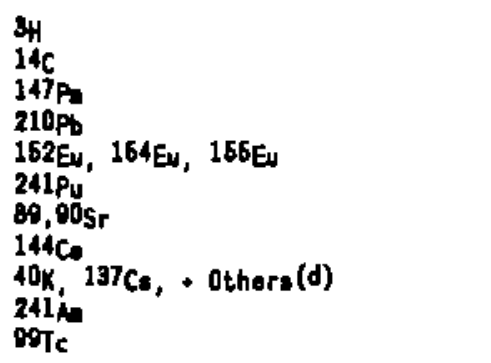 & $\begin{array}{c}500 \mathrm{dpa} / 1 / 1 \\
100 \mathrm{dpp} / \mathrm{in} \\
8 \\
20 \\
140 \\
20 \\
90 \\
75 \\
--500 \mathrm{~T} \\
20 \\
80\end{array}$ & $\begin{array}{r}10,000 \\
8,000 \\
340 \\
600 \\
450 \\
450 \\
146 \\
10.00 \\
8,000\end{array}$ & $\begin{array}{l}1 /- \\
1 / 8 \\
0 / 8 \\
4 / 8 \\
3 / 8 \\
4 / 8 \\
4 / 8 \\
3 / 3 \\
3 / 3 \\
3 / 3 \\
8 / 8\end{array}$ & daye \\
\hline $\begin{array}{l}\text { Sequontial Aralysos: } \\
\text { Pu(a) iso. } 241 \text { (IPA) } \\
\text { Sr tot, 14tCe, 147P (ISCP) } \\
\text { Pu(a) ieo., Sr tot (IPSR) } \\
\text { Pu(a) iso., Sr tot, 24IPu (IPSA) }\end{array}$ & 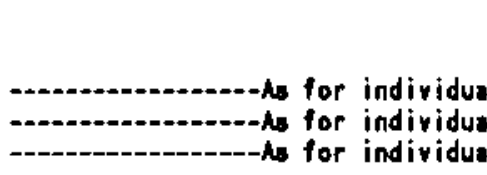 & $\begin{array}{l}\text { oma ysos-- } \\
\text { analysos- }\end{array}$ & 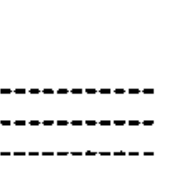 & $\begin{array}{l}5 / 8 \\
5 / 8 \\
6 / 8 \\
5 / 8\end{array}$ & \\
\hline
\end{tabular}

(a) Dotection lovel in teras of disintegrations por ainute per 300 ol for urine sapplos in excess of 300 al. Detection lisit is in terms of disintegrations por ainute por 60 grans for foces anples in exceses of 60 grace.

(b) Tius allowed following oral report for delivery of oritten results to Internel Dosisetry.

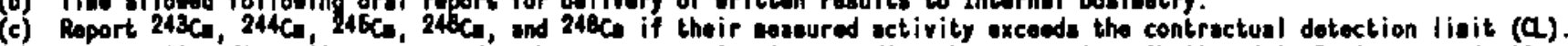

(d) Roport all radionuclides obeerved to be present ot lovele oxceeding the appropriate $Q$ listed in Table 6.5 and all other redionuclides obsarved. If ordared by tha Battolle Technical Adminiatrator, report reaulte for radionuclides in Table 6.6 epecified in the procose ing instructions, ragardioes of the activity asaured. 
TABLE 6.5. Contractual Detection Levels for Routine, Priority, and Expedite Processed Gama Spectroscopy Analyses(a)

\begin{tabular}{ccc} 
Isotope & $\begin{array}{c}\text { CL for Urine } \\
\text { (dpm/sample) }\end{array}$ & $\begin{array}{c}\text { CL for Feces } \\
\text { (dpm/sample) }\end{array}$ \\
\hline $60 \mathrm{Co}$ & 15 & 15 \\
$59 \mathrm{Fe}$ & 15 & 15 \\
$54 \mathrm{Mn}$ & 10 & 10 \\
$106 \mathrm{Ru}$ & 60 & 75 \\
$141 \mathrm{Ce}$ & 15 & 20 \\
$144 \mathrm{Ce}$ & 40 & 50 \\
$134 \mathrm{Cs}$ & 10 & 10 \\
$137 \mathrm{Cs}$ & 15 & 15 \\
$95 \mathrm{Zr}$ & 15 & 20 \\
$140 \mathrm{Ba}$ & 35 & 35 \\
$131_{\mathrm{I}}$ & 10 & 20 \\
$24 \mathrm{Na}$ & 15 & 15 \\
$22 \mathrm{Na}$ & 15 & 15 \\
$65 \mathrm{Zn}$ & 20 & 20 \\
$239 \mathrm{~Np}$ & 25 & 30 \\
$241_{\mathrm{Am}}$ & 70 & 65 \\
\hline
\end{tabular}

(a) The Lab shall resolve and quantify unknown mixtures of ganma-emitting radionuclides. The nuclides and contractual detection levels (CLS) listed should be interpreted as minimum capability; the Lab shall detect and quantify all other gamma-emitters present at a nominal detection level of $20 \mathrm{dpm}$ for each unspecified nuclide with gamma energy $>100 \mathrm{keV}$. Internal Dosimetry may relax the CLs for individual nuclides in mixtures if requested and justified by the Lab.

(b) The CLs are in units of $\mathrm{dpm} / 1$ for samples $\geq 11$. 
IABLE 6.6. Contractual Detection Levels for Emergency Processing of Gama Spectroscopy Analyses (a)

\begin{tabular}{ccc} 
Isotope & $\begin{array}{c}\text { CL for Urine } \\
\text { (dpm/sample) }\end{array}$ & $\begin{array}{c}\text { CL for Feces } \\
\text { (dpm/sample) }\end{array}$ \\
\hline $60 \mathrm{Co}$ & 35 & 35 \\
$59_{\mathrm{Fe}}$ & 35 & 55 \\
$54 \mathrm{Mn}$ & 20 & 35 \\
$106 \mathrm{Ru}$ & 115 & 220 \\
$141_{\mathrm{Ce}}$ & 20 & 35 \\
$144 \mathrm{Ce}$ & 75 & 145 \\
$134 \mathrm{Cs}$ & 20 & 30 \\
$137 \mathrm{Cs}$ & 20 & 35 \\
$95 \mathrm{Zr}$ & 30 & 50 \\
$140 \mathrm{Ba}$ & 60 & 115 \\
$131 \mathrm{I}$ & 15 & 25 \\
$24 \mathrm{Na}$ & 25 & 25 \\
$22 \mathrm{Na}$ & 25 & 25 \\
$65 \mathrm{Zn}$ & 40 & 65 \\
$239 \mathrm{~Np}$ & 40 & 70 \\
$241 \mathrm{Am}$ & 100 & 180 \\
& &
\end{tabular}

(a) The Lab shall resolve and quantify unknown mixtures of gamna-emitting radionuclides. The nuclides and contractual detection levels (CLs) listed should be interpreted as minimum capability; the Lab shall detect and quantify other unspecified gama-emitters present. Internal Dosimetry may relax the CLs for individual nuclides in mixtures if requested and justified by the Lab.

(b) The CLs are in units of $\mathrm{dpm} / 100 \mathrm{ml}$ for samples $>100 \mathrm{ml}$. 


\subsubsection{Whole Body Counts (contd)}

count will be performed on the preview counter, which is a standup counter that uses five MaI detectors. If the preview counter indicates the presence of an occupationally related radionuclide or if there are interferences that limit the usefulness of NaI spectronetry, the sled counter is also used. The sled counter, which uses two germanium detectors, can better resolve and quantify radionuclides, especially in the presence of interfering radionuclides, such as radon progeny.

The whole body count produces results under two different assumptions for the distribution of the activity in the body: 1) evenly distributed throughout the body, and 2) in the lung only. Table 6.7 lists the detection capabilities for radionuclides routinely quantified by the preview counter for the two distribution assumptions. The sled counter provides sensitivity equal to or better than the preview counter for all listed radionuclides.

\subsubsection{Chest Counts}

Chest counting is also performed when there is concern about the presence in the lung of radionuclides that emit photons with energies of less than $200 \mathrm{keV}$. A chest count must be scheduled in advance with the whole Body Counter (WBC) staff. When possible, annual chest counts are scheduled to coincide with a worker's whole body measurement and physical examination. There are two types of chest counts: a normal count (code $C$ ) and an extra-sensitive count (code $\mathrm{C} 2$ ). They differ only in the time of the count. Detection capabilities for chest counts are listed in Table 6.8 under "lung."

If activity is detected in a chest count, a measurement of chest wall thickness and a head count may also be needed to make appropriate corrections to the chest count data. These measurements may be performed on the same day or rescheduled for a later date.

\subsubsection{Special Counts}

Other counts performed by special request include liver counts (for low-energy photons), head counts (to determine skeletal content for low-energy photons), thyroid counts (for radioiodines), wound counts, and selected lymph node counts. These counts are normally performed as part of special investigations or as long-term follow-up of known depositions. These counts are arranged through Internal Dosimetry.

Table 6.8 lists the detection capabilities for radionuclides emitting low-energy photons, which are analyzed 


\section{IABLE 6.7. Accuracy and Sensitivity for Whole Body Counts in the Preview}

Counter(a)

\begin{tabular}{|c|c|c|c|c|c|c|}
\hline Radionucl ide & $\begin{array}{l}\text { Gana Ray } \\
\text { Enorar. Hoy }\end{array}$ & $\begin{array}{l}\text { Counting } \\
\text { Ties } \\
\text { (ace) }\end{array}$ & Organ (c) & $\begin{array}{l}95 x \text { Conf idence } \\
\text { Ins Statistieal } \\
\text { Error (mCi) } \\
\end{array}$ & $\begin{array}{c}\text { Lo } \\
\text { Precigion(d) } \\
(x)\end{array}$ & $\begin{array}{l}10 \text { Eatioato } \\
\text { oody Shapa and } \\
\text { Size Error ( }(0)(0)\end{array}$ \\
\hline 197CE-197B & 0.602 u. & 2000 & $\begin{array}{l}\mathrm{IB} \\
\mathrm{L}\end{array}$ & $\begin{array}{l}3 \\
2.4\end{array}$ & $\begin{array}{l}5 \\
5\end{array}$ & $\begin{array}{l} \pm 10 \\
\pm 10\end{array}$ \\
\hline $51 \mathrm{Cr}$ & 0.32 b V V & 200 & $L^{\mathbf{B}}$ & $\begin{array}{l}22 \\
18\end{array}$ & $\begin{array}{l}5 \\
5\end{array}$ & $\begin{array}{l} \pm 15 \\
\pm 15\end{array}$ \\
\hline${ }^{80} \mathrm{Co}$ & $\begin{array}{l}1.17 \text { and } \\
1.33 \text { bov }\end{array}$ & 200 & $\mathrm{~L}$ & $\begin{array}{l}3 \\
2.4\end{array}$ & $\begin{array}{l}5 \\
5\end{array}$ & $\begin{array}{l} \pm 10 \\
\pm 10\end{array}$ \\
\hline 131I & $0.36 \mathrm{buV}$ & 200 & L & $4.5(f)$ & $\begin{array}{l}5 \\
5\end{array}$ & $\begin{array}{l} \pm 15 \\
\pm 20\end{array}$ \\
\hline $58 \mathrm{Fo}$ & $\begin{array}{l}1.10 \text { and } \\
1.20 \mathrm{Wh}\end{array}$ & 200 & $L^{18}$ & 4.6 & $\begin{array}{l}5 \\
5\end{array}$ & $\begin{array}{l} \pm 10 \\
\pm 10\end{array}$ \\
\hline S4 & $0.84 \mathrm{HoV}$ & 200 & IB & $\begin{array}{l}3 \\
2.4\end{array}$ & $\begin{array}{l}5 \\
5\end{array}$ & $\begin{array}{l} \pm 10 \\
\pm 10\end{array}$ \\
\hline 108RU-108Rh & $0.51 \mathrm{HoV}$ & 200 & L & $\begin{array}{r}12 \\
8\end{array}$ & $\begin{array}{l}5 \\
5\end{array}$ & $\begin{array}{l} \pm 10 \\
\pm 10\end{array}$ \\
\hline $40 \mathrm{k}$ & $1.40 \mathrm{WbV}$ & 200 & 18 & 15 & 5 & \pm 10 \\
\hline $110_{\mathrm{Ag}}$ & 0.858 LoV & 200 & IB & $\begin{array}{l}3 \\
2.4\end{array}$ & $\begin{array}{l}5 \\
5\end{array}$ & $\begin{array}{l} \pm 10 \\
\pm 10\end{array}$ \\
\hline 222 $\mathrm{Na}$ & $1.28 \mathrm{WVV}$ & 200 & DB & 1.5 & 5 & \pm 10 \\
\hline 24 & $\begin{array}{l}1.37 \text { and } \\
2.76 \text { bov }\end{array}$ & 200 & TH & 0.7 & 5 & \pm 10 \\
\hline 232Th & $\begin{array}{l}\text { Laing } 208 \mathrm{Tl} \\
2.01 \mathrm{HbV}\end{array}$ & 200 & IB & $\begin{array}{l}2 \\
1.6\end{array}$ & $\begin{array}{l}5 \\
5\end{array}$ & $\begin{array}{l} \pm 10 \\
\pm 10\end{array}$ \\
\hline$B 5 Z n$ & $1.12 \mathrm{bV}$ & 200 & L & $\begin{array}{l}4.5 \\
3.4\end{array}$ & $\begin{array}{l}5 \\
5\end{array}$ & $\begin{array}{l} \pm 10 \\
\pm 10\end{array}$ \\
\hline $95 \mathrm{Zr}-95 \mathrm{Nb}$ & $\begin{array}{l}0.724 \text { and } \\
0.768\end{array}$ & 200 & L & $\begin{array}{l}3 \\
2.4\end{array}$ & $\begin{array}{l}5 \\
5\end{array}$ & $\begin{array}{l} \pm 10 \\
\pm 10\end{array}$ \\
\hline $1265 b$ & $176 \mathrm{keV}$ & 200 & $\mathbf{T B}^{\mathrm{T}}$ & 8.6 & $\begin{array}{l}5 \\
5\end{array}$ & \\
\hline 164Eu & 1.274 & 200 & L & $\begin{array}{l}4.6(0) \\
3.4\end{array}$ & $\begin{array}{l}5 \\
5\end{array}$ & $\begin{array}{l} \pm 10 \\
\pm 10\end{array}$ \\
\hline $144 \mathrm{Co}_{0}-144 \mathrm{Pr}$ & 2.18 & 200 & L & ${ }_{75}^{100(g)}$ & $\begin{array}{l}5 \\
5\end{array}$ & $\begin{array}{l} \pm 10 \\
\pm 10\end{array}$ \\
\hline 140La & $1.5 \mathrm{mo}$ & 200 & L & $\begin{array}{l}2 \\
1.5\end{array}$ & $\begin{array}{l}5 \\
5\end{array}$ & $\begin{array}{l} \pm 10 \\
\pm 10\end{array}$ \\
\hline
\end{tabular}

(a) Roproduced from Paleor ot al. (1987)

(b) Soe Equation 7.1 in the Ihole Body Counting Henual (Palmor ot al. 1987).

(c) IB $=$ thol body; $L=$ lung.

(d) Precision values are for cueas where the count rate is high onough that the count rato orror is ingignificant cospared with the precision orror.

(a) Activity in the gastrointastinal tract can give counting rates that vary $\pm 5 x$, dopanding on the location vithin the tract.

(f) Lower an can be obtzined by other nothods (soe Table 7.3 in the thole Oody Counting Hanual [Paleor ot al. 1987]).

(a) Wuch lower un ia obtained using six geraaniue planar detector systoes (oes Tablo 7.1 in the Whole Body Counting Hanual [Palnor ot al. 1987]). 
TABLE 6.8. Accuracy and Sensitivity for In Vivo Measurements of Common Radionuclides Using Various Numbers of Germanium Planar Detectors (a)

Low-Energy Photon Eitters

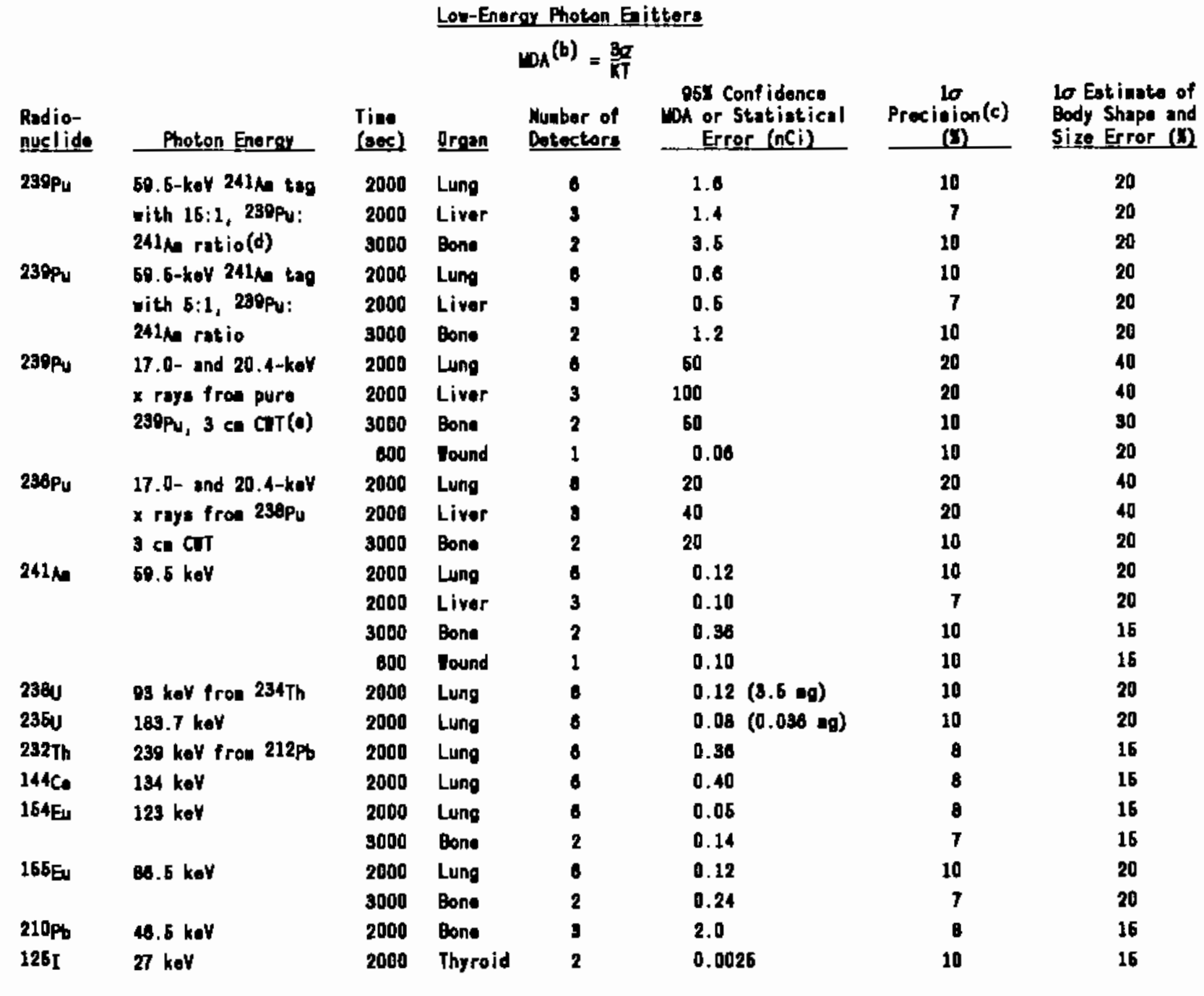

(a) Rioproduced fron Palnor at al. (1097).

(b) Sow Equation 7.2 in Paloer ot al. (1697).

(c) Precieion values are for coses there the count rote is high enough that the counting rate orror is ineignificant Precision values aro for ceace shoro

(d) This asaumed ratio does not nan that this is a contonly found ratio nor dow it woan that the ratio of

238pu to 241 a reasine conatant is it transfers froe lung or cound to liver and bone.

(o) CIT = chest wall thiskness. 


\subsubsection{Special Counts (contd)}

using germanium detectors, assuming normal count times. slightly lower MDAs can be achieved if longer count times can be arranged.

\subsection{SCHEDULING AND RECORD KEEPING}

This section discusses scheduling of bioassay measurements, reporting of routine results to Field Dosimetry, and record keeping. Follow-up of detected activity is discussed in Section 6.4. Assessment of confirmed intakes is covered in Chapter 3.0, and response to incidents is covered in Chapter 7.0.

\subsubsection{Contacting the Worker}

All contacts with the worker concerning the scheduling and results of bioassay measurements are conducted by Field Dosimetry. (During a response to an incident, both Field Dosimetry and Internal Dosimetry usually work directly with the worker.) Internal Dosimetry also consults with a worker at other times at the request of Field Dosimetry.

\subsubsection{Scheduling Indirect Bioassay Measurements}

Summory

The PNL 08EP Section coordinates all bioassay measurement requests to the Lab, either through Internal Dosimetry or through Radiological Records using the ORE database.

The details of scheduling depend on the reason the sample is needed. Currently used sample reason codes are described in Table 6.9, and scheduling details categorized by reason type are discussed below. Table $B .3$ in Appendix $B$ provides explanations of both current and historical sample reason codes.

Beginning Work, Ending Work, New Hire. Termination
To schedule a worker for a beginning or ending work, new hire, or termination sample, Field Dosimetry must complete two steps:

1. Field Dosimetry submits an Employee and Dosimetry Changes form (Exhibit 6.1) to Radiological Records to delete the old routine schedule (if there is one) and to establish the new routine schedule. This information is entered into the ORE database, and the form is kept in the worker's ORE file. (An Employee and Dosimetry Changes form is not needed for beginning and ending work samples for planned offsite exposures.) 


\section{TABLE 6.9. Reason Codes for Indirect Bioassay Measurement}

Reason for

Measurement

Routine

New hire

Beginning work

Ending work

Contractor request

Incident

Exposure evaluator

(EE) request

Termination

Recount

Investigate high rout ine

Follow-up

Research/Quality Control

Visitor
Code

$\mathbf{R}$

H

B

Sample is collected before a worker begins a specific type of radiation zone work or before an offsite trip where potential internal exposure could occur. Routine processing time is normally used.

E Sample is collected after a worker completes a specific type of radiation zone work or after return from a trip where potential offsite internal exposure could have occurred. Routine processing time is normally used.

F Sample is requested by Field Dosimetry for reasons other than an indication of a potential occupational exposure.

I Sample is requested after a potential occupational internal exposure.

$X \quad$ Sample is requested by an EE for special purposes not covered by other reason codes.

T Sample is collected when a worker terminates employment. No entry into radiation zones should occur after sample is collected. Priority processing time is normally used.

C Original measurement is recounted to confirm the detected activity.

$\checkmark \quad$ Sample is collected after the report of an unexpectedly high result. Usually priority or expedite processing time is used.

$\checkmark \quad$ Sample is collected for long-term follow-up after an evaluation. Usually routine processing time is used.

Q Sample is collected for research or quality control.

2 Sample is collected from a visitor to Hanford. 


\subsubsection{Scheduling Indirect Bioassay Measurements (contd)}

Beginning Work, Ending Work, New Hire, Termination (contd)

Routine

Contractor

Request

Incident, Exposure Evaluator (EE) Request, Investigate High Routine, Follow-Up
2. The sample request is either called in by field Dosimetry to the Internal Dosimetry clerk or sent in on a Field Dosimetry Bioassay Request Sheet form (see Exhibit 6.2).

The Employee and Dosimetry Changes form (Exhibit 6.1) initiates the request for a routine bioassay measurement schedule. It should be completed and sent to Radiological Records at the time the new hire or beginning work sample request is made. Information from the form is put on the ORE database and sent to Field Dosimetry for review about 1 month before the scheduled sample time. The reviewed list is then sent to the Lab 1 week before the scheduled sample month, and this pattern is repeated routinely until another Employee and Dosimetry Changes form is received.

If the routine sample is not collected for some reason, or is of insufficient volume, or is "lost in lab," the Lab notifies Field Dosimetry directly. Field Dosimetry reschedules the sample request through the Internal Dosimetry clerk, either by telephone or by using the Field Dosimetry Bioassay Request Sheet form (Exhibit 6.2). Internal Dosimetry has the request information entered into the ORE database.

Contractor-requested measurements are made by Field Dosimetry to the exposure evaluator (EE), usually by telephone.

Incident measurement requests, EE-requested measurements, requests for investigation of high routine measurements, and follow-up measurements are requested by an EE after consultation with Field Dosimetry. During incident response, the EE often gives sample kits directly to the worker. Incident codes and investigatehigh-routine codes are used while data are being collected for an assessment. After a preliminary or final assessment has been made, samples collected for further surveillance of the intake are referred to as follow-up samples.

\subsubsection{Reporting Results from Indirect Measurements}

Volid Results

A result from a routinely processed sample is verbaliy reported to Internal Dosimetry if it exceeds the reporting level. For most indirect analyses, the reporting level is equal to the contractual detection level (CL). The reporting level for plutonium in urine is $0.01 \mathrm{dpm}$ per sample. Reporting requirements for indirect bioassay measurements are listed in Tables 6.1 through 6.4 under "Reporting Time--Oral." A result from a priority-, 


\subsubsection{Reporting Results from Indirect Measurements (contd)}

Volid Results

(contd)

Invalid or

No Results

Lost in $\operatorname{Lab}(L L)$

Insufficient

Volume Sample (IS)

Lost Kit (LC)

Can-not-out (CNO)

No Sample (NS) expedite-, or emergency-processed sample is reported verbally regardless of the level of the result. All sample results are transferred electronically from the Lab to the ORE database at least once a week.

There are a number of reasons why a sample may not be obtained or a result not be provided. When such circumstances occur, the Lab notifies Field Dosimetry or Internal Dosimetry to take appropriate follow-up action. These circumstances and appropriate actions are discussed below.

An LL indicates that a valid sample was provided by the worker; however, due to analytical problems, a valid analytical result could not be obtained. Examples of these problems include spillage, cross-contamination, analytical procedure errors, inadequate yield, or out-ofspecification quality control samples. For LL results, the Lab verbally notifies Internal Dosimetry and writes a nonconforming data report that is placed in the worker's ORE file. Generally, a worker whose result is lost in the Lab should be rescheduled for the lost analysis.

If a urine sample does not meet the minimum volume requirement specified for the sample type (see Tables 6.1 through 6.4), then the sample is not analyzed and is is noted in the ORE database results column. A worker who provides an insufficient volume sample should be contacted to ensure that the sample kit instructions will be followed, and then the sample and analysis should be rescheduled.

If the Lab delivered a sample kit, but was unsuccessful in retrieving the kit, then one of three codes may be assigned to the ORE database results field. The LC means that the Lab was unable to obtain a sample for analysis.

If the kit was not out at the time of the scheduled pickup, a CNO is assigned. The Lab will advise Field Dosimetry of the attempted pickup and will make one more attempt to pick it up. Samples not retrieved within 5 days of the scheduled pickup are assigned a "lost kit" designation and should be rescheduled.

The NS means that a sample kit was delivered to the designated residence; however, it was not used and remained outside at the residence on the scheduled pickup date. The Lab notifies Field Dosimetry or Internal Dosimetry of no samples. The worker should be contacted before rescheduling pickup. 


\subsubsection{Scheduling In Vivo Bioassay Measurements}

Summary

Beginning Work, Ending Work, New Hire, Termination

Rout ine

Rout ine whole Body Count
All in vivo bioassay measurement requests are arranged by the 0\&EP Section, either by Internal Dosimetry or by the WBC staff.

The details of scheduling depend on the reason the measurement is needed. Currently used measurement reason codes are discussed in Table 6.10 and scheduling details, categorized by reason type, are discussed below. Appendix B. Table B.9 provides explanations for both current and historical measurement reason codes.

To schedule a worker for a beginning work, ending work, new hire, or termination in vivo measurement, Field Dosimetry follows a two-step scheduling process similar to the scheduling of indirect bioassay samples:

1. Field Dosimetry submits an Employee and Dosimetry Changes form (Exhibit 6.1) to Radiological Records to delete the old routine schedule (if there is one) and to establish the new routine. This information is entered into the ORE database, and the form is kept in the worker's permanent file. (An Employee and Dosimetry Changes form is not needed for beginning and ending work samples for planned, offsite exposures.)

2. Field Dosimetry schedules the measurement directly with the WBC staff.

The Employee and Dosimetry Changes form (Exhibit 6.1) initiates the request to put a worker on a routine in vivo measurement at the time of the new hire or beginning work measurement. This information is entered into the ORE database and is used by the HBC staff and Field Oosimetry as needed.

For a whole body measurement no other scheduling is necessary. Field Oosimetry is responsible for having the worker show up at the 747-A Building on the scheduled day. When possible, a routine whole body measurement is coordinated with the annual medical physical examination. Boeing Computer Services-Richland (BCSR) maintains the schedules for annual physical examinations for Hanford workers. Once a month, the Hanford Environmental Health Foundation (HEHF) has BCSR send a schedule to Field Dosimetry, identifying which workers are due for their physical examinations. Field Dosimetry arranges the date of the physical exam and whole body count with the worker and enters the date on the Hanford Medical Scheduling (HMS) database. That information is also transferred to the ORE database, from which the WBC staff print out the list, as needed. 
IABLE 6.10. Reason Codes For In Vivo Bioassay Counting

Reason for

Measurement

Routine

New hire

Termination

Unusual exposure

(incident)

Evaluator exposure

(EE) request

Contractor request

Recount

Follow-up

Beginning work

Ending work

Visitor

Contract work

Research project

Investigate high routine
Code

1

2

3

4

5

6

7

8

9

10

11

12

13

16
Description of Reason

Measurement is performed on a predetermined, periodic schedule for routine surveillance.

Measurement is performed before worker begins employment or enters a radiation zone.

Measurement is performed when a worker terminates employment. No entry into radiation zones should occur after measurement is performed.

Measurement is requested after an incident of potential occupational internal exposure.

Measurement is requested by an EE for special purposes not covered by other reason codes.

Measurement is requested by Field Dosimetry for reasons other than an indication of potential occupational internal exposure.

Count is performed to verify an original measurements.

Measurement is performed 1) as a follow-up to any unexpected activity, or 2) for a long-term follow-up to an incident.

Measurement is performed before a worker begins a specific type of radiation zone work or before a trip offsite where potential internal exposure could occur.

Measurement is performed after a worker completes a specific type of radiation zone work or after the worker returns from a trip where potential off-

site internal exposure could have occurred.

Measurement is performed on a visitor to Hanford.

Measurement is performed by special contract work to the PNL WBC Facility.

Measurement is performed specifically for a research project.

Measurement is performed after the report of an unexpectedly high result. 


\subsubsection{Scheduling In Vivo Bioassay Measurements (contd)}

Routine Chest Count

Incident

Investigate

High Routine

Contractor

Request

Follow-up

Exposure

Evaluator (EE)

Visitor
If a routine chest measurement is needed, Field Dosimetry schedules the measurement by telephoning the HBC staff.

Field Dosimetry notifies Internal Dosimetry of any incident involving possible internal exposures. Bioassay measurements needed because of the incident are arranged by Internal Dosimetry with the concurrence of Field Dosimetry (details are provided in Chapter 7.0). All incident-related measurements taken prior to issuing a dose assessment are also called incident measurements and are arranged through Internal Dosimetry.

Either Internal Dosimetry or the WBC staff arrange for the investigate-high-routine measurement(s) after consultation with Field Dosimetry. All measurements taken to investigate the high routine result are so coded until a preliminary or final assessment is issued.

Field Dosimetry initiates contractor requests through Internal Dosimetry. Internal Dosimetry provides advice on the types of measurements needed and arranges the counts with the WBC staff.

Internal Dosimetry may recommend a specialized long-term follow-up schedule as a result of a worker's intake. Field Dosimetry can have the schedule placed on the ORE database using an Employee and Dosimetry Changes form and make arrangements with the $W B C$ staff in the same manner as for routine measurements. Also, Internal Dosimetry reviews the monthly list of workers scheduled for in vivo measurements and may issue a request for follow-up measurements to Field Dosimetry at that time.

Internal Dosimetry consults with Field Dosimetry concerning EE-requested measurements.

Field Dosimetry schedules visitor counts by directly contacting the WBC staff by telephone. Internal Dosimetry assists if so requested.

\subsubsection{Reporting Results of In Vivo Measurements}

Volid Results
An in vivo measurement result is verbally reported to Internal Dosimetry if it exceeds the reporting level. The reporting levels for routinely scheduled in vivo measurements have been set equal to the screening levels of Appendix A. In addition, results from incident, evaluator-requested, and contractor-requested measurements are reported verbally to Internal Dosimetry, regardless of the level of the results. Internal Dosimetry, in turn, relays the results to Field Dosimetry with 


\subsubsection{Reporting Results of In Vivo Measurements (contd)}

recommendations for follow-up, if necessary. All results are officially transmitted weekly to the ORE database.

No Results

Invalid results or no results may be obtained for an in vivo measurement for a variety of reasons, such as radon daughter interference, equipment problems, or interference from medically administered radioactivity. A comprehensive list of no-result codes is given in Appendix B, Table B.16.

\subsubsection{Reporting "No Shows"}

The fact that a worker does not show up for an in vivo measurement is noted in the "no show" file of the ORE database. It is the responsibility of Field Dosimetry to notify the worker. The worker can make up a whole body measurement on another day without scheduling an appointment; however, Field Dosimetry must reschedule a chest count or special count with the WBC staff.

\subsection{FOLLOH-UP MEASUREMENTS AMD REPORTS}

Follow-up measurements and their associated documentation are handled as described in the following subsections.

\subsubsection{Indirect Bioassay Measurements}

The need for follow-up indirect bioassay measurements depends on the initial measurement result and its relationship to the screening levels of Appendix $A$.

$<$ Screening Level

$\geq$ Screening Level
If the indirect bioassay measurement result is below the screening levels of Appendix $A$, no follow-up is performed by Internal Dosimetry and a computer-generated letter is sent to Field Dosimetry (see Exhibit 6.3).

If the result is above the screening levels of Appendix $A$, different actions are taken, depending on the reason for the sample, according to the practices discussed in Chapter 2.0. If the reason code is for a new hire, beginning work, incident, or contractor-requested measurement, any result above the reporting level is investigated. If the reason code is for a routine, ending work, or termination measurement, then the result is compared with 1) the expected result because of prior assessed intakes, if applicable, and 2) a level that would possibly indicate an intake resulting in an annual effective dose equivalent greater than 10 mren (see Appendix A, Table A.1). If the result is greater than expected or implies that an intake greater than the 10-mrem dose criterion has occurred, then the result is 


\subsubsection{Indirect Bioassay Measurements (contd)}

investigated. Otherwise, the letter shown in Exhibit 6.3 is sent to Field Dosimetry and no follow-up is performed by Internal Dosimetry.

QUS

An exception to the above practice exists for results from individuals working with soluble uranium, where the principal hazard is chemical toxicity. The analysis code for these samples is QUS, and two action levels exist for QUS results: 1) a screening level, and 2) a follow-up level (see Appendix A, Table A.2). If a screening level is exceeded, Field Dosimetry is notified but no other action is taken by Internal Dosimetry. If a follow-up level is exceeded, the result is investigated.

Recounts If a routine- or priority-processed plutonium urinalysis result is at or above $0.01 \mathrm{dpm}$ but less than $0.02 \mathrm{dpm}$, generally the first step in an investigation is to order two recounts of the sample. This step reduces random false positive results that ensue from counting statistics alone. If both recounts are less than $0.01 \mathrm{dpm}$, then the letter shown in Exhibit 6.3 is sent to Field Dosimetry. If the recount is also at or above $0.01 \mathrm{dpm}$, then Field Dosimetry is notified, a formal assessment is performed, and eventually a letter summarizing the results of the assessment is sent to Field Dosimetry. Details about the assessment of internal dose are discussed in Chapter 3.0.

Recounts may be ordered under other circumstances at the discretion of the $\mathrm{EE}$.

\subsubsection{In Vivo Measurements}

The need for follow-up in vivo measurements depends on the measurement result and its relation to the screening levels listed in Appendix A. For in vivo measurements, the reporting levels are equal to the screening levels.

Preliminary Report

The worker receives a preliminary report on the results of in vivo measurements at the end of each visit to the WBC Facility (see Exhibit 6.4). The preliminary report places the results of the measurements into one of three categories: 1) less than the screening level, 2) not imediately available, e.g., final calculations by computer are delayed or calculation/evaluation by hand is required, and 3) equal to or exceeding the screening level. 


\subsubsection{In Vivo Measurements (contd)}

Final Report

$<$ Screening Level

Final Report

$\geq$ Screening Level
When a result is finalized, and if the result is below the screening level and is not associated with an incident, no follow-up is performed by Internal Dosimetry. If the information in the preliminary report needs no change, then no further correspondence is necessary. If the final result differs from the preliminary report, then the letter shown in Exhibit 6.5 is sent to Field Dosimetry.

If the result is above the screening level, different actions are taken depending on the reason for the measurement, according to the practices discussed in Chapter 2.0. If the reason code is for a new hire, beginning work, or contractor-requested measurement, any result above the screening level is investigated. If the reason code is for a routine, ending work, or termination measurement, the result is compared with 1) the expected result because of prior assessed intakes, if applicable, and 2) a level that would possibly indicate an intake resulting in an annual effective dose equivalent greater than 10 mrem (see Appendix A, Table A.1). If the result is greater than expected or implies that an intake greater than the 10-mrem dose criterion has occurred, then the result is investigated. Otherwise, the letter shown in Exhibit 6.5 is sent to Field Dosimetry and no follow-up is performed by Internal Dosimetry.

\subsection{OCCUPATIONAL RADIATION EXPOSURE DATABASE}

The results of all bioassay measurements are permanently retained in the ORE database. Field Dosimetry, Internal Dosimetry, WBC, and Lab staff all have access to only those parts of the ORE database that are essential to their task responsibilities. Examples of the actual computer screen data and code descriptions of some files available in the ORE database are given in Appendix $B$. 
Exhibit 6.1

\section{Employee and Dosimetry Changes Form}

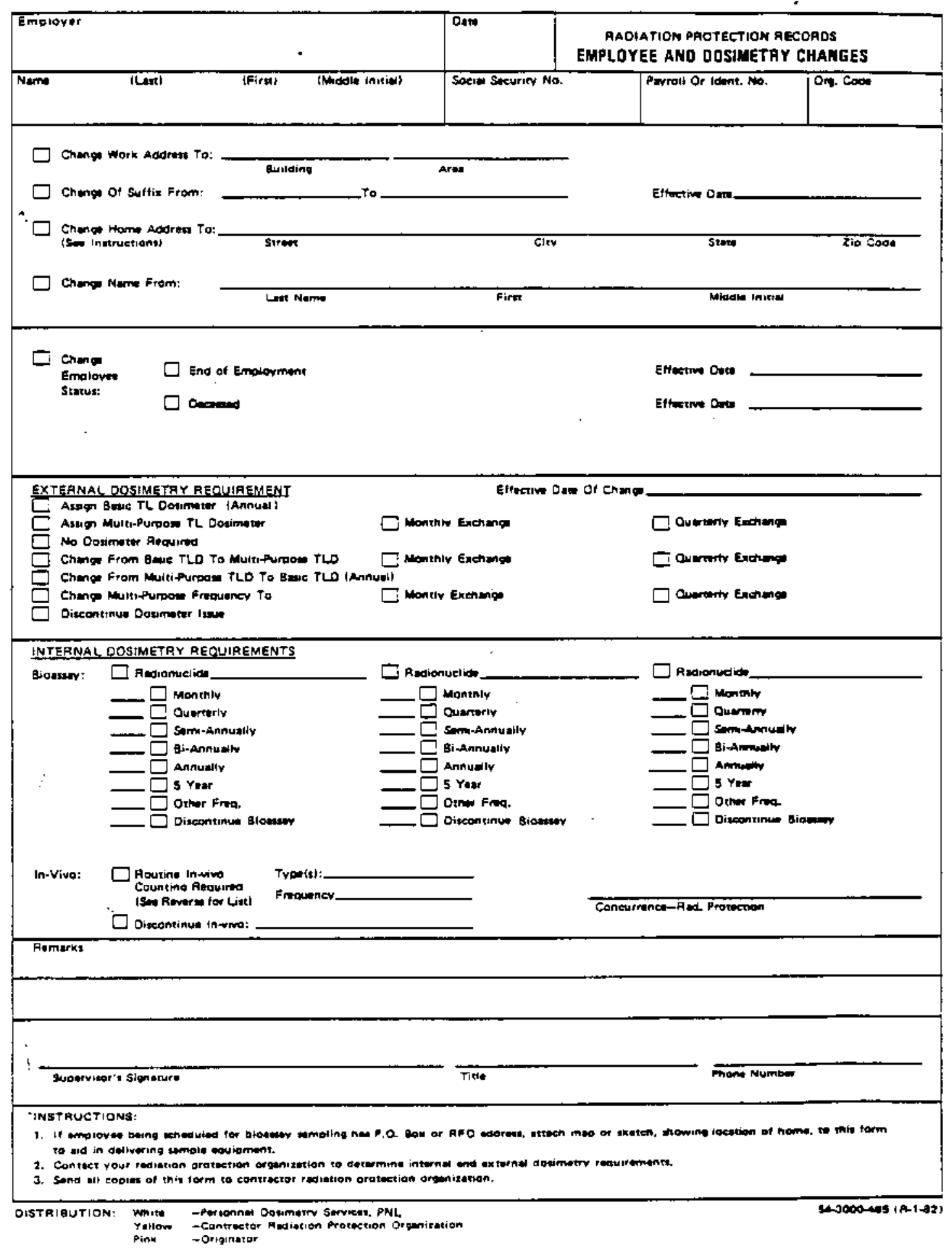


Exhibit 6.2

\section{Field Dosimetry Bioassay Request Form}

BIOASSAY REQUEST SHEET

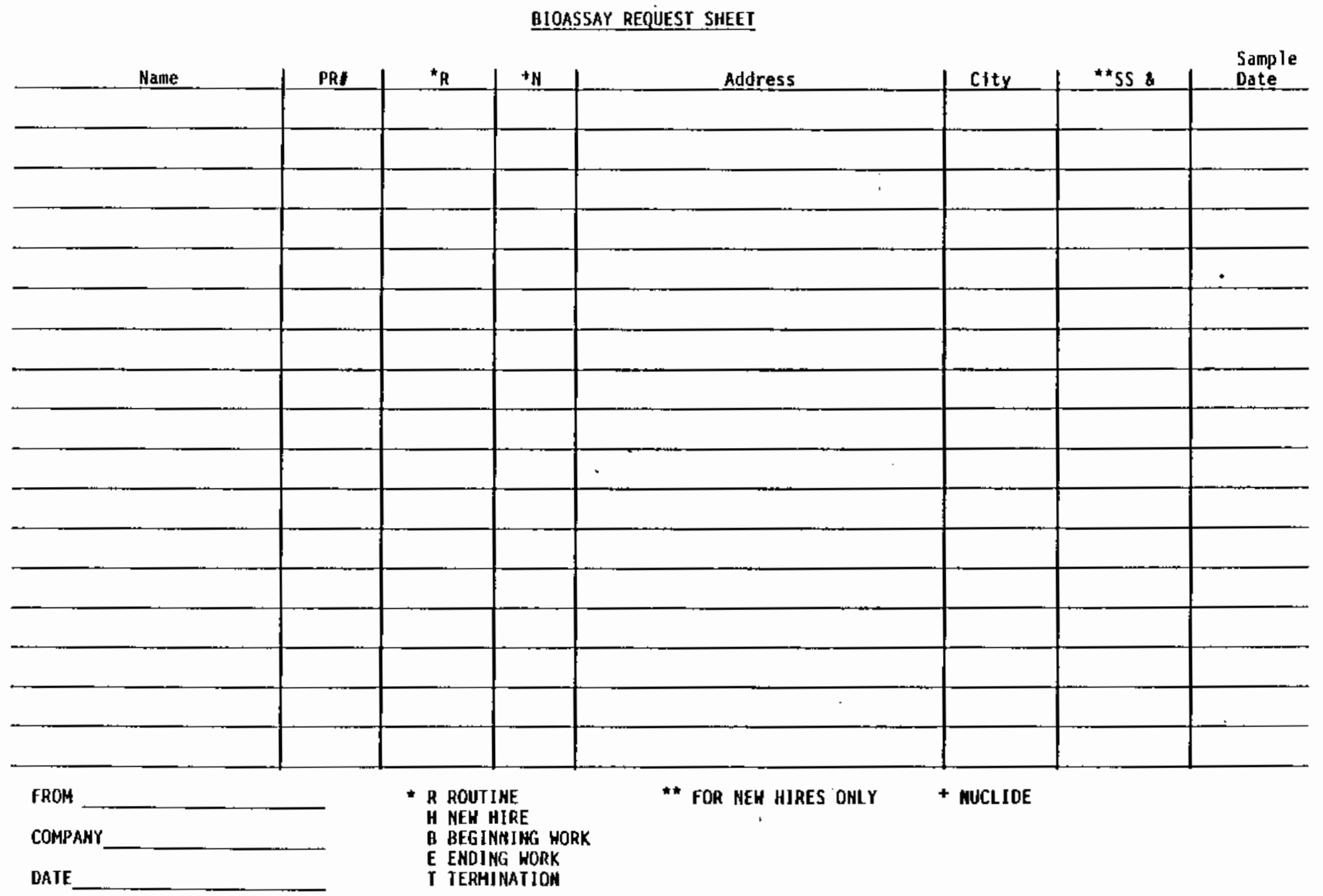


Exhibit 6.3

Sample Form - Bioassay Urine Sample Results

STRICTLY PRIVATE

(Addressed to individual worker)

\section{BIOASSAY URINE SAMPLE RESULTS}

Analysis of your recent bioassay urine sample submitted by you on (date) is normal and indicates no unusual intake of radioactive material.

Bioassay urinalyses are just one of several monitoring techniques used at Hanford to determine if an intake of radioactive material has occurred in excess of the dose limits established by the Department of Energy and the Hanford Internal Dosimetry Program.

The details of this bioassay sample analysis are included with all your personal radiation dosimetry records and are available for your inspection upon request. If you wish to review these, or other records in your file, please contact (Field Dosimetry Representative) Telephone no __ to arrange for an appointment. 
Exhibit 6.4

Sample Letter - Preliminary Analys is of In Vivo Examination

NAME PAYROLL DATE

Preliminary analysis of your in vivo examinations(s) indicates: Your in vivo measurements are completed, and the results do not exceed the criteria for follow-up.

Analysis of the examination data is not immediately avai1able. The results of this examination will be provided to your company's radiation protection organization when available.

- Your measurement exceeded a screening level." A further review of the examination will be performed and your radiation protection organization will be notified of the results. Follow-up measurements may be required.

* The screening level is used to determine if there is a need for further evaluation of possible internat radioactivity.

Please note: This report is based on a preliminary evaluation of your measurement by computer and is subject to change based upon additional review. If there is a change from the abovereported results, Internal Dosimetry will notify your company's radiation protection organization.

If you have any questions concerning your in vivo examination, please contact the following representative of your company's radiation protection organization: 
Exhibit 6.5

Sample Letter - In Vivo Measurements Results

STRICTLY PRIVATE

DATE PRI

NAME ORG CODE

WHOLE BODY COUNTER EXAMINATION REPORT

Analysis of your recent in vivo examination on has been completed. Results do not exceed the criteria for followup measurements. The results of this examination do not change previous assessments of internal dose or current bioassay measurement schedules.

Records of this and your other bioassay examinations are maintained in your personal exposure history file. Contact your company's radiation protection or radiation dosimetry office on if you have any questions regarding your occupational radiation exposure status.

This statement was prepared by Hanford Internal Dosimetry. 


\section{CHAPTER 7.0}

\section{INTERNAL EXPOSURE INCIDENT RESPONSE}




\subsection{INTERNAL EXPOSURE INCIDENT RESPONSE}

This chapter provides guidance for recommended dosimetry response to potential internal exposure incidents. The roles of contractor, Internal Dosimetry (the EE), and other support groups in obtaining dosimetry data and in performing early assessments of internal exposure are addressed. In addition, some of the EE tasks described are performed under the auspices of the IDP but are not directly related to internal dosimetry.

For the purposes of this chapter, an internal exposure incident is defined as any circumstance involving loss of containment or administrative control that may result in a worker incurring an intake requiring an internal dose assessment. Section 2.1.1 requires that a dose assessment be performed for any potential occupational internal exposure.

\subsection{INCIDENT RESPONSE OBJECTIVES OF THE HANFORD INTERNAL DOSIMETRY PROGRAM}

In responding to an internal exposure incident, the IOP's principal objective is to perform initial and follow-up assessments of the seriousness of the exposure. Such assessments support the contractors' reporting and investigating requirements, and address the medical considerations regarding the effectiveness of dose-reduction therapy. In addition to the role in responding to internal exposure incidents, the IDP EE provides notification services for other types of incidents at Hanford.

\subsection{INCIDENT RESPONSE SERVICES PROVIDED BY THE HANFORD INTERMAL DOSIMETRY} PROGRAM

The IDP provides incident response by means of its EE function. The EE is a sitewide 24-hr/day contact for dosimetry and notification assistance.

The following internal exposure assessment services are available through the EE:

- consultation regarding the need for and priority of special bioassay measurements

- arrangements for bioassay measurements and samples

- identification of supplemental measurements and samples to aid in the performance of internal exposure evaluations (e.g., measurement of air filters, smears, etc.) 
7.2 INCIDENT RESPONSE SERVICES PROVIDED BY THE HANFORD INTERNAL DOSIMETRY PROGRAM (contd)

- arrangement with PNL Radiation Protection for Radiation Protection Technologist (RPT) support for the NBC Facility and Emergency Decontamination Facility (EDF)

- initial assessment of the potential severity of intakes based on early data

- discussion with workers about the results of specific measurements (done in conjunction with Field Dosimetry)

- arrangement for appropriate follow-up bioassay measurements.

The following services, not related to internal dosimetry, are also available through the EE:

- dosimetry assistance for unusual external exposure situations

- activation of the Unified Dose Assessment Center (UDAC)

- activation of PNL Hanford environmental monitoring teams

- activation of the DOE Region 8 Radiological Assistance Team

- request for assistance from PHL Radiation Protection for monitoring potentially contaminated Hanford patients who report to Kadlec Medical Center, HEHF first aid stations, the EDF, or the HBC Facility.

\subsection{DETERMINATION OF THE NEED FOR INTERNAL DOSIMETRY SUPPORT}

Internal Dosimetry should be contacted whenever an intake of radioactivity is suspected, or when the dosimetric significance of an observation or event is in doubt.

The following are examples of circumstances that could warrant contacting Internal Dosimetry:

- suspected intake of radioactive material with the potential for an annual effective dose equivalent of 100 mrem

- extended or extensive personal skin contamination 


\subsection{DETERMINATION OF THE MEED FOR INTERNAL DOSIMETRY SUPPORT (contd)}

- loss of containment or exposure control, such as failure of a ventilation system or respiratory protection, resulting in exposure to high concentrations of radioactivity in the air

- spread of contamination that results in levels of radionuclides at or exceeding levels given in Table 7.1.

- unplanned releases of radioactive material to the environment

Recommendations are provided below for two levels of Internal Dosimetry support for potential internal exposure situations.

It is also recommended that Internal Dosimetry be included on distribution for radiation occurrence reports.

Notify HEHF

Internal Dosimetry recommends that HEHF Occupational Medicine be promptly alerted to potential internal exposures when the criteria of Table 7.2 are exceeded. The primary purpose of this notification is to alert HEHF to the possibility that dose reduction therapy may be warranted. At the request of the contractor, the EE makes this notification.

\subsubsection{Notifications for Prompt Internal Exposure Evaluation and Dose Reduction Therapy}

Not ify Exposure Evaluator (EE)
The EE should be notified immediately when prompt actions may be required to evaluate internal exposure. The criteria recommended for immediate notification and request for EE support are shown in Table 7.1. These criteria are based primarily on Hanford experience, and may be taken as conservative indicators that annual effective dose equivalents may exceed 10 to 100 mrem.

The EE should be notified the same day that intakes or potential intakes occur or are identified to assure that adequate provision is made to obtain bioassay measurements for dose assessment.

When the criteria of Table 7.1 are not met, it is unlikely that therapeutic actions would be taken based on early bioassay measurements. Bioassay measurements are still needed for dose assessment purposes. In some cases 
IABLE 7.1. Contamination Levels for Internal Dosimetry Notification, dpm

Indicator

Nasal or mouth smears

Facial contamination

Spotty, loose

General, loose

Skin breaks

Head, neck contamination

Spotty, loose

General, loose

Contamination inside respirator

Hands, forearms, clothing(a) Spotty, loose

General, loose

Airborne contamination
Alpha Emitters

50

500

200

Any skin breaks while handiing alpha-emitters
Mixed Fission or

$90 \mathrm{Sr} \quad$ Activation Products

5,000

1,000

10,000

4,000

50,000

20,000

Any detectable activity around a skin break; or undetectable activity but with potential for intake based on other information (e.g., blood smear).

$$
\begin{array}{rrr}
5,000 & 100,000 & 250,000 \\
2,000 & 40,000 & 100,000
\end{array}
$$

Oetectable activity inside respirator after use.

$$
\begin{array}{rrr}
10,000 & 200,000 & 500,000 \\
5,000 & 100,000 & 250,000
\end{array}
$$

Acute exposure equivalent to 40 OAC-hours after

\begin{tabular}{|c|c|}
\hline Alpha Emitters & $90 s r$ \\
\hline$>5,000$ & $>100,000$ \\
\hline$>25,000$ & $>500,000$ \\
\hline$>1,000$ & $>20,000$ \\
\hline
\end{tabular}
incorporating respiratory protection factor. (b)

(a) Clothing contamination levels apply to exposure without respiratory protection, such as contamination levels on inner coveralls while undressing.

(b) DAC-hours = time-integrated exposure to airborne contamination.

TABLE 7.2. Contamination Levels for Notification of the Hanford Environmental Health Foundation, dpm

Indicator

Nasal or mouth smears

Facial contamination

Skin breaks
Mixed Fission or Activation Products 


\subsubsection{Notifications for Prompt Internal Exposure Evaluation and Dose Reduction Therapy (contd)}

Notify Exposure Evaluater (EE) (contd) the measurements may not need to be immediate (i.e., same day), and may be scheduled on a priority basis a few days after the potential intake. Under these circumstances, the EE may suggest a delayed measurement protocol in consideration of convenience and cost.

\subsubsection{Information to Provide When Notifying the Exposure Evaluator}

Exhibit 7.1 provides a summary check list of information that may be useful to the EE for dosimetry evaluation purposes. The EE office maintains a telephone log for each separate incident notification, using a form similar to the one shown in Exhibit 7.2.

\subsection{CONTACTING THE EXPOSURE EVALUATOR}

Contacting the on-call EE may be done using several methods described in the following subsections. During normal working hours, it should be possible to contact the EE within a few minutes by one phone call. Afterhours procedures have been established with the intent that the maximum response time for obtaining $E E$ support should not exceed 40 minutes.

\subsubsection{Preferred Method}

\section{Coll $376-2222$}

The preferred method of contacting the EE is to call the EE office phone number $(376-2222)$. During working hours, the Internal Dosimetry clerk usually answers the phone. After working hours, the phone is forwarded to the on-call EE's residence. If no answer is obtained, wait 5 minutes and try again. Make at least two attempts, waiting at least 5 minutes between each call. If contact cannot be made by this method, use one of the alternate methods described below.

\subsubsection{Alternate Methods}

Potrol Operations Center or PNL-Single Point Contoct
Call one of the following and ask them to contact the EE:

Patrol 0perations Center: $373-3800$

PNL Single Point Contact: $375-2400$

Both the Hanford Patrol Operations Center (POC) and the PNL Single Point Contact have emergency procedures for contacting the $E E$, including radio pager, two-way radio, and alternate contacts. 


\subsubsection{Alternate Methods (contd)}

Rodio Poger 85-618 The on-call EE carries a pager that can be activated from a Hanford Site telephone (prefix 373, 376) by calling 85-618. This method is particularly useful after hours if the $E E$ is not at home to answer 376-2222. Pager messages should be simple, brief, and to the point; for example, "Exposure Evaluator, call John Jones at 6-6543." Messages should be repeated. Expect some delay in response in order to allow the EE to reach a telephone. If no response is received within 15 minutes, contact the Hanford Patrol or the PNL Single Point Contact and request an alternate EE.

Two-Way Portable Radio (P-66)
The two-way portable radio can be used at the discretion of the EE to contact the POC, primarily if the EE plans to be away from a phone. The EE would be advised of the need to contact the POC by the radio pager (85-618) and could respond by radio to the POC. Under most circumstances, however, this is not a reliable way to contact the $E E ;$ it is simply a convenience for EE-to-POC communications.

\subsection{EXPOSURE EVALUATOR RESPONSE TO INCIDENTS}

This section briefly describes the general EE response to an internal exposure incident.

\subsubsection{Receiving Incident Notification}

Upon notification of an incident, the EE initiates an incident telephone log (similar to Exhibit 7.2). Based on the information provided by the contractor and the specifically requested services, the EE makes appropriate emergency notifications, arranges for appropriate bioassay measurements, and identifies additional information that might assist in assessing the significance of the exposure.

The EE Office does not normally report incidents to DOE or HEHF. The decision to report to DOE or HEHF is the responsibility of the contractor, unless other arrangements have been made with the EE Office. However, if the probability of exposure is considered serious enough to warrant therapy, HEHF may be informally advised by the EE office.

The previous statements should not be construed as restricting the EE office in any way from responding to requests from DOE or HEHF regarding the dosimetry associated with an incident. 


\subsubsection{Receiving Incident Notification (contd)}

The initial priority of the EE is to obtain the identification of the workers and the circunstances surrounding the exposure, determine the appropriate type of bioassay measurements, arrange for the measurements, and make a preliminary assessment of the potential effectiveness of therapeutic measures.

\subsubsection{Scheduling and Performing Bioassay Measurements}

A variety of bioassay measurements may be requested. Some of the typical reasons for requesting certain bioassay measurements are described in Table 7.3.

The EE arranges to obtain suitable bioassay measurements. The EE establishes priorities for measurement types and, if necessary, for individuals needing measurements.

In addition to direct in vivo counts that can be performed within a few hours of the incident, rapid processing of excreta samples can provide an analytical result within a few hours of sample delivery to the Lab. With rapid sample processing, analytical sensitivity is sacrificed for quick turn-around time. The purpose of rapid processing is to obtain immediate results to assess the potential need for, or effectiveness of, dose reduction therapy. The EE should determine if trading analytical sensitivity for quick results is appropriate for dosimetry. Circumstances may also warrant rapid processing to provide the contractor with preliminary information.

Based on initial measurements, the EE determines the need for follow-up bioassay measurements and advises field Dos imetry of the needed measurements. In some cases, it may be appropriate for the EE to arrange follow-up measurements directly with the worker at the time of the initial measurements. As information becomes available, the EE advises the contractor and discusses results with workers, if requested. The intent of the $\mathrm{EE}$ function is to work through Field Dosimetry for all but the most pressing worker communications.

The EE determines measurement protocols for incidents. Although the circumstances will vary for each incident, the protocols of Table 7.4 provide general guidance on measurements that may be required to assess internal exposure following an incident. 
TABLE 7.3. Typical Incident Response Bioassay Measurements and Their Purposes

\section{Measurement \\ Whole body counts and lung counts}

Head counts

Organ counts or wound count

Urine samples

(s imulated $12 \mathrm{hr}$ ) (s imulated $24 \mathrm{hr}$ ) (total)

Urine samples

(single voiding or "spot")

Fecal samples
Purpose

Measure activity present in a person at a specific post-intake time. Multiple measurements are used to establish the specific retention pattern in the person.

Estimate skeleton burden of bone-seeking radionuclides. This estimate is used to confirm skeleton deposition and to convert chest count results to lung content by correcting for interference from skeleton activity.

Measure activity present in a specific organ or tissue at a specific post-intake time. Used to estimate the retention pattern of the individual.

Estimate excretion rate of radionuclides not readily detectable by direct in vivo counting. Internal deposition of such nuclides is estimated based on standard models. Multiple samples may be required to determine the individual excretion patterns and appropriate excretion model.

Provide initial order-of-magnitude estimate of exposure based on excretion model. This measurement is also suitable for routine and nonroutine tritium dosimetry.

Confirm intake. Provide isotope identification and ratio information. Estimate dose based on early clearance (may require multiple samples). Differentiate soluble from insoluble materials. 
TABLE 7.4. Example Protocols for Incident Bioassay Measurements

Relative Contamination Level (a)

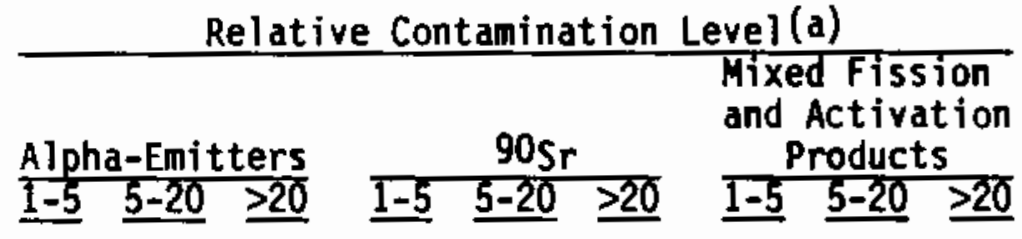

Time Post Intake

Same Day

In vivo counts

Spot urine

Total urine

Overnight urine

Feces

\begin{tabular}{|c|c|c|c|c|c|c|c|}
\hline$x$ & $x$ & $x$ & $x$ & $x$ & $x$ & $x$ & $x$ \\
\hline & $\begin{array}{l}x \\
X\end{array}$ & $\hat{x}$ & $x$ & $x$ & $x$ & & \\
\hline
\end{tabular}

Next Day

In vivo counts

Total urine

Simulated 24-hr urine

Feces

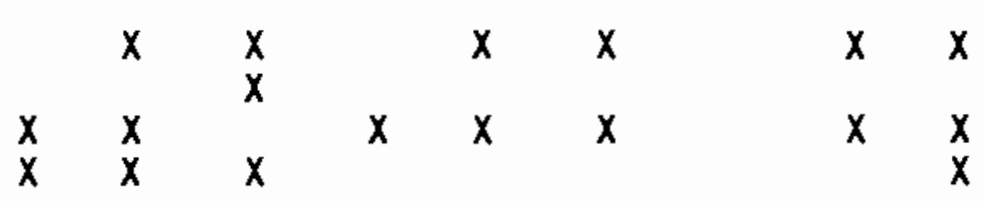

First Week

In vivo counts

Additional urine

3-5 feces

$\begin{array}{lllllllll} & & x & & & & x & x & x \\ x & x & x & x & x & x & & & x \\ x & x & & & x & & & x\end{array}$

Follow-Up

In vivo counts

Additional urine

Additional feces

$\begin{array}{lllllll}x & x & x & x & x \\ x & x & x & & x\end{array}$

Special Measurements

Isotopic smear

Particle size

Solubility

$\begin{array}{llll}x & x & x & x \\ x & x\end{array}$

$\mathrm{x} \quad \mathrm{X}$

(a) Expressed as a multiple of the criteria in Table 7.1.

\subsubsection{Dose Assessment Capability}

The dose assessment and reporting practices are described in Chapters 3.0 and 4.0 of this manual. Summary statements are provided here because they are related to incident response.

Dose Sensitivity

The IDP has the capability to assess an annual effective dose equivalent of 100 mrem for all radionuclides of

concern at hanford. In some cases the ability to do so is contingent upon obtaining appropriate bioassay measurements (fecal samples, urine samples, in vivo measurements) within the first 5 to 10 days post-exposure. For most nuclides, if early data are obtained within the 


\subsubsection{Dose Assessment Capability (contd)}

Dose Sensitivity (contd)

Preliminary

Dose Assessment

Final Dose

Assessment first few days following exposure, the dose assessment capability is 10 mren or less. The Technical Basis provides more in-depth discussion of the capability of bioassay measurements with regard to dose assessment sensitivity.

An initial assessment of the magnitude of a potential internal exposure or dose is made as soon as the data permit. Because the circumstances of each internal exposure are different, initial estimates may be inaccurate. In general, when bioassay measurements confirm an intake, follow-up measurements are required to estimate an internal dose accurately. Early estimates of an exposure should be considered as order-of-magnitude estimates only.

Initial assessments are normally communicated directly to Field Dosimetry without a formal evaluation and transmittal letter. A preliminary dose assessment letter is provided, if requested by the contractor.

Final dose assessments are issued when sufficient data have been obtained to confidently estimate the annual and committed doses required to be reported to DOE. These dose assessments become part of the permanent ORE files.

\subsection{GUIDANCE FOR EXPOSURE EVALUATOR RESPONSE TO INCIDENTS}

This section provides general guidance for EE responses to some anticipated situations. It is not intended to be an all-encompassing statement of EE response, nor is it intended to replace other contractor and EE policies, procedures, or requirements.

\subsubsection{Managing Externally Contaminated Uninjured Workers}

The incident contractor is responsible for the management of externally contaminated uninjured workers. Mormally, workers should be decontaminated before being released from the facility. If external contamination is detected on workers at the HBC Facility, the EE, RPT, contractor, and WBC staff must determine the course of action. The WBC Facility is not used as a decontamination center, and workers with removable contamination should not be counted until such contamination has been removed.

Clothing or personal items discovered to be contaminated in surveys made at the HBC Facility or EOF are bagged and dispositioned according to the contractor instructions. Normally, the contractor radiation protection organization deals with these items. 


\subsubsection{Managing Externally Contaminated Injured Horkers}

The primary responsibility for management of all injured workers, whether contaminated or not, lies with HEHF. When dealing with contaminated workers, the EE supports HEHF by providing advice in matters of dosimetry for the patients and attending staff. The decontamination of an injured worker is HEHF's responsibility, although the EE or RPT may be requested to assist in the decontamination efforts. HEHF also determines the priority of medical treatment versus decontamination.

The EDF is the facility designated to receive contaminated injured workers who do not have life-threatening medical conditions. It is HEHF's responsibility to decide whether to treat a worker at the EDF or to send the worker to a hospital.

When notified of EDF activation, the EE arranges for PNL Radiation Protection support at the EDF. In addition, an EE is dispatched to the EDF to participate as part of the treatment team. A second EE may also be sent to assist. In addition to patient dosimetry evaluation, the EE also provides initial radiation protection coverage for the team until RPT support arrives. The overall responsibility for all EDF-related activities lies with the lead HEHF physician.

If decontamination efforts fail to completely remove personal contamination, it may be appropriate to release a worker with residual skin contamination. This decision must be made by the contractor representative. Under such circumstances, the worker should be advised of appropriate techniques to limit the potential spread of contamination after his/her release. Such techniques might include the use of shower caps, gloves, bandage, etc. , to provide a barrier against contamination spread. In addition, it is suggested that the worker be advised when spread of contamination would not be a significant concern upon his/her release. In some cases, home surveys may be appropriate and are the responsibility of the event contractor and the worker's employer.

\subsubsection{Taking Therapeutic Measures to Reduce Internal Dose}

Therapeutic measures to reduce dose are the responsibility of HEHF Occupational Medicine. These methods may include the use of various drugs (e.g., diethylenetriamine pentaacetic acid [DTPA], potassium iodide, alginates, diuretics, etc.) and surgical techniques (minor tissue excision, wound debridement). The EE advises HEHF of the potential effectiveness of various 


\subsubsection{Taking Therapeutic Measures to Reduce Internal Dose (contd)}

treatment alternatives to reduce dose, and informs HEHF of the potential internal dose to patients as subsequent bioassay data become available.

\subsubsection{Releasing Workers following an Incident}

The initial bioassay measurements that are necessary following an incident should be performed before the worker is released. The personal comfort of a worker is considered if extensive hold-over following a workday has already occurred or if discomfort occurs because of injury or extensive counting times. Actual measurements for the initial worker assessment should not normally require more than about 2 hours at the WBC Facility. If more than one worker is involved in an incident, this time could be extended, or workers may be requested to return for additional counts at a later time.

When workers involved in an incident are initially counted or treated, a contractor representative should be present. This representative bears the responsibility for release of the worker and for dealing with the worker's questions about overtime compensation, when to return, and other pertinent questions. The EE addresses, to the extent that the available data allow, questions about the worker's potential internal dose and arranges for necessary excreta samples.

\subsubsection{Assisting in External Radiation Exposure Situations}

If the contractor requests special assistance regarding an external radiation exposure incident or concern, the EE arranges for the Hanford External Dosimetry Program to provide this assistance.

\subsubsection{Requesting Region 8 Radiological Assistance Program Teams}

Upon request by $\mathrm{DOE}$, the $\mathrm{EE}$ activates Region 8 Radiological Assistance Program teams according to the Emergency Preparedness Project protocol.

7.6.7 Requesting Activation of the Unified Dose Assessment Center

If requested by DOE or appropriate contractor personnel, the EE activates or caucuses UDAC according to the Emergency Preparedness Project protocol. 


\subsubsection{Requesting Offsite Assistance}

If the $E E$ receives a request for offsite assistance from a non-Hanford source, the EE attempts to determine the nature of the requested assistance and to direct the inquiry to the appropriate authority. Specific requests for Hanford services are directed to DOE-RL. Examples of such requests include support to be provided by Region 8 Radiological Assistance Program teams in the event of transportation accidents or support in dealing with a potentially contaminated patient at a local hospital. 


\section{EXHIBIT 7.1}

\section{Check List for Incident Data}

GEMERAL INFORMATION

- Description of incident--one or two sentences and date and time of incident

- Location of incident (area, building, room)

- Personnel involved (name, payroll number, job title, and address for each person).

INTERMAL EXPOSURE-RELATED INFORMATION

- Retaín any object causing contamination for possible investigation

- Radionuclides

- Form of material (wet/dry, chemical form, soluble/insoluble)

- Mode of intake

- Respiratory protection (type, evidence of leakage)

- Nasal, mouth, or blood smear results (dpm)

- Facial contamination level (dpm)

- Other skin contamination (dpm)

- Clothing contamination (dpm)

- Area contanination (dpm)

- Airborne activity concentration $(\mu \mathrm{Ci} / \mathrm{cc})$

- Correlation of contanination levels to potential exposure of worker.

EXTERNAL EXPOSURE-RELATED INFORMATIOH

- Radionuclides (or type and energy of emission)

- Source activity

- Source geometry

- Estimated dose rate (type of instrument and distance)

- Pencil dosimeter reading or pocket alarming dose integrator (PADI) dose

- Duration of exposure

- Worker position relative to source

- Shielding around worker

- Shielding around source

- Anticipated delivery of dosimeters for processing.

\section{CRITICALITY EXPOSURE-RELATED INFORMATION}

- How detected?

- Number of workers exposed?

- Quick sort performed? Results of gut readings?

- Readings on worker personal effects

- Iten, reading

- Instrument used, efficiency and background

- Elapsed time between criticality and reading

- Orientation and distance of worker to critical assembly

- Any imediate symptoms? (describe)

- Fissile material

- Shielding material and thickness

- Current status of area; any chance for recurrence?

- Environmental release?

- Have nuclear accident dosimeters (NADs or "candles") been collected?

- Have worker dosimeters been collected? 


\section{EXHIBIT 7.2}

\section{Incident Telephone Log}

PACIFIC NORTHWEST LABORATORY

RICHLAND, WASHINGTON

\section{RADIATION INCIOENT - TELEPHONE REPORT}

Date of Report Unusual Radiation Exposure Report Mo.

Time of Report

Report by Contractor Incident No.

Contractor

$=$.
1.
2.
3.
5.
5.

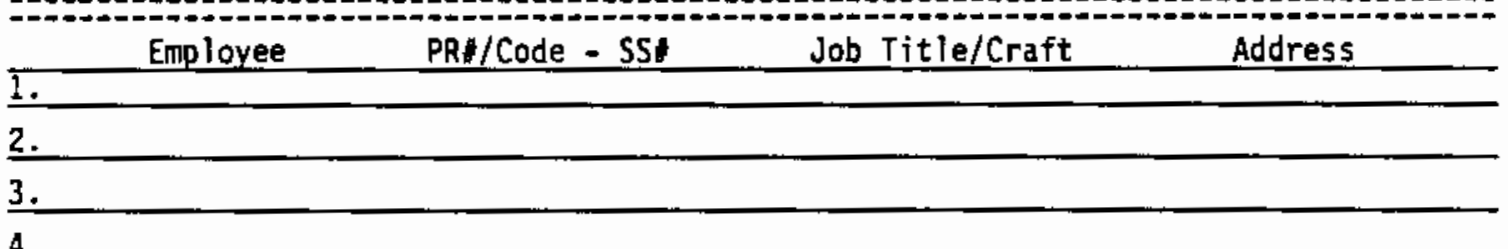

Incident Date

Time

Bldg.

Area

Incident Description:

RADIATION MONITORING RESULTS

INTERHAL
Enitter I sotope
Mode of Intake
Chenical Form
Wet or Dry
Skin Contam.
Nasal Smears
Right
Left
Floor Contam.
Airborne Contam.

EXTERNAL

Source Emitter

Type of Radiation

Pencil

Dose Rate

Time

Distance

Location

Orientation

Shielding

Airborne Contam. 
EXHIBIT 7.2 (contd)

ACTION TAKEN BY:

Internal

Scheduled

Date/Time

Results

Date/Time

Chest Count

•

HBC

_ Other Count

_ Spot Urine Sample

Particle Size (Analysis)

OTPA Administered

External

Dosimeter Special

Processing

Verbal Notification

Contractor Representative

By:

Time

Results

Exposure Evaluator Conments

Miscel Ianeous

Exposure Evaluator

Date 
CHAPTER 8.0

\section{QUALITY ASSURANCE}




\subsection{QUALITY ASSURANCE}

The IOP has been designated as an Impact Level III Project in accordance with the internal manual on quality assurance (QA). By this designation, the program must comply with the Good Practices Standard (GPS), detailed in the QA Manual, and is cormitted to meeting the mandatory good practices.

The $Q A$ and quality control (QC) features of the program are briefly summarized in the following sections.

\subsection{QUALITY ASSURANCE AND QUALITY CONTROL FOR BIOASSAY ANALYSES}

Quality assurance and QC for sample analysis are assured by the Analytical Services Laboratory's QA and QC programs, Internal Dosimetry's Lab-audit program, and the WBC program.

\subsubsection{Analytical Services Laboratory}

The Analytical Services Laboratory (Lab) measures essentially all indirect bioassay samples and is required by contract to maintain rigorous, extensive, well-documented $Q A$ and $Q C$ programs.

The Lab is required to maintain a QA manual that outlines responsibilities and also provides requirements for data control, document control, maintenance/test equipment calibration and checks, procedures, training, corrective action in the event of noncompliance, and traceability to standardizing bodies such as the National Institute of Standards and Technology (NIST).

The QC program involves analyzing blanks and spiked samples with each batch of real samples, constant reviewing of data, and publishing quarterly and annual QC reports. Approximately 10 to $15 \%$ of all samples processed are blanks and spikes.

The QC samples are used to demonstrate compliance with requirements specified in the contract between the Lab and PNL. The requirements in the contract are at least as restrictive, and in some areas more restrictive, than the recomnendations in the draft ANSI N13.30(a) on

(a) American National Standards Institute (ANSI). 1987. Performance Criteria for Radiobioassay. Draft ANSI Standard N13.30, New York, New York. 


\subsubsection{Analytical Services Laboratory (contd)}

performance criteria for radiobioassay. These requirements determine detection levels (MDAs) for each radionuclide and matrix, as well as the allowable bias and required precision of the results. The Lab must demonstrate that actual MDAs are no greater than the levels specified in the contract and that bias and precision are within specified limits.

All routine analyses (i.e., not research and procedure development work) must be done according to written and approved procedures.

All technicians must be trained and certified in each procedure before they can routinely perform the applicable analysis.

\subsubsection{Internal Dosimetry Audit of the Lab's Quality Control Program}

Internal Dosimetry conducts an independent audit program as a check on the validity of the Lab'S QC results. The program consists of a combination of blank and spiked samples, which may be submitted for analysis as known audit samples (open audits), masked for analysis as authentic worker samples (blind audits), or split with another laboratory for simultaneous analytical intercomparison (split samples). The results of the audit samples are used to determine Lab performance relative to the CLs in essentially the same manner as the Lab's own QC program. This serves as an additional check on the Lab's ability to meet draft ANSI $N 13.30$ (a) recommendations and requirements of the contract.

The results of Internal Dosimetry's audit program are documented annually by means of a letter report to Field Dosimetry and to the Kanford Radiation Protection Historical Files. Discrepancies between the results of the Lab's and Internal Dosimetry's QC data are investigated, and corrective actions are taken as necessary.

\subsubsection{Quality Assurance of In Vivo Measurements}

The QA of in vivo measurements is detailed in Palmer et al. (1987). In brief, the program consists of daily equipment calibration and background checks using secondary reference sources and periodic calibrations using primary sources (i.e., NIST-traceable) in

(a) American National Standards Institute (ANSI). 1987. Performance Criteria for Radiobioassay. Draft ANS1 Standard N13.30, New York, New York. 


\subsubsection{Quality Assurance of In Vivo Measurements (contd)}

phantoms. In addition, the WBC Facility participates in laboratory intercomparison studies, in which spiked phantoms are sent to national and international facilities and the results are compared.

The results of workers' counts are tracked on computer by payroll number and name and are transmitted to the ORE database weekly. The QA data are kept in hard-copy form in the WBC Facility library.

\subsection{QUALITY ASSURANCE ANO QUALITY CONTROL FOR DOSE ASSESSMENTS}

The intention of the IDP is that internal dose assessments meet the DOE requirements as stipulated in DOE 5480.11 (1989). The methods used to assess internal dose are described briefly in Chapter 3.0 of this manual and are addressed more completely in the Technical Basis. Generally, the methods are consistent with those recommended by national and international authorities, such as the ICRP and the NCRP.

All internal dose assessments are performed by IOP technical professional staff members and include or reference all methods and data used in the evaluation. Documentation of the assessment should be sufficient, such that a technically qualified health physicist could reconstruct the assumptions, methods, and conclusions of the assessment.

Before an internal dose evaluation is issued, it is peer reviewed by a second technical professional staff menber to verify its technical accuracy and completeness. In addition, the evaluation and its summary letter must both be approved by the Internal Dosimetry program manager and the D\&EP Section manager before they are issued.

The original evaluation and a copy of the summary letter are placed in the workers' ORE files by Radiological Records staff. The original summary letter is sent to the designated contractor dosimetry representative.

\subsection{INTERNAL DOSIMETRY PROGRAM RECOROS}

The records generated by the IDP are maintained in files within the 0\&EP Section of PNL. The IDP manager is responsible for the designation and maintenance of these records. Additional information is provided in Section 9.0, Documents and Records. 


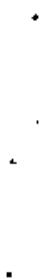


CHAPTER 9.0

DOCUMENTS AND RECORDS 


\subsection{DOCUMENTS AND RECORDS}

Documentation related to the services and activities of the IDP is of two general types: programmatic and technical assessment. These and the documentation of changes are briefly described in the following subsections.

\subsection{PROGRAMMATIC DOCUMENTATION}

Programmatic documentation includes a variety of reports and manuals, which provide information related to the design and operation of the IDP. Programmatic documentation is provided primarily by the following three documents :

- The Technical Basis for Internal Dosimetry at Hanford (Sula, Carbaugh, and Bihl 1989)--includes technical methods, supporting evidence, and reference information used to provide the technical foundation for the IDP.

- The Hanford Internal Dosimetry Program Manual-includes a guide to the services and capabilities provided by the IDP including policies, recommendations for good practice, and general guidance to contractor dosimetry organizations.

- The draft "Hanford Internal Dosimetry Program Procedures Manual" (a) --includes procedures for the dayto-day operations of the Program including records management, communications, data review, and exposure evaluation documentation.

These documents help provide for the long-term consistency, continuity, and quality of the IDP. The purposes of each of the documents and their interrelationships are exhibited in Figure 9.1. In addition to these documents, there are a number of ancillary reports and documents that pertain to specific aspects of IDP operation. These document program plans, computer codes, Analytical Services Laboratory activities, and QA activities and are included in the summary list of documentation in

Table 9.1.

(a) In preparation; to be issued in 1990. Information about this manual may be obtained from E. H. Carbaugh at PNL, Richland, Washington. 


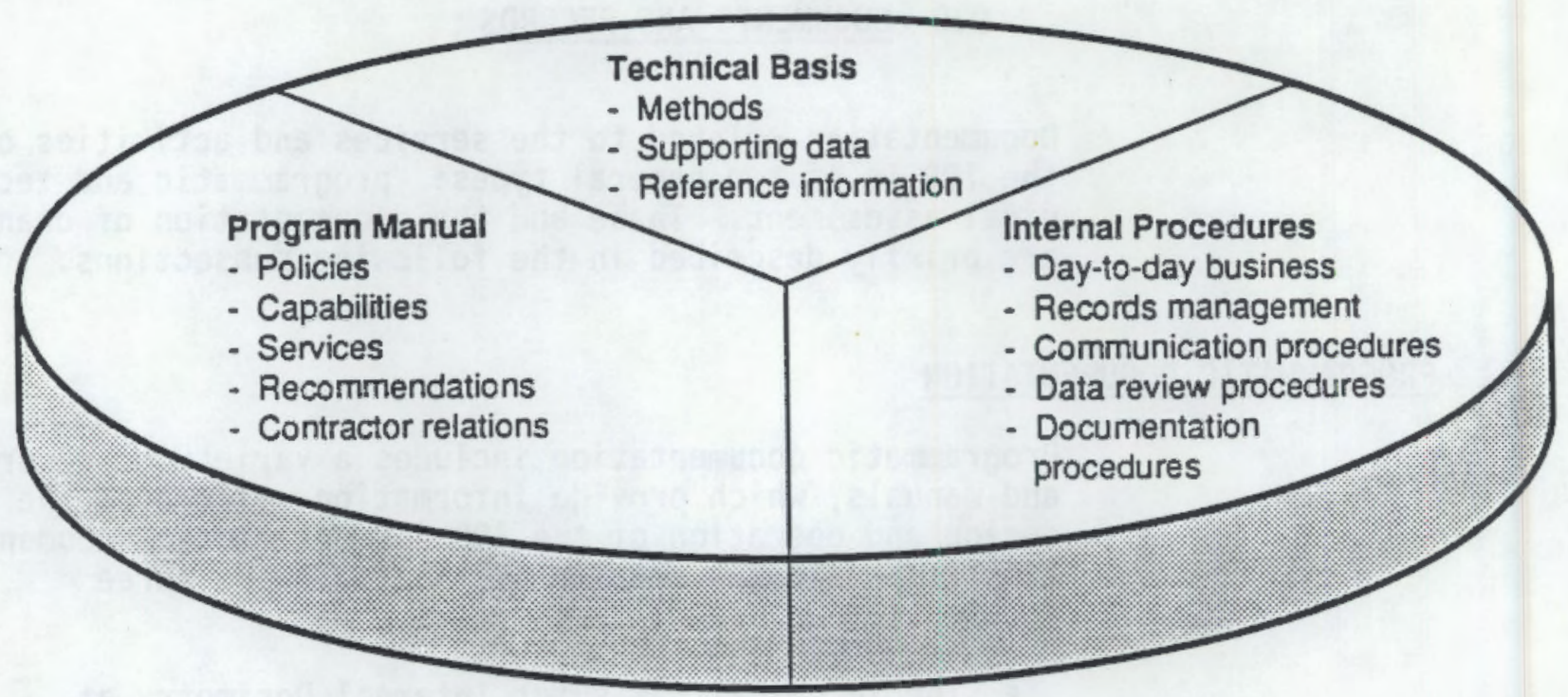

FIGURE 9.1. Hanford IDP Programmatic Documentation

\subsection{TECHNICAL ASSESSMENT DOCUMENTATION}

Technical assessment documentation includes reports and records that provide information related to the technical products of the IDP, that is, bioassay measurements and internal dose assessments. These assessments may be documented in formally issued topical reports, letter reports, or as database entries. A summary of the types of IDP technical assessment documentation and their disposition is provided in Table 9.2.

\subsection{DOCUMENTATION OF CHANGES}

Changes may be made to programmatic documents and to technical assessment records when new methods are developed and implemented, new requirements are established, or as a result of errors or deficiencies in practices or assessments. The processes for documenting these changes are provided below. 
IABLE 9.1. Summary of Progranmatic Documents for the Hanford Internal Dosimetry Progran

\begin{tabular}{|c|c|c|c|c|}
\hline Content & Form (a) & Custodian & Storage & Disposition \\
\hline $\begin{array}{l}\text { Technical support } \\
\text { for program }\end{array}$ & 1 & $\operatorname{IDP}(b)$ & PNL(c) controlled & Permanent \\
\hline $\begin{array}{l}\text { Policies, services, } \\
\text { capabilities, and } \\
\text { recompendations }\end{array}$ & 1 & IDP & PNL controlled & Permanent \\
\hline $\begin{array}{l}\text { Daily operating } \\
\text { procedures }\end{array}$ & 1 & IDP & $\begin{array}{l}\text { To be PNL } \\
\text { controlled } \\
\text { (when issued) }\end{array}$ & $\begin{array}{l}\text { To be } \\
\text { Permanent } \\
\text { (when issued) }\end{array}$ \\
\hline $\begin{array}{l}\text { Technical support } \\
\text { for the Whole } \\
\text { Body Counting } \\
\text { Program including } \\
\text { policies, services, } \\
\text { and capabilities }\end{array}$ & 1 & WBCP(d) & PNL controlled & Permanent \\
\hline $\begin{array}{l}\text { Good practices and } \\
\text { standards for } \\
\text { program operations }\end{array}$ & 1 & PHL & PNL controlled & Permanent \\
\hline $\begin{array}{l}\text { Excreta analysis and } \\
\text { other procedures }\end{array}$ & 2 & RRL (e) & $\begin{array}{l}\text { Historical } \\
\text { Files }(f)\end{array}$ & Permanent \\
\hline $\begin{array}{l}\text { Requirements for } \\
\text { services provided } \\
\text { by the Analytical } \\
\text { Services Laboratory }\end{array}$ & 1 & PNL & PNL Subcontracts & Permanent \\
\hline
\end{tabular}


IABLE 9.1. (contd)

\begin{tabular}{|c|c|c|c|c|c|}
\hline Title or Subject & Content & Form(a) & Custodian & Storage & Disposition \\
\hline $\begin{array}{l}\text { Hanford Dosimetry } \\
\text { Advisory Committee }\end{array}$ & Committee minutes & 1 & RRL & Historical files & Permanent \\
\hline Program change record & $\begin{array}{l}\text { Program change } \\
\text { documentation and } \\
\text { support }\end{array}$ & 1 & RRL & Historical files & Permanent \\
\hline $\begin{array}{l}\text { Vendor Quality } \\
\text { Assurance Manual }\end{array}$ & $\begin{array}{l}\text { Vendor's quality } \\
\text { assurance program }\end{array}$ & 2 & RRL & Historical files & Permanent \\
\hline $\begin{array}{l}\text { Vendor Quality } \\
\text { Control Manual }\end{array}$ & $\begin{array}{l}\text { Vendor's quality } \\
\text { control program }\end{array}$ & 2 & RRL & Historical Files & Permanent \\
\hline $\begin{array}{l}\text { Vendor Control of } \\
\text { Radiation Counters } \\
\text { Manual }\end{array}$ & $\begin{array}{l}\text { Bioassay Laboratory } \\
\text { count ing room } \\
\text { procedures }\end{array}$ & 2 & RRL & Historical files & Permanent \\
\hline Program computer codes & $\begin{array}{l}\text { Design and user's } \\
\text { guide to software } \\
\text { implemented by the } \\
\text { IDP }\end{array}$ & 1 & RRL & Historical Files & Permanent \\
\hline $\begin{array}{l}\text { Quality assurance } \\
\text { audits }\end{array}$ & $\begin{array}{l}\text { Audit of internal } \\
\text { dosimetry program }\end{array}$ & 1 & RRL & Historical files & Permanent \\
\hline $\begin{array}{l}\text { (a) } 1=\text { hard-copy report } \\
2=\text { microfilm } \\
\text { (b) IDP = Internal Dosime } \\
\text { (c) PNL = Pacific Northwe } \\
\text { (d) } W B C P=\text { Whole Body Cot } \\
\text { (e) RRL = Radiological Re } \\
\text { (f) Historical Files = Ha }\end{array}$ & $\begin{array}{l}\text { ry Program } \\
\text { t Laboratory } \\
\text { ting Program } \\
\text { ords Library } \\
\text { ford Radiation Protect }\end{array}$ & n Histo & Files & & \\
\hline
\end{tabular}


TABLE 9.2. Summary of Technical Assessment Documents for the Hanford Internal Dosimetry Program

\begin{tabular}{|c|c|c|c|c|c|}
\hline Title or Subject & Content & Form (a) & Custodian & Storage & Disposition \\
\hline $\begin{array}{l}\text { Internal dose } \\
\text { assessments }\end{array}$ & $\begin{array}{l}\text { Documentation of worker } \\
\text { dose assessment }\end{array}$ & 1 & RRL (b) & ORE personnel file & 75 years \\
\hline $\begin{array}{l}\text { Annual summary } \\
\text { report for } \\
\text { active workers }\end{array}$ & Internal dose report & 2 & RRL & $\operatorname{Ltrb}(c)$ & $\begin{array}{l}\text { As long as } \\
\text { usable }\end{array}$ \\
\hline $\begin{array}{l}\text { INTERTRAC report-- } \\
\text { annual report } \\
\text { for DOE } \\
\text { contractors }\end{array}$ & $\begin{array}{l}\text { Annual dose equivalent for } \\
\text { active workers }\end{array}$ & 2 & RRL & $\operatorname{Ltrb}(c)$ & $\begin{array}{l}\text { As long as } \\
\text { usable }\end{array}$ \\
\hline $\begin{array}{l}\text { INTERTRAC report-- } \\
\text { termination }\end{array}$ & $\begin{array}{l}\text { Internal dose report for } \\
\text { terminated worker }\end{array}$ & 2 & RRL & ORE files & 75 years \\
\hline Bioassay data & $\begin{array}{l}\text { Excreta and in vivo } \\
\text { measurement results }\end{array}$ & 3 & RRL & ORE personnel file & 75 years \\
\hline $\begin{array}{l}\text { Bioassay annual } \\
\text { quality control } \\
\text { for } F y \text { 19xX }\end{array}$ & $\begin{array}{l}\text { Annual letter report of } \\
\text { bioassay laboratory } \\
\text { internal quality control } \\
\text { samples }\end{array}$ & 1 & RRL & $\begin{array}{l}\text { Historical } \\
\text { Files (d) }\end{array}$ & Permanent \\
\hline
\end{tabular}


TABLE 9.2. (contd)

\begin{tabular}{|c|c|c|c|c|c|}
\hline Title or Subject & Content & Form (a) & Custodian & Storage & Disposition \\
\hline $\begin{array}{l}\text { Results of the PNL } \\
\text { audit program } \\
\text { for FY } 19 X X\end{array}$ & $\begin{array}{l}\text { Annual letter report of } \\
\text { summary of IDP quality } \\
\text { control audit sample } \\
\text { progran }\end{array}$ & 1 & RRL & Historical Files & Permanent \\
\hline $\begin{array}{l}\text { Vendor laboratory } \\
\text { records }\end{array}$ & $\begin{array}{l}\text { Records and documents } \\
\text { supporting excreta sample } \\
\text { analyses }\end{array}$ & 1 & Vendor & ----- To be de & lined-........ \\
\hline $\begin{array}{l}\text { Whole body count- } \\
\text { ing records }\end{array}$ & $\begin{array}{l}\text { Records and documents } \\
\text { supporting in vivo } \\
\text { measurements }\end{array}$ & 1 & WBC & ------To be de & lined-------- \\
\hline
\end{tabular}

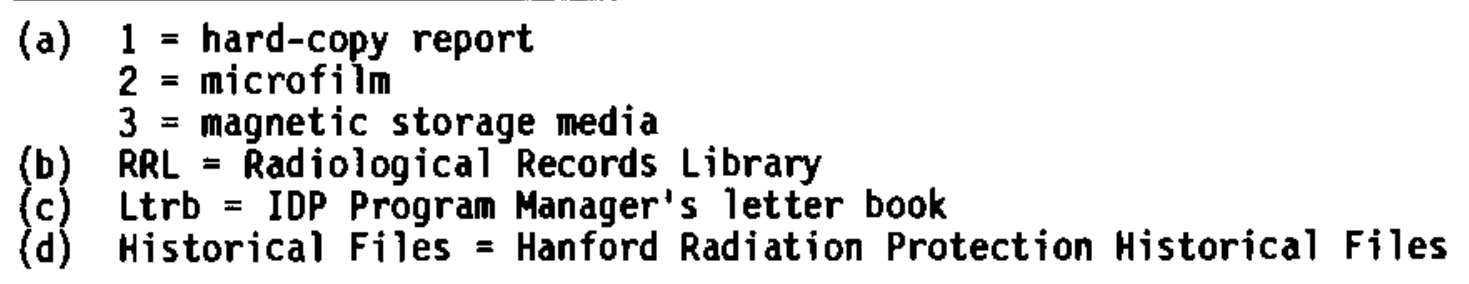




\subsubsection{Program Change Record}

Changes and additions to the IDP are recorded via the Program Change Record. The purpose of the record is to document program changes, to assure proper program review of changes, and to help assure that appropriate notification of the changes are made. The Program Change Record consists of the record form show as Exhibit 9.1 and any attachments identified on the form. The change record includes a description of the change and its effective date. The records are maintained in the ORE historical file by year according to a sequentially assigned number. For example, the first change recorded in calendar year 1989 is numbered 89-1. Change records are approved by the IDP manager.

A Program Change Record is used to document changes to policies, practices, assumptions, analytical and computational methods, technical assessment techniques, and recording and reporting practices. Types of changes for which the record is used include those that

- affect the quality, meaning, accuracy, or interpretation of bioassay measurements or dose assessments

- alter procedures used to perform bioassay measurements

- affect the cost or scheduling of internal dosimetry services provided by PHL

- alter generic practices, techniques, or assumptions

- affect the manner in which internal dosimetry information is recorded or reported

- supersede information previously documented.

\subsubsection{Revision/Update of Documents and Manuals}

Changes may be made to information in documents and manuals at any time. Before the change can become effective, however, it must be documented via either a Program Change Record, or by revision of the document or manual. It is often most efficient to initially document the change via a Program Change Record and reserve the option to revise the document after several changes have accumulated. 


\subsubsection{Revision of Technical Assessments}

Modifications to technical assessments are documented as follows:

- Dose Assessment--A revised Evaluation Report is prepared with a copy to the contractor dosimetry representative and a copy to the Hanford Radiation Protection Historical Files. The revised evaluation is identified using the Evaluation Number sequence described in Section 3.2.2. (It is the practice of Hanford contractors to obtain a signed statement from the subject individual acknowledging receipt of the revised doses).

- In Vivo Measurement--A notice of correction to an in vivo ORE record is issued by the WBC staff in the form of a letter to Internal Dosimetry. The correction letter describes the reason for the change and the new result. After Internal Dosimetry submits the correction to Radiological Records data processing personnel, the original correction letter is provided to the ORE personnel file.

- Excreta Measurement--A notice of correction to an excreta ORE record is issued by UST to Internal Dosimetry. The correction is reported using a NonConforming Data report and a cover letter. After Internal Dosimetry submits the correction to Radiological Records data processing personnel, the original letter and report are provided to the ORE personnel file. 
Exhibit 9.1

Change Record Number:

Issue Date:

\begin{abstract}
PROGRAM CHANGE RECORD
HAMFORD INTERNAL DOSIMETRY PROGRAM

Category: WBC Bioassay Lab Other

change title: (descriptive phrase)

description:

(State the reason for and describe the change. Try to keep the description brief by referencing manuals, reports, letters, etc. when possible. Include as attachments supporting information not referenced.)
\end{abstract}

(use attachments or additional pages if necessary)

impact:

(Briefly state the affect the change will have on program quality, operation, cost, etc.)

(use attachments or additional pages if necessary)

supercedes (if manual, provide page and section):

originated by:

date:

project manager:

date:

Internal Dosimetry Program Mgr.

notification (copies sent to):

ORE historical file Responsible Proj. Mgr. Internal Dosimetry file Int.Dos.Staff (route) WBC Staff (route)

(List names and affiliation of others not covered by the above distribution list who should receive a copy of this change record. 


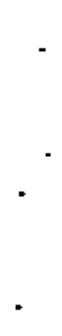


CHAPTER 10.0

\section{REFERENCES}




\subsection{REFERENCES}

American National Standards Institute (ANSI). 1978. American National Standard for Internal Dosimetry for Mixed Fission and Activation Products. ANSI N343-1978, New York, New York.

American Kational Standards Institute (ANSI). 1966. American National Standard Practice for Occupational Radiation Exposure Records Systems. ANSI N13.6-1966 (R 1972), New York, New York.

Brodsky, A. 1980. "Resuspension Factors and Probabilities of Intake of Material in Process" (or 'Is 10-6 a Magic Number in Health Physics?')." Health Physics $39(6): 992-1000$.

International Commission on Radiological Protection (ICRP). 1979. Limits for Intakes of Radionuclides by Workers. ICRP Publication 30, Parts 1, 2, 3, and Supplements, Pergamon Press, Hew York, New York.

International Commission on Radiological Protection (ICRP). 1986. The Metabolism of Plutonium and Related Elements. ICRP Publication 48, Pergamon Press, New York, New York.

International Commission on Radiological Protection (1CRP). 1974. Report of Task Group on Reference Man. ICRP Publication 23, Pergamon Press, New York, New York.

Johnson, J. R., and R. C. Myers. 1981. "Alkaline Earth Metabolism: A Model Useful in Calculating Organ Burdens, Excretion Rates, and Comitted Effective Dose Equivalent Conversion Factors." Radiation Protection Dosimetry 1(2):87-95.

Jones, S. R. 1985. "Derivation and Validation of a Urinary Excretion Function for Plutonium Applicable Over Tens of Years Post Uptake." Radiation Protection Dosimetry $11(1): 19-27$.

National Council on Radiation Protection and Measurments (NCRP). 1987. Use of Bioassay Procedures for Assessment of Internal Radionuclide Deposition. NCRP Report No. 87, Bethesda, Maryland.

Palmer, H. E., C. P. Brim, J. A. Rieksts, and M. C. Rhoads. 1987. Whole Body Counting Manual. PNL-6198, Pacific Northwest Laboratory, Richland, Washington.

Privacy Act, 44 Fed. Reg. 510772 (1974).

Sula, M. J., E. H. Carbaugh, and D. E. Bihl. 1989. Technical Basis for Internal Dosimetry at Hanford. PNL-6866, Pacific Northwest Laboratory, Richland, Washington.

U.S. Department of Energy (DOE). 1981. Environmental Protection, Safety and Health Protection Reports. DOE 5484.1, Washington, D.C.

U.S. Department of Energy-Richland Operations Office (DOE-RL). 1983. Hanford Site Services Handbook. RLPI 9-50.5, Richland, Washington. 
U.S. Nuclear Regulatory Comission (NRC). 1988. Criteria for Establishing a Tritium Bioassay Program. NRC Regulatory Guide 8.32, U.S. Government Printing Office, Washington, D.C.

Watson, E. C., and Fisher, D. R. 1987. Feasibility Study on a Data-Based System for Decisions Regarding Occupational Radiation Protection Measures. NUREG/CR-4856, PNL-6137, Pacific Northwest Labortory, Richland, Washington. 


\section{APPENDIX A}

\section{REPORTING, SCREENING, AND FOLLOW-UP LEVELS FOR ROUTINE BIOASSAY MEASUREMENTS}


APPENDIX A

REPORTING, SCREENING, AND FOLLOW-UP LEVELS FOR

ROUTINE BIOASSAY MEASUREMENTS

This appendix lists levels of routine bioassay measurement results that initiate response by Internal Dosimetry according to practices discussed in Chapter 2.0.

The bioassay measurement laboratories provide prompt verbal notification to Internal Dosimetry for any results that exceed the reporting level. Reporting levels for excreta analyses processed using the routine processing code are identical to the contractual detection leve1s listed in Chapter 6, Tables 6.1 and 6.5, with the exception of plutonium in urine, which has a reporting level of $0.01 \mathrm{dpm}$ per sample. All excreta analysis results processed using priority, expedite or emergency processing codes are verbally reported to Internal Dosimetry. The reporting level for "Routine" in vivo measurements have been set equal to the screening levels discussed below and listed in Table A.1.

The reporting level for "New Hire" or "Beginning Work" in vivo measurements is the detection of any positive result other than $40 \mathrm{~K}$. The resuits of all "Incident" and "Field Request" in vivo measurements are verbally reported to Internal Dosimetry.

When Internal Dosimetry is advised of a "Routine" bioassay measurement result that exceeds the reporting level, the result is compared with the screening levels of Tables A.1 and A.2. The screening level is used to determine if additional investigation is required, or if the dose assessment process is initiated based on the specifics of the worker's assigned bioassay measurement progran and history.

If the screening level is exceeded, the magnitude of the potential dose indicates the need for additional measurements. In some cases, notably for soluble uranium, follow-up levels for additional bioassay measurements have been established. For most nuclides, the follow-up levels are determined once the screening level has been exceeded, based on the criteria in Section 2.1.2. 
TABLE A.1. Screening Levels for Routine Bioassay Measurement Results Based on a Potential First-Year Effective Dose Equivalent of 10 mrem(a)

\begin{tabular}{|c|c|c|c|}
\hline Measurement Type & Radionuclide & $\begin{array}{l}\text { Frequency of } \\
\text { Measurement }\end{array}$ & Screening Level \\
\hline Whole body count & $\begin{array}{l}40 \mathrm{~K} \\
60 \mathrm{Co} \\
137 \mathrm{Cs} \text { with } 90 \mathrm{Sr} \\
137 \mathrm{Cs} \text { only } \\
154 \mathrm{Eu} \\
\text { Other radionuclides }\end{array}$ & $\begin{array}{l}\text { Annual } \\
\text { Annual } \\
\text { Annual } \\
\text { Annual } \\
\text { Annual } \\
-\end{array}$ & $\begin{array}{r}200 \mathrm{nCi}(\mathrm{b}) \\
8 \mathrm{nCj}(\mathrm{c}) \\
9 \mathrm{nCj}(\mathrm{d}) \\
19 \mathrm{nCj} \\
8 \mathrm{nCi}(\mathrm{e}) \\
\text { Anything detected }\end{array}$ \\
\hline $\begin{array}{l}\text { Thyroid count on } \\
\text { germanium } \\
\text { detector }\end{array}$ & $125 \mathrm{I}$ & Quarterly & $4 \mathrm{nCi}(\mathrm{f})$ \\
\hline $\begin{array}{l}\text { Urinalysis, } \\
24-h r \text { simulated } \\
\text { or total }\end{array}$ & $\begin{array}{l}90 \mathrm{Sr} \\
\text { U natural }\end{array}$ & $\begin{array}{l}\text { Biennial } \\
\text { Annual } \\
\text { Annual } \\
\text { Quarterly }\end{array}$ & $\begin{array}{l}11 \mathrm{dpm} / \mathrm{s} \text { ample }(g) \\
26 \mathrm{dpm} / \mathrm{s} \text { amp } l \mathrm{e}(\mathrm{g}) \\
0.2 \mu g / \mathrm{s} \text { amp } \mathrm{le}(\mathrm{h}) \\
0.2 \mu g / \mathrm{s} \text { ample } \mathrm{h}(\mathrm{h})\end{array}$ \\
\hline $\begin{array}{l}\text { Urinalysis } \\
\text { 12-hr simulated }\end{array}$ & U natural & $\begin{array}{l}\text { Annual } \\
\text { Quarterly }\end{array}$ & $\begin{array}{l}0.1 \mu \mathrm{\mu g} / \mathrm{sample}(\mathrm{h}) \\
0.1 \mu \mathrm{s} / \mathrm{sample}(\mathrm{h})\end{array}$ \\
\hline $\begin{array}{l}\text { Urinalys is } \\
\text { single void }\end{array}$ & U natural & Annual & $0.14 \mu g / 1(i)$ \\
\hline $\begin{array}{l}\text { Urinalys is } \\
\text { any volume }\end{array}$ & Tritium & $\begin{array}{l}\text { Monthly } \\
\text { Biweekly }\end{array}$ & $\begin{array}{r}80 \mathrm{dpm} / \mathrm{m}\} \\
110 \mathrm{dpm} / \mathrm{mi}\end{array}$ \\
\hline
\end{tabular}

(a) Except for the measurement/radionuclide/frequency combinations listed in this table, any detected internal activity in a routine bioassay measurement is of interest to Internal Dosimetry and could indicate an intake exceeding the 10 mrem first-year effective dose equivalent.

(b) Potassium-40 in the general public ranges up to about $200 \mathrm{nCi}$.

(c) Assumes an intake of a class $Y$ corrosion product mixture with equal activities of 60 Co and 54 Mn.

(d) Assumes an intake mixture of equal activities of $137 \mathrm{Cs}$ and $90 \mathrm{Sr}$. If the subject is on a routine monitoring program for $90 \mathrm{Sr}$, then the screening level for $137 \mathrm{Cs}$ only is more appropriate.

(e) Assumes an activity ratio of 2:1 for 154Eu:155Eu at intake.

(f) Based on potential exposure each quarter with a possible dose of $2.5 \mathrm{mrem}$ each quarter.

(g) Assumes the individual receives an annual whole body count and thus only $90 \mathrm{Sr}$ is considered in the evaluation of the urine sample result.

(h) Based on the upper level for environmental urinary excretion of uranium, estimated at $0.2 \mu \mathrm{g} /$ day for individuals living in this area.

(i) $0.14 \mu \mathrm{g} / \mathrm{l}$ is equivalent to a daily excretion rate of $0.2 \mu \mathrm{g} / \mathrm{day}$, assuming a urine output rate of 1.41 /day. 
TABLE A.2 Screening and Follow-Up Levels for Possible Chemical Toxicity

\begin{tabular}{|c|c|c|c|c|}
\hline Measurement Type & Radionuclide & $\begin{array}{l}\text { Frequency of } \\
\text { Measurement }\end{array}$ & $\begin{array}{c}\text { Screening } \\
\text { Level (a) }\end{array}$ & $\begin{array}{l}\text { Follow-up } \\
\text { Level (b) }\end{array}$ \\
\hline $\begin{array}{c}\text { 12-hr simulated } \\
\text { urinalysis }\end{array}$ & $\begin{array}{l}U \text { natural } \\
\text { (code QUS) }\end{array}$ & $\begin{array}{l}\text { Monthly } \\
\text { Biweekly }\end{array}$ & $\begin{array}{l}1.2 \mu \mathrm{g} / \mathrm{sample} \\
3.5 \mu \mathrm{g} / \mathrm{s} \text { smp le }\end{array}$ & $\begin{array}{r}4 \mu \mathrm{g} / \mathrm{sample} \\
11 \mu \mathrm{g} / \mathrm{samp} \text { le }\end{array}$ \\
\hline $\begin{array}{l}\text { Single void } \\
\text { urinalysis }\end{array}$ & $\begin{array}{l}U \text { natural } \\
\text { (code QUS) }\end{array}$ & $\begin{array}{l}\text { Monthly } \\
\text { Biweekly }\end{array}$ & $\frac{1.7 \mu g / 1}{\mu} \mu g / 1$ & $\begin{array}{r}6 \mu \mathrm{g} / 1 \\
16 \mu \mathrm{g} / 1\end{array}$ \\
\hline
\end{tabular}

(a) Levels shown indicate a potential intake at one-tenth of the assumed threshold for acute toxicity.

(b) Levels shown indicate a potential intake at one-third of the assumed threshold for acute toxicity. 


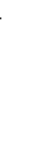




\section{APPENDIX B}

COMPUTER REPORT SCREENS AND CODES OF THE OCCUPATIONAL RADIATION EXPOSURE DATABASE 
COMPUTER REPORT SCREENS AND CODES

OF THE OCCUPATIONAL RADIATION EXPOSURE DATABASE

This appendix provides an explanation of selected computer report screens and data field codes pertinent to the Hanford Internal Dosimetry Program. Appendix $B$ includes figures of data screens or hard-copy reports with annotations describing selected data fields. The data fields are cross-referenced to the tables, which follow the figures and contain explanations of the various codes used within the field. A list of the figures and tables is provided below.

Figure/

Table

Title

Figures

B.1

B.2

B.3

B. 4

B. 5

B. 6

B.7

B.8

B.9

B. 10

B. 11

B. 12

B. 13

B. 14

ORE Master Menu

Available Records - Submenu

Data Retrieval - Submenu

Available Records - Bioassay Results Screen

Available Records - In Vivo Records Screen

Available Records - Dosimeter Results Screen

Available Records - Incident Records Screen

Available Records - Scheduies Screen

Data Retrieval - Emergency Search Screen

Data Retrieval - Bioassay Display Screen

Data Retrieval - In Vivo Display Screen

Data Retrieval - Incident Display Screen

Emergency Search - Bioassay Results Screen

Emergency Search - In Vivo Display Screen

Tables

B.1

B.2

B.3

B. 4

B.5

B. 6

B.7

B.8

B.9

B. 10

B. 11

B. 12

B. 13

B. 14

B. 15

B. 16

Company Codes

Sample Type Codes

Sample Reason Codes

Sample Kit Codes

Processing Codes

Units Codes

Multiple Results Codes

Bioassay Frequency Codes

Reason Codes for In Vivo Measurements

Body Location Codes for In Vivo Measurements

In Vivo Detector Codes

Modes of Intake

Contacts and Special Analysis Requests

ORE Isotope Codes

In Vivo Schedule Types

In Vivo Mo-Result Codes 


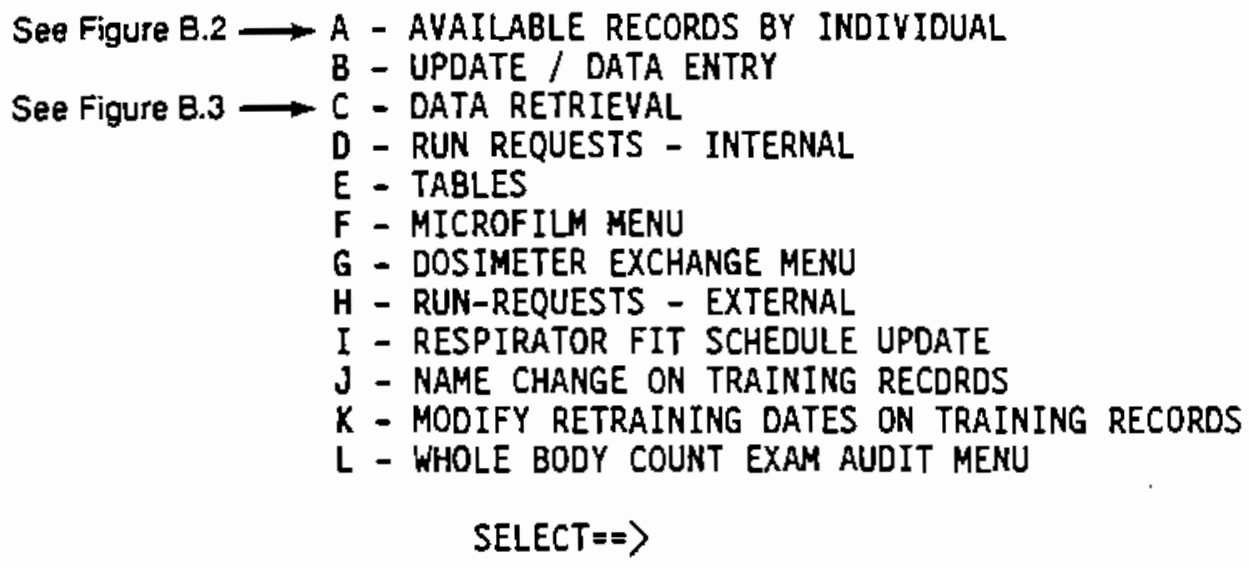

FIGURE B.1. ORE Master Menu 


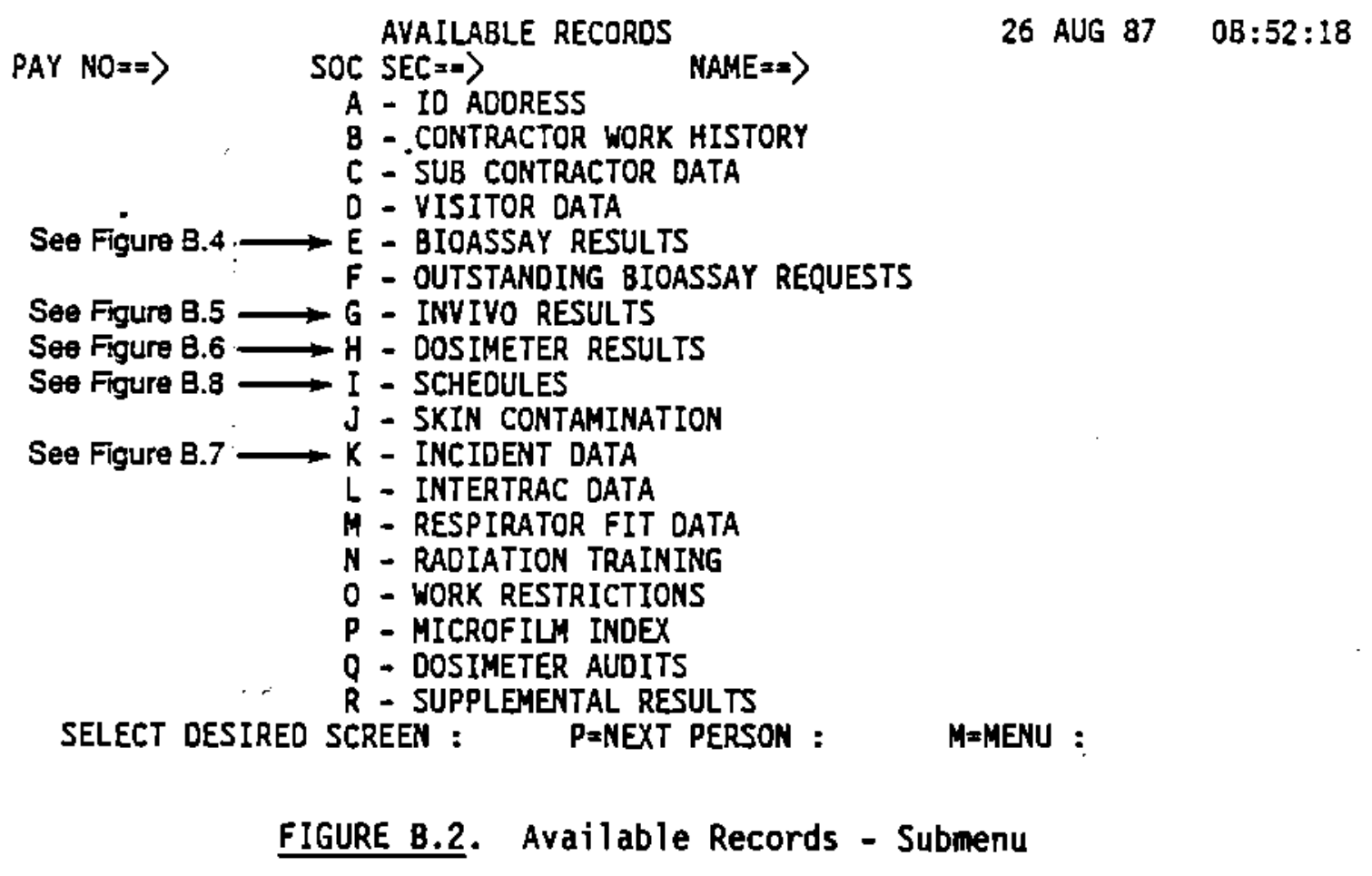




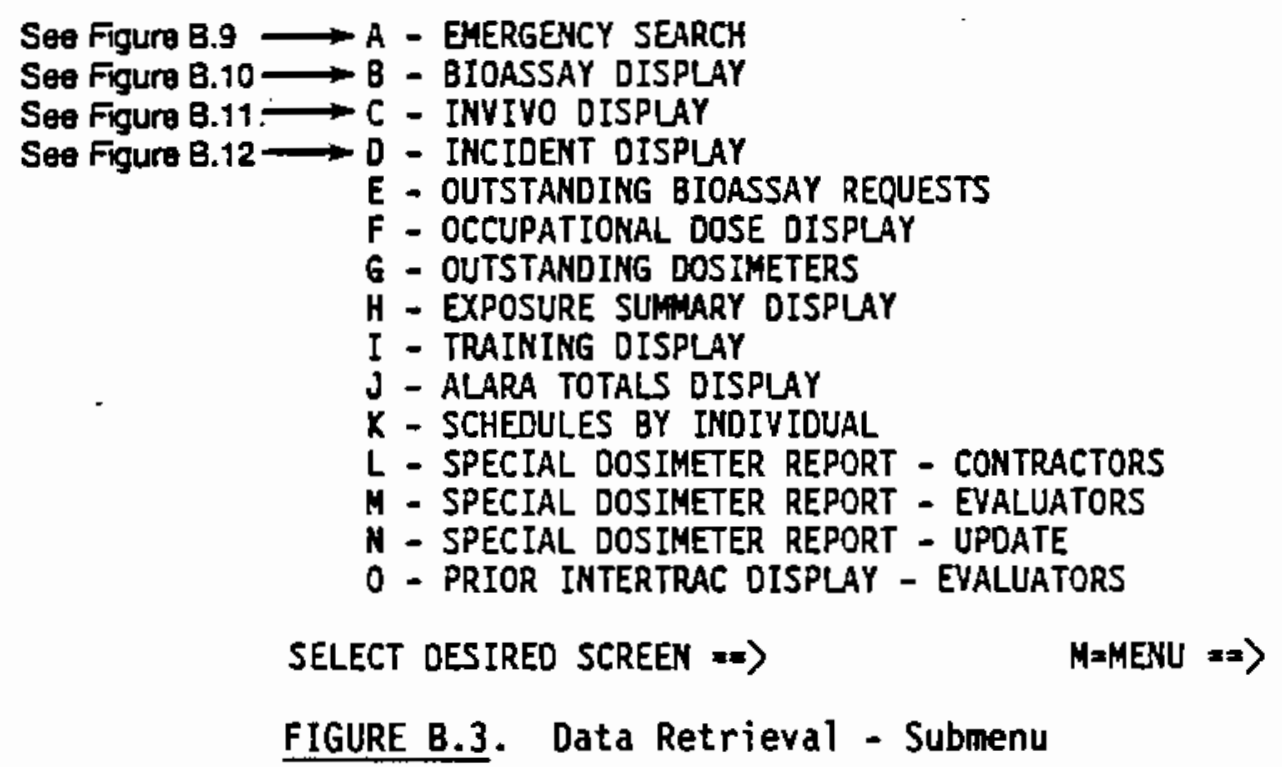




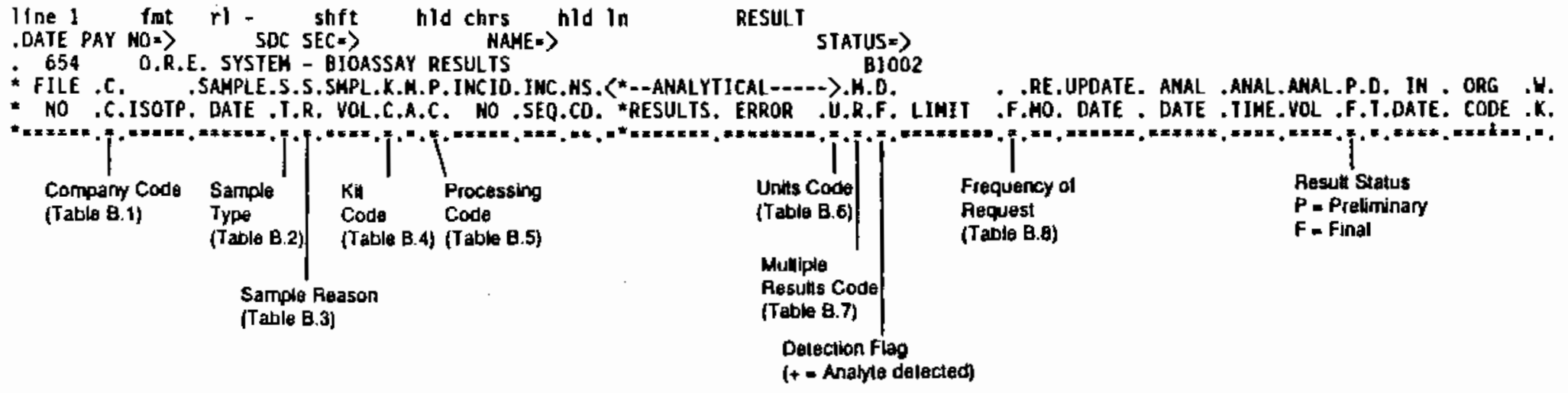

FIGURE B.4. Available Records - Bioassay Results Screen 


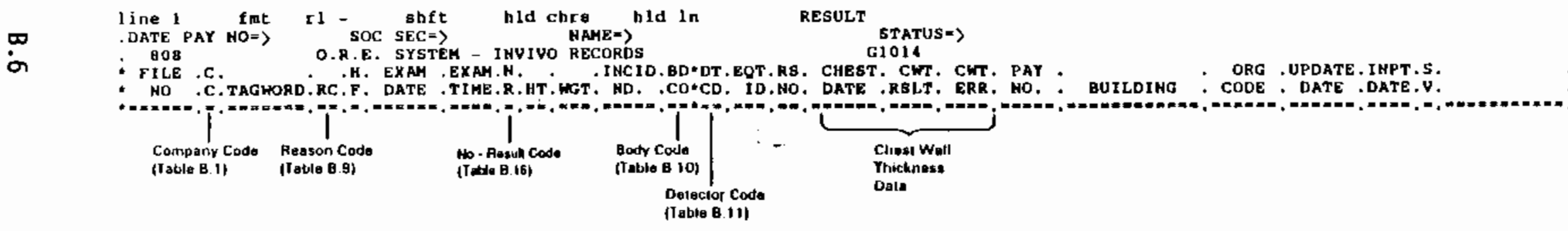

\section{FIGURE B.5. Available Records - In Vivo Records Screen}




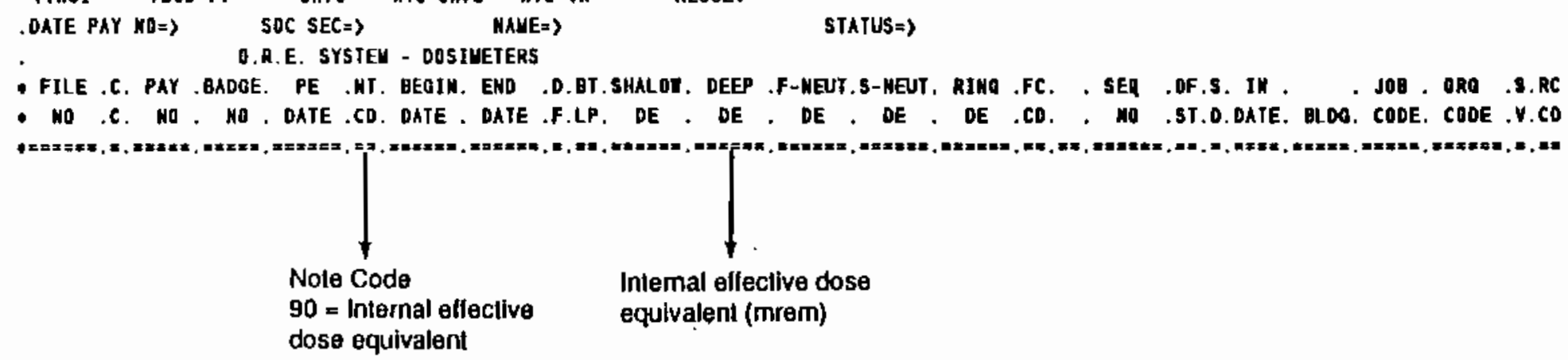

\section{FIGURE B.6. Available Records - Dosimeter Results Screen}




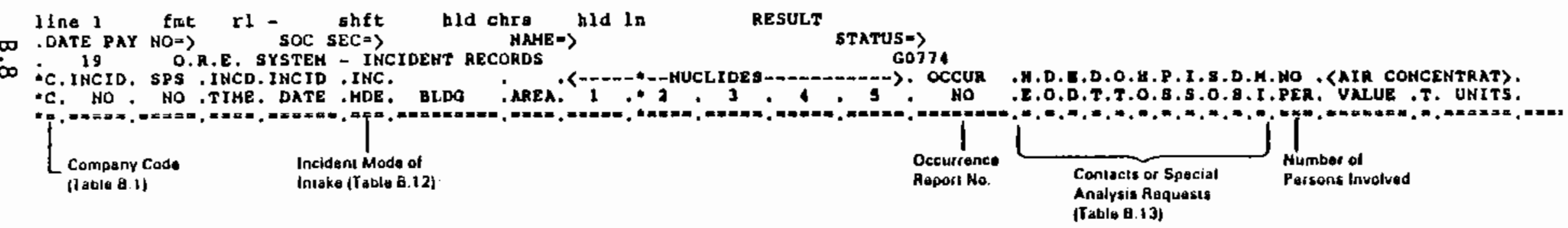

FIGURE B.7. Available Records - Incident Records Screen 


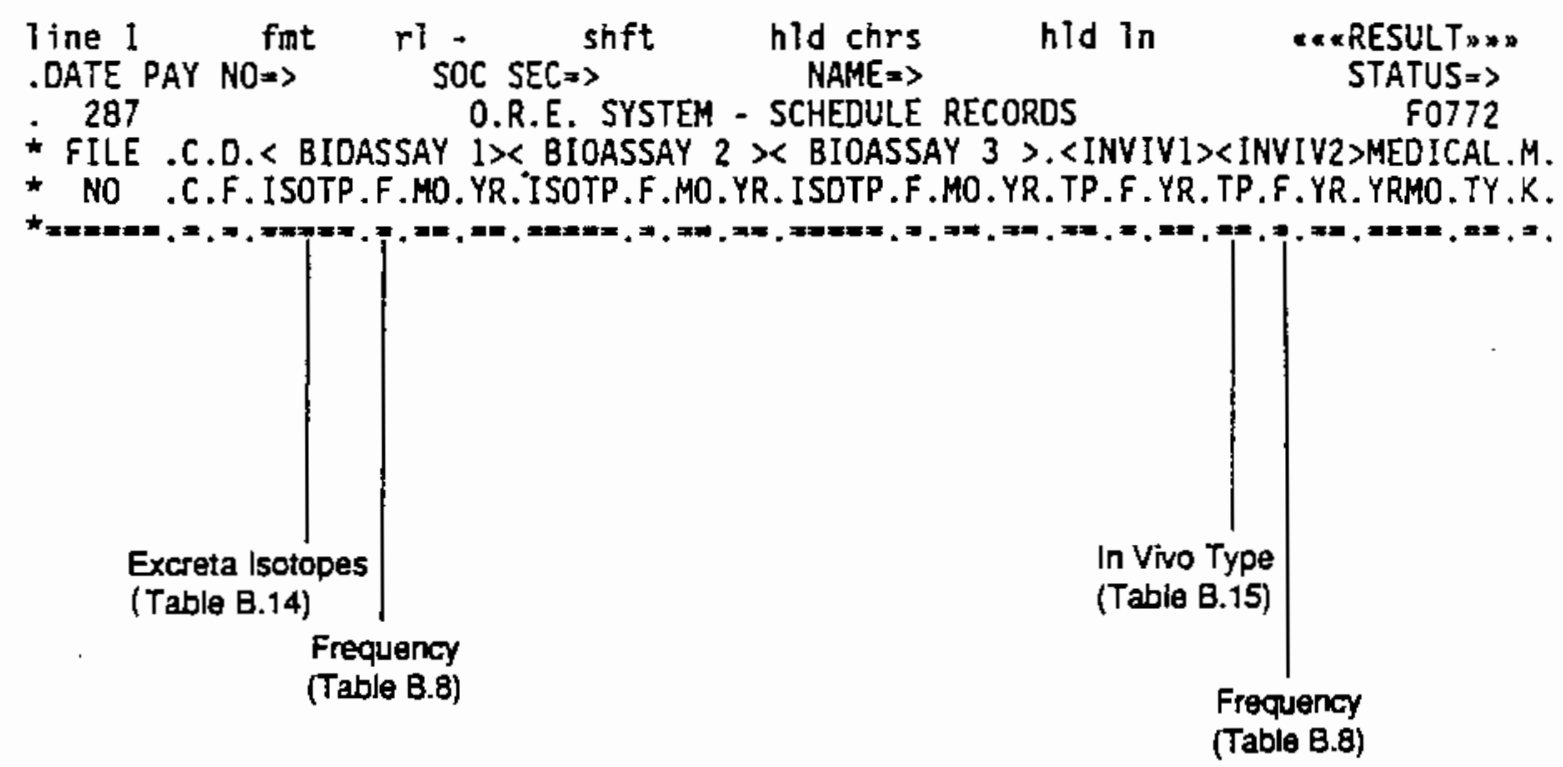

FIGURE B.8. Available Records - Schedules Screen 
.DATE 27 APR 89 08:14:04 REPORT GENERATION MAY

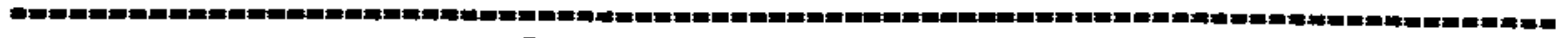
EMERGENCY SEARCH

PAY NUM:
ADORESS:

PARAMETER DATES: TO

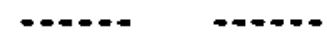

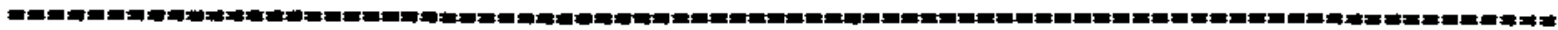
INTERTRAC MASTER RECORD

$\ll$ EVALUATION $\Rightarrow P \quad P \quad R \quad I \quad A$ BEGIN END INT A $D$ R PRINCIPAL

ND SEQ DATE $F \quad F \quad E$ I $C$ DATE DATE MDE $R \quad R \quad S$ RADIONUCLIDE

|

INTERTRAC ANNUAL DOSE RECORD

EVALUATION

NO SEQ ORGAN NUCLID YR DDSE EQ (REM)

ט INCIDENT

NO NO DATE NUCLIDE MODE BLDG AREA TREATMENT

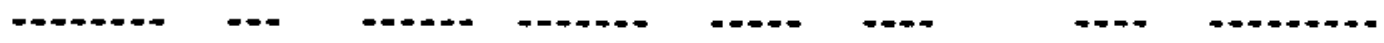

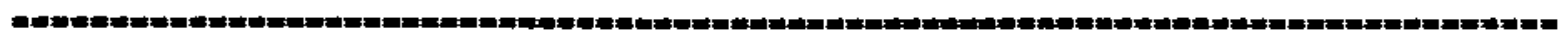
SKIN CONTAMINATION

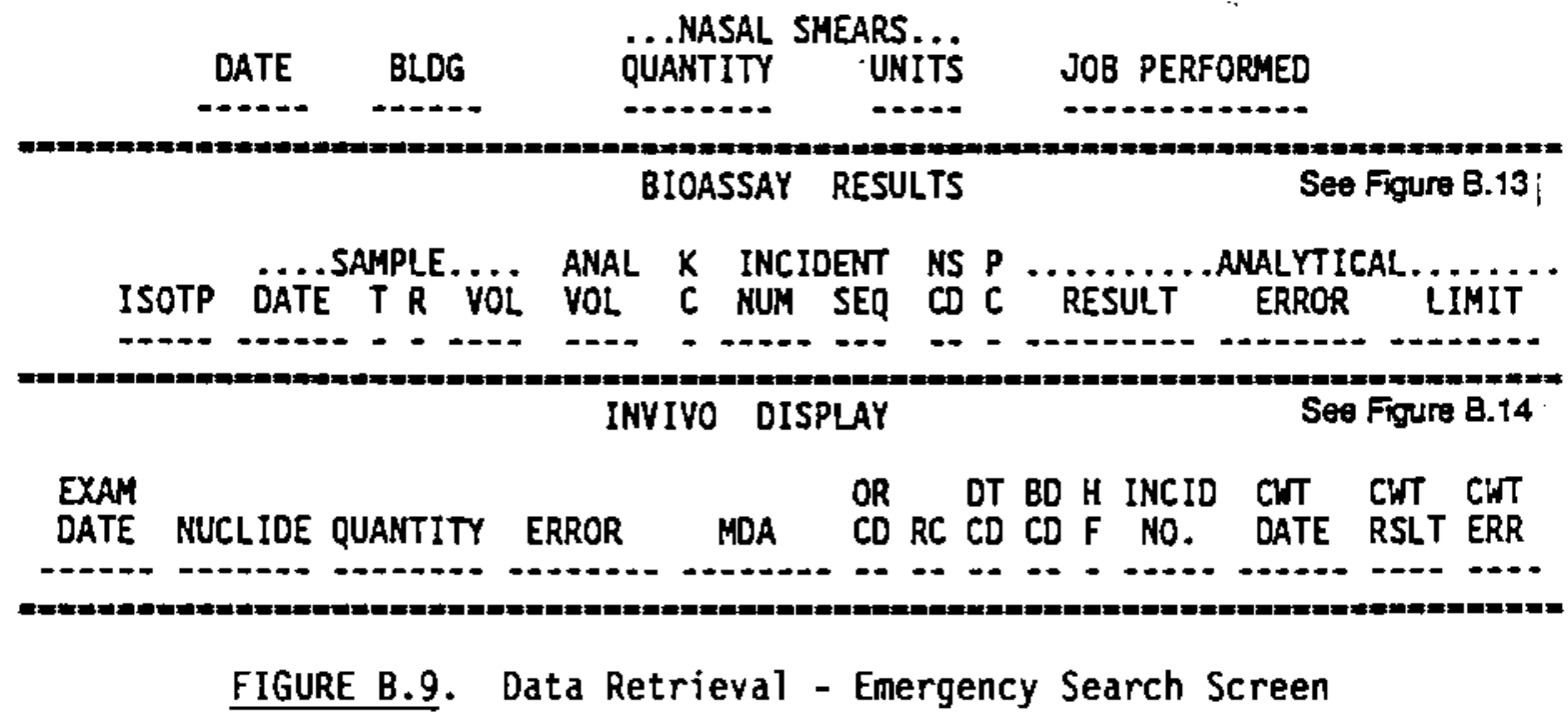




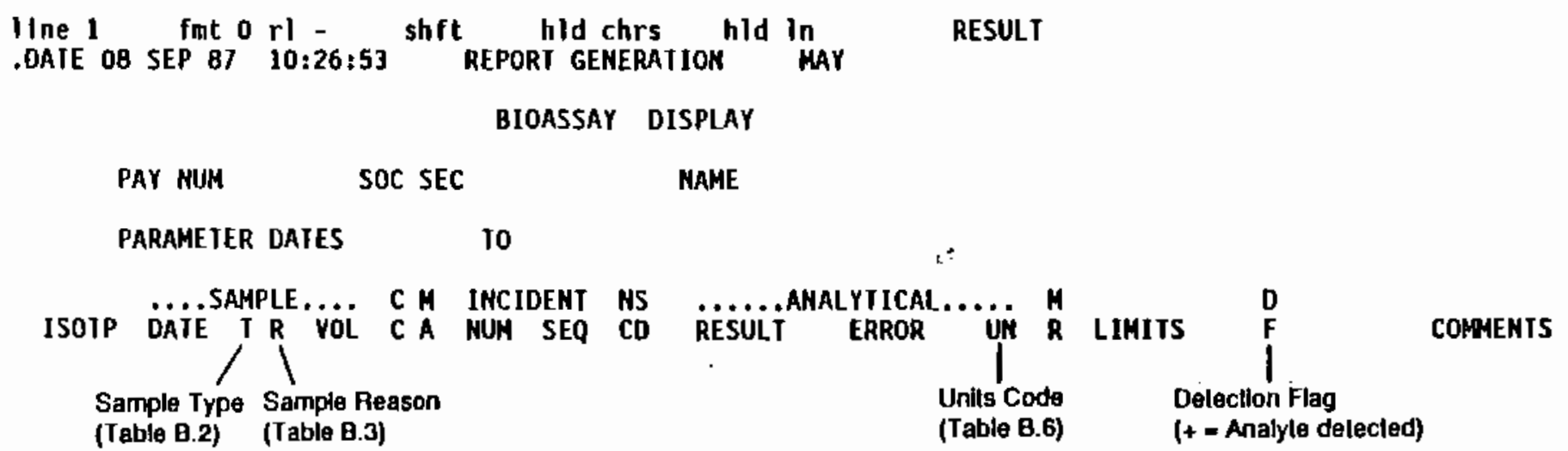

FIGURE B.10. Data Retrieval - Bioassay Display Screen 


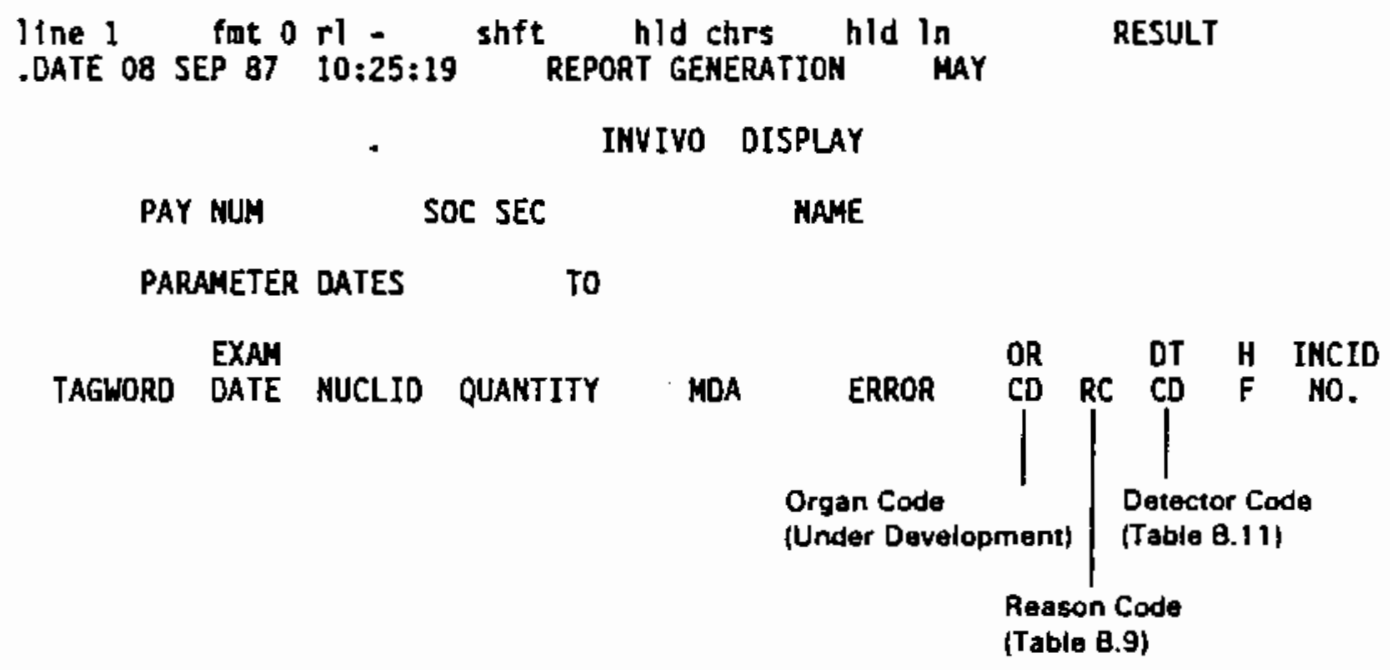

FIGURE B.11. Data Retrieval - In Vivo Display Screen 


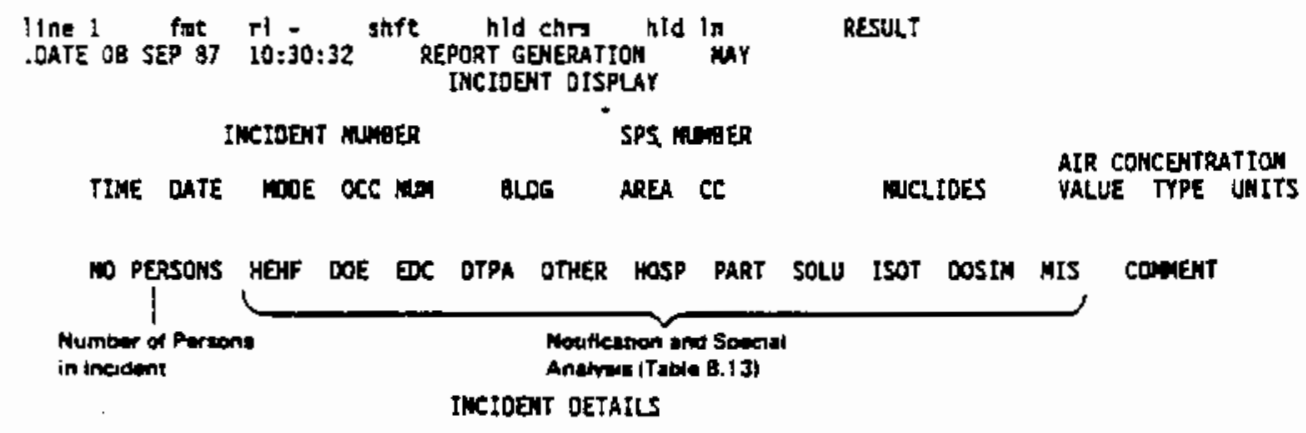

LAST NAME IN PAY MA CE PROMPT EYALUATION TREATHENT MODEL TRE MSAL UNITS RESP

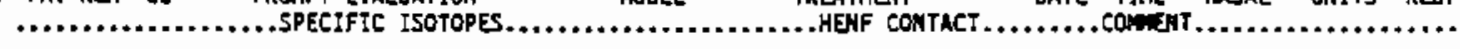

FIGURE B.12. Data Retrieval - Incident Display Screen 


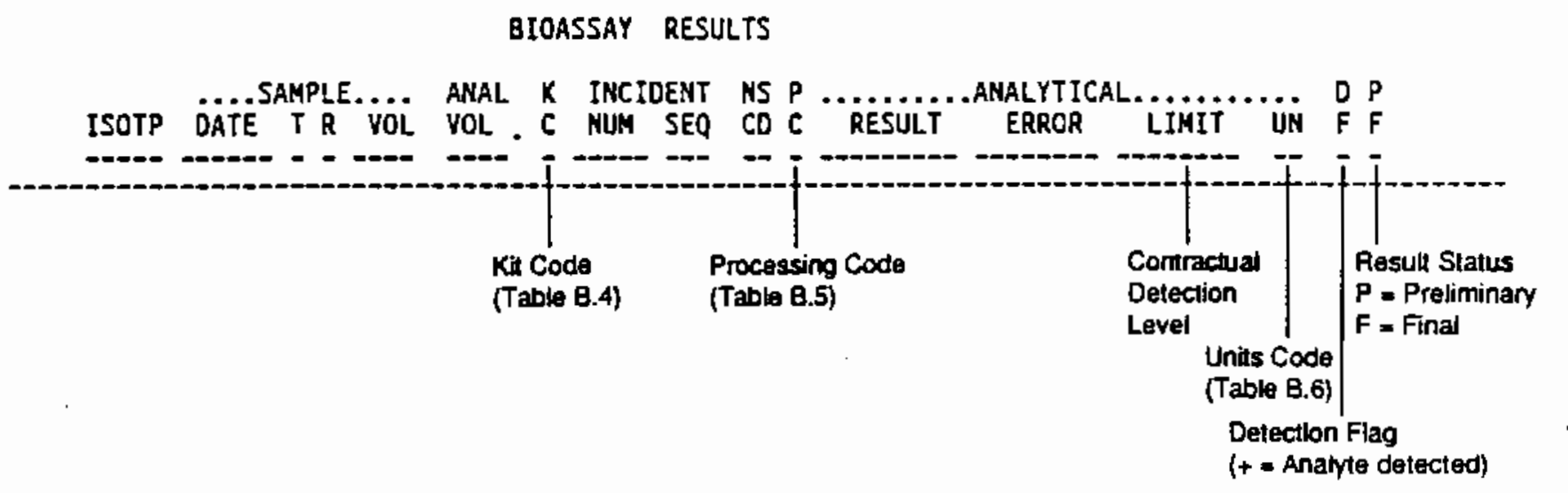

FIGURE B.13. Emergency Search - Bioassay Results Screen 


\section{INVIVO OISPLAY}

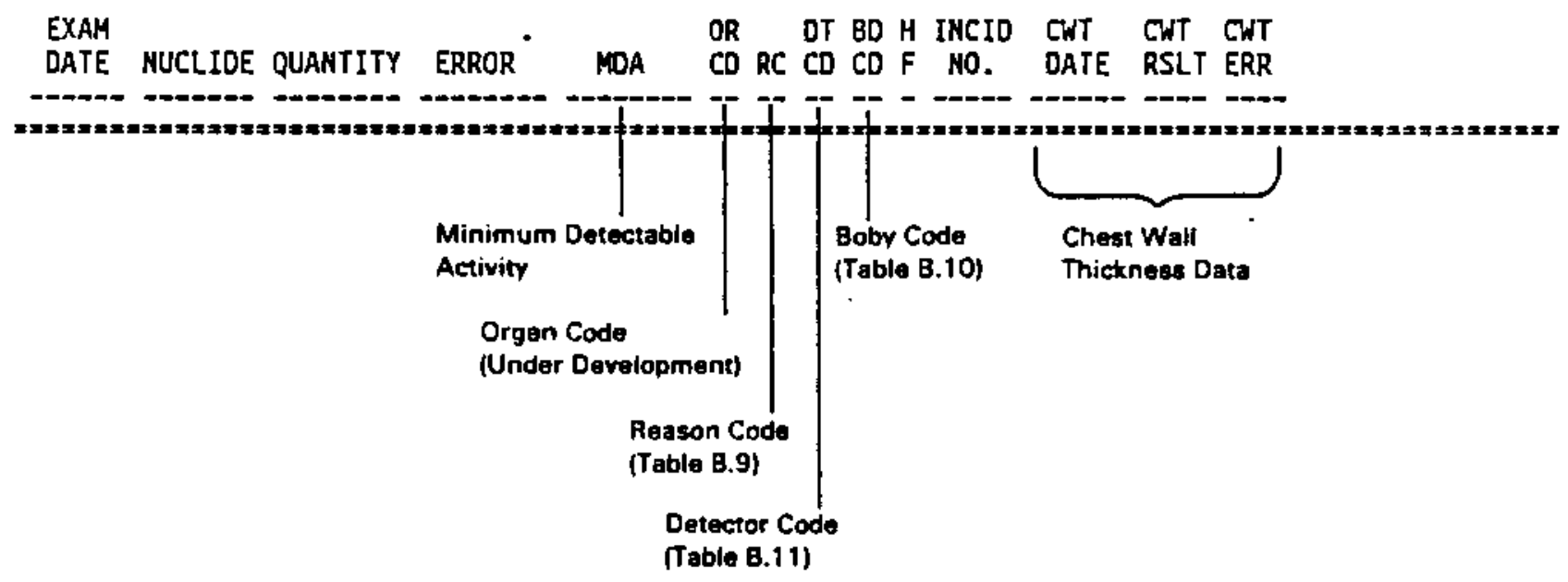

FIGURE B.14. Emergency Search - In Vivo Display Screen 
TABLE B.1. Company Codes

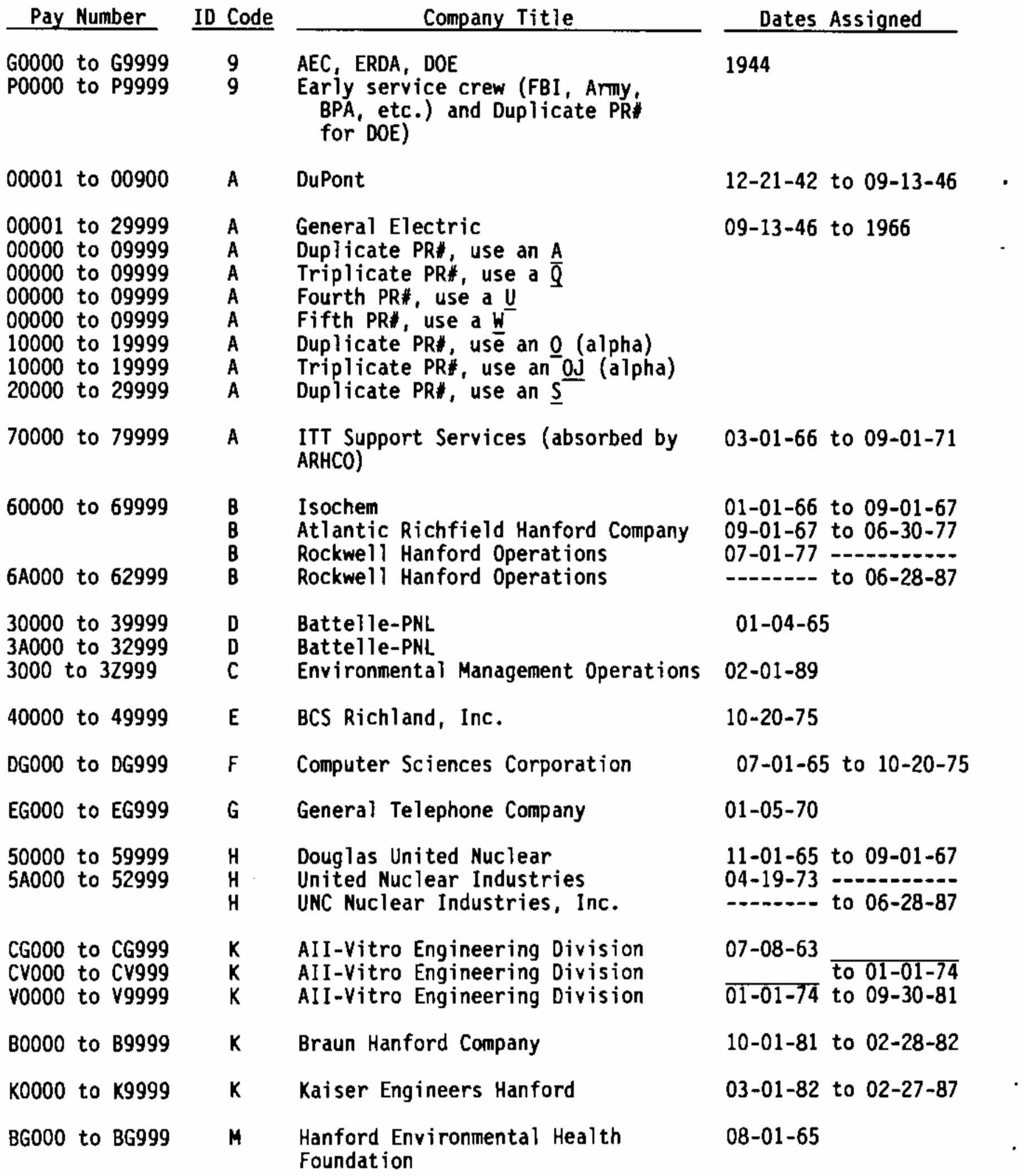


IABLE B.1. (contd)

Pay Number

$\begin{array}{ll}\text { HG000 to HG199 } & \text { P } \\ \text { K0000 to K9999 } & R \\ \text { Z0000 to Z9999 } & R \\ \text { Y0000 to Y9999 } & R \\ \text { YA000 to YA999 } & \end{array}$

M0000 to $M 9999$

MA00O to M2999

$Z 0000$ to $Z 9999$

Y0000 to Y9999

YA000 to YA999

AZ000 to A2999

BZ000 to IZ999

ZZ000 to Z2999

ZA000 to ZY999

FG000 to FG099

90000 to 99999

90000 to

80000 to 89999

50000 to 59999

60000 to 69999

$6 \mathrm{~A} 000$ to

AG000 to AG999

OGO00 to $0 G 999$

IG000 to 16999

XG000 to XG999

RG000 to RG999
ID Code

Company Title

Washington Public Power Supply

Systern (UNC)

Kaiser Engineers Hanford

Kaiser Engineers Hanford

Kaiser Engineers Hanford

Kaiser Engineers Hanford Subcontractors badged for compliance

S Shippingport

$S$ Shippingport Subcontractors

T JA Jones Construction Company

T JA Jones Construction Company

$T$ JA Jones - Subcontractors badged for compliance

T George A. Grant (Subcontractor)

JA Jones (Subcontractors)

Conam Inspection, Inc. (JA Jones subcontractor)

$T$ Construction without $Z$ \# and duplicate Z*

T Combustion Engineers

$\checkmark$ Westinghouse Hanford Co. (WADCO/ HEDL)

W Westinghouse Hanford Company

W Westinghouse Hanford Company

W Westinghouse Hanford Company

W Westinghouse Hanford Company

W Westinghouse Hanford Company

$X$ Records combined in database for one or more companies

* Resident Non-Employee

* Resident Non-Employee

* Resident Non-Employee

* Resident Non-Employee

Resident Non-Employee
Dates Assigned

$03-31-72$ to $12-30-82$

$02-28-87$

$05-10-84$

05-10-84

06-01-53 - -

-.-.-. to $02-27-87$

$06-01-75$ to $02-27-87$

01-01-65 to $06-07-75$

$01-01-66$ to $06-07-75$

$12-26-73$ to $09-30-77$

Any date

12-05-66 to $06-25-71$

07-01-70 to $06-28-87$

$06-29-87$

01-01-65

$03-20-73$

06-07-79

$09-29-83$

$11-22-83$ 
TABLE B.1. (contd)

\begin{tabular}{llll} 
Pay Number & ID Code & \multicolumn{1}{c}{ Company Title } & Dates Assigned \\
FG100 to FG999 & $\star$ & Visitors & $05-21-85$ \\
TR000 to TR299 & $*$ & U.S. Transuranium Registry & 1985
\end{tabular}

- Any company. 
TABLE B.2. Sample Type Codes

\begin{tabular}{cl} 
Sample Type \\
Code & Description \\
\hline
\end{tabular}

B

Blood

$\mathbf{F}$

Feces

$\mathrm{S}$

Sputum

T

Tissue

U

Urine

B. 19 
TABLE B.3. Sample Reason Codes for Excreta

Sample Reason
Code

R

H

B

E

$\mathbf{F}$

I

$x$

$T$

Z

Q

C

V

U
Reason for

Measurement

Rout ine

New hire

Beginning work

Contractor

Incident

Exposure evaluator

Termination

Visitor

Research

Recount

Investigate high routine

Follow-up
Description of Reason

Sample collected for routine surveillance (see Table 6.9)

Sample collected before a worker begins employment or enters a radiation zone

Sample collected before a worker begins a specific type of radiation zone work, or before an offsite trip where potential exposure could occur

Sample collected after a worker completes a specific type of radiation zone work or after a return from a trip where potential offsite exposure could have occurred

Sample collected by request of a contractor for a specific need (code used in 1987-88 for verifying intakes below an investigation level 1)

Sample requested after an incident of potential occupational exposure

Sample requested by an EE for special purposes

Sample collected when a worker terminates employment. No entry into radiation zones should occur after sample is collected

Sample collected from a visitor to Hanford (new as of 1989)

Sample collected for research or quality control (new as of 1989)

Recount of an original measurement to confirm the detected activity reported to PNL Internal Dosimetry

Sample collected after the report of an elevated routine type measurement (i.e., $R, B, E, F$ ) to PNL Internal Dosimetry

Sample collected for long-term follow-up evaluation 
TABLE B.3. (contd)

Sample Reason Reason for

Code

Measurement

Description of Reason

D

Contractor

request (baseline)

J

Contractor request

(other)

Sample requested by Field Dosimetry to re-establish a baseline excretion level (after entry clearance), following a potential intake less than an investigation level intake (used from 1987 to 1988 only)

Sample requested by Field Dosimetry from 1987 to 1988 for any reason other than reason codes $D$ or $F$. 
TABLE B.4. Sample Kit Codes

\section{Kit Code}

1

2

3

4

5

6
Sample Media

Urine

Urine

Urine

Urine

Feces

Urine

Urine
Sample Description

Simulated 24-hour urine collection. Collected at home over a 2-day period. Used for routine sampling and when a larger volume sample is desired. Designated sample date is the day after kit delivery to the employee.

12-hour urine collection for termination sampling only. Collected at home overnight. Designated sample date is the date of kit delivery to the employee.

Total 24-hour urine collection. Collected at home and at work (if necessary) to collect ALL urine voided during a 24-hour period. Generally used for sampling imediately following an occurrence or for work restriction sampling. Designated sample date is the day after delivery or the date on which the sample collection began.

Single void (spot urine) collection. Collection in a single bottle, used for initial indications of an intake. Designated sample date is the date of voiding.

Collection of a single fecal voiding usually for investigation of a potential intake. Rapid or priority processing. Sample date is the date on which the sample is collected.

Partial day or simulated 12-hour collection. Usually collected at home overnight. Used for collection following an occurrence or when a large volume urine sample is not necessary, such as for tritium or uranium determination. Designated sample date is the date of delivery to the employee.

Simulated 12-hour collection Sunday-Monday sample (Friday delivery only). Generally used for uranium workers. Designated sample date is the Sunday in the sampling period. 
IABLE B.4. (contd)

Kit Code Sample Media Sample Description

8

Feces

Collection of a single fecal voiding used for a special program for plutonium oxide workers. Designated sample date for shift workers is the Tuesday of long shift change, and for day workers is the appropriate Sunday.

$9 \quad$ Urine

Kit designed for collection of urine outside the local service area. Transportation is handled by private carrier. Generally used for temination samples not collected locally. 
TABLE B.5. Processing Codes

\begin{tabular}{|c|c|}
\hline $\begin{array}{c}\text { Computer } \\
\text { Code } \\
\end{array}$ & Description \\
\hline $\mathbf{R}$ & Routine processing \\
\hline $\mathbf{P}$ & Priority processing \\
\hline$x$ & Expedite processing \\
\hline $\mathbf{E}$ & Emergency processing \\
\hline
\end{tabular}


TABLE B.6. Units Codes

\begin{tabular}{|c|c|}
\hline $\begin{array}{l}\text { Computer } \\
\text { Code }\end{array}$ & Description of Units \\
\hline 1 & dpm/sample \\
\hline 2 & dpm/volume analyzed \\
\hline 3 & $\begin{array}{l}\mu \mathrm{g} / 1 \text { until } 07-01-82 \\
\mu \mathrm{g} / \mathrm{s} \text { ample after } 07-01-82\end{array}$ \\
\hline 4 & $\begin{array}{l}\mu \mathrm{g} / \mathrm{gram} \text { unt } i 1 \text { 07-01-82 } \\
\mu \mathrm{g} / \mathrm{sample} \text { after 07-01-82 }\end{array}$ \\
\hline 5 & $\mu \mathrm{Ci} / 1$ \\
\hline 6 & $\mu \mathrm{Ci} / 1$ \\
\hline
\end{tabular}


IABLE B.7. Multiple Results Codes

\begin{tabular}{|c|c|c|c|}
\hline Description & $\begin{array}{c}\text { Multiple } \\
\text { Result } \\
\text { Code } \\
\end{array}$ & $\begin{array}{c}\text { Computer } \\
\text { Code } \\
\end{array}$ & Results Reported \\
\hline Pu Isotopic & $Q$ & IPU & $238 \mathrm{Pu}, 239,240 \mathrm{Pu}$ \\
\hline Gamma Spectroscopy & $w$ & ISPEC & $40 \mathrm{~K},{ }^{137} \mathrm{Cs}$, and others \\
\hline Gamma Spectroscopy & $\star$ & LEPD & $241_{\text {Am }}$ \\
\hline $\begin{array}{l}\text { Seq. Pu Isotopic, } \\
\text { Am Isotopic, Cm }\end{array}$ & $k$ & ITPAC & $238 \mathrm{Pu}, 239,240 \mathrm{Pu}, 241_{\mathrm{Am}}, 244 \mathrm{Cm}, 242 \mathrm{Cm}$ \\
\hline Seq. ${ }^{90} \mathrm{Sr}, \mathrm{Ce}, \mathrm{P}_{\mathrm{m}}$ & $s$ & ISCP & $90 \mathrm{Sr},{ }^{144} \mathrm{Ce}, 147 \mathrm{Pm}$ \\
\hline $\begin{array}{l}\text { Seq. Sr-Total, } \\
\text { Ce, } \mathrm{Pm}\end{array}$ & I & SCP & $\mathrm{Sr},{ }^{144 \mathrm{C}}, 147 \mathrm{Pm}$ \\
\hline Cm Isotopic & D & ICM & $244 \mathrm{Cm}, 242 \mathrm{~cm}$, and others \\
\hline Eu Isotopic & $\mathbf{F}$ & IEU & $152 \mathrm{Eu}, 154 \mathrm{Eu}, 155 \mathrm{Eu}$ \\
\hline U Isotopic & U & IU & $233,234 \mathrm{Pu}, 235 \mathrm{U}, 238 \mathrm{U}$ \\
\hline Seq. Pu, $90 \mathrm{Sr}$ & $\mathbf{P}$ & IPS & $238 \mathrm{pu}, 239,240 \mathrm{pu}, 90 \mathrm{sr}$ \\
\hline $\begin{array}{l}\text { Seg. Pu Isotopic, } \\
\text { 24IAm }\end{array}$ & $\mathrm{J}$ & IPA & $238 \mathrm{Pu}, 239,240 \mathrm{Pu}, 241_{\mathrm{Am}}$ \\
\hline $\begin{array}{l}\text { Seq. Pu Isotopic, } \\
\text { Sr-Total }\end{array}$ & M & IPSR & $238 \mathrm{pu}, 239,240 \mathrm{pu}, \mathrm{Sr}$ \\
\hline $\begin{array}{l}\text { Seq, Pu Isotopic, } \\
\text { Sr-Total, 241 }\end{array}$ & $\mathrm{L}$ & IPSA & $238 \mathrm{Pu}, 239,240 \mathrm{Pu}, \mathrm{Sr}, 241_{\mathrm{Am}}$ \\
\hline Sr Isotopic & Y & ISR & ${ }^{89} \mathrm{Sr},{ }^{90} \mathrm{Sr}$ \\
\hline Pu Isotopic, 241Pu & N & IPUBA & $238 \mathrm{Pu}, 239,240 \mathrm{Pu}, 241 \mathrm{Pu}$ \\
\hline $\begin{array}{l}\mathrm{Pu} \text { Isotopic, } 241 \mathrm{Pu}, \\
241_{\mathrm{Am}}\end{array}$ & $z$ & IPUBA & $238 \mathrm{Pu}, 239,240 \mathrm{Pu}, 241 \mathrm{Pu}, 241_{\mathrm{Am}}$ \\
\hline Pu Isotopic/U-Natural & $Q$ & IUPU & $238 \mathrm{pu}, 239,240 \mathrm{Pu}, \mathrm{U}$ \\
\hline U-Natural (Soluble) & H & QUS & U \\
\hline Th Isotopic & $\mathrm{T}$ & ОТН & $228 \mathrm{Th}, 230 \mathrm{Th}, 232 \mathrm{Th}$ \\
\hline Ra Isotopic & $\mathbf{R}$ & IRA & $224 R a, 225 R a$ \\
\hline
\end{tabular}


TABLE B.8. Bioassay Frequency Codes

Computer

$\begin{array}{cll}\text { Code } & & \text { Frequency of Bioassay } \\ \text { A } & & \text { Annual } \\ \text { B } & & \text { Biennial } \\ \text { F } & & \text { Five years } \\ \text { Q } & & \text { Quarterly } \\ \text { S } & & \text { Semiannual } \\ \text { W } & & \text { Weekly } \\ \text { X } & & \text { Biweekly (every } 2 \text { weeks) }\end{array}$


TABLE B.9. Reason Codes for In Vivo Measurements

\begin{tabular}{|c|c|}
\hline Code & Reason \\
\hline 1 & Routine \\
\hline 2 & New hire \\
\hline 3 & Termination \\
\hline 4 & $\begin{array}{l}\text { Unusual exposure } \\
\text { (incident) }\end{array}$ \\
\hline 5 & Evaluator request \\
\hline 6 & $\begin{array}{c}\text { Contractor request } \\
\text { (verification) }\end{array}$ \\
\hline 7 & Recount \\
\hline 8 & Fol low-up \\
\hline
\end{tabular}

Description of Reason

Measurement is performed on a predetermined, periodic schedule for routine surveillance

Measurement is performed before worker begins employment or enters a radiation zone

Measurement is performed when a worker terminates employment. No entry into radiation zones should occur after count is performed

Measurement is requested after an incident of potential occupational exposure

Measurement is requested by EE as an additional count to be performed along with the worker's routine count or requested for evaluation of prior exposure

Count is performed by request of a contractor for a specific need

Count is performed to verify an original count

Count is performed at some time after detection of activity in a worker

9 Beginning of work

Count is performed before a worker begins a specific type of radiation zone work, or before offsite trip where potential exposure could occur

10 End of work

Count is performed after a worker completes a specific type of radiation zone work or after a return from a trip where potential offsite exposure could have occurred

11 Visitor

Count is performed on a visitor to Hanford

12 Contract work

Count is performed by special contract work to the PNL Whole Body Counter

13 Research project Count is performed specifically for a research project

14 Contractor request (baseline)

Count is requested by Fjeld Dosimetry to re-establish baseline activity (after early clearance) from a potential intake that was less than an investigative level (used in 1987 and 1988 only) 
TABLE B.9. (contd)

Code

15 Contractor request (other)

16 Investigate high routine
Description of Reason

Count requested by Field Dosimetry for any reason other than the two other contractor request codes (6 and 14). Used only in 1987 and 1988.

Measurement performed after the report of an unexpectedly high result 
TABLE B.10. Body Location Codes for In Vivo Measurements

$\begin{array}{cll}\begin{array}{c}\text { Computer } \\ \text { Code }\end{array} & & \begin{array}{c}\text { Body } \\ \text { Location }\end{array} \\ 01 & & \text { Whole body } \\ 02 & & \text { Head } \\ 03 & & \text { Chest } \\ 04 & & \text { Abdomen } \\ 05 & & \text { Knee } \\ 06 & & \text { Throat } \\ 07 & & \text { Hand } \\ 08 & & \text { Special } \\ 09 & & \text { Thorax }\end{array}$


TABLE B.11. In Vivo Detector Codes

Code Type of Detector

A

4" $\times$ g" NaI single crystal

B $3 / 8^{\prime \prime} \times 5 "$ NaI four-crystal array

C $\quad 3 / 8^{\prime \prime} \times 5^{\prime \prime}$ NaI single crystal

D $\quad 1 \mathrm{~mm} \times 1^{11} \mathrm{NaI}$ single crystal

D1 Wound count using $D$ detector

E $\quad 3^{\prime \prime} \times 3^{\prime \prime}$ NaI single crystal

E1 Thyroid count using $E$ detector

F $\quad 3 / 8 " \times 5 "$ NaI four-crystal array

G $4 " \times 11 " \mathrm{NaI}$ single crystal

H $\quad 6 " \times 11^{\prime \prime}$ NaI single crystal

I $32 \%$ and $35 \%$ GeLis

I2 Lung count using two coaxial detectors

J Planar GeLi single crystal

J2 Lymph node count using J detector

K $\quad 18 \%$ GeLi single crystal

L $\quad 35 \%$ GeLi single crystal

M Intrinsic germanium single array $10 \mathrm{~cm}^{2}$

N $\quad 3 / 8^{\prime \prime} \times 5^{\prime \prime}$ Phoswich single crystal

$0 \quad 4^{\prime \prime} \times 4^{\prime \prime} \times 16^{\prime \prime}$ NaI single array

P $\quad 3 / 8 " \times 5^{\prime \prime}$ Phoswich single crystal

Q Specialized counting

Q1 Head count using two intrinsic germanium detectors set at $0.25 \mathrm{keV} /$ channel

Q2 Thyroid count using two intrinsic germanium detectors set at $0.25 \mathrm{keV} / \mathrm{channel}$

$R \quad$ Intrinsic germanium three-crystal array $20 \mathrm{~cm}^{2}$

R1 Liver or head count using three intrinsic gemanium detectors set at $0.5 \mathrm{keV} / \mathrm{channel}$

$5 \quad 6 " \times 11^{\prime \prime} \mathrm{NaI}$ and two $2 \mathrm{GeLis} 032 \%$ and $35 \%$

S1 Sled counter 
IABLE B.11. (contd)

\begin{tabular}{ll} 
Code & Type of Detector \\
\cline { 3 - 3 }$T$ & Intrinsic germanium five-crystal array $20 \mathrm{~cm}^{2}$ \\
$U$ & $4 " \times 9 " \mathrm{NaI}$ (4) and $6 " \times 11^{\prime \prime} \mathrm{NaI}$ \\
U1 & Sum spectra calculation \\
U2 & Also includes individual detector calculation \\
V & Intrinsic germanium six-crystal array $20 \mathrm{~cm}^{2}$ \\
V1 & Lung count using V-detector array set at \\
V2 & $0.5 \mathrm{keV} / \mathrm{channel}$ Lung count using V-detector array set at \\
& $0.25 \mathrm{keV} /$ channel
\end{tabular}


TABLE 8.12. Mode of Intake Codes

\begin{tabular}{|c|c|}
\hline Code & Mode of Intake \\
\hline ABS & Absorption \\
\hline ING & Ingestion \\
\hline INH & Inhalation \\
\hline NON & None (no intake) \\
\hline UNK & Unknown \\
\hline WND & Wound \\
\hline
\end{tabular}


TABLE B.13. Contacts and Special Analysis Requests

\begin{tabular}{ll} 
Code & \multicolumn{1}{c}{ Description } \\
DO & DOE - Department of Energy \\
DS & Dosimeter \\
DT & DTPA - chelation agent administered \\
ED & EDF - Emergency Decontamination Facility \\
HE & HEHF - Hanford Environmental Health Foundation \\
HO & Hospital \\
IS & Isotopic \\
MI & Miscellaneous \\
OT & Other \\
PS & Particle Size \\
SO & Solubility
\end{tabular}


TABLE B.14. ORE Isotope Codes

\begin{tabular}{|c|c|c|c|}
\hline Isotope & $\begin{array}{r}\text { Multiple } \\
\text { Result Code }\end{array}$ & I sotope & $\begin{array}{r}\text { Multiple } \\
\text { Result Code } \\
\end{array}$ \\
\hline $\begin{array}{l}\text { AM241 } \\
\text { C } 14 \\
\text { CE144 } \\
\text { CM242 } \\
\text { CM244 } \\
\text { CS137 } \\
\text { CO } 60 \\
\text { EU154 } \\
\text { EU155 } \\
\text { EU156 } \\
\text { GS } \\
\text { H } \\
\text { I } 131 \\
\text { IAM } \\
\text { IBK } \\
\text { ICF } \\
\text { ICM } \\
\text { IES } \\
\text { IEU } \\
\text { IPA } \\
\text { IPS } \\
\text { IPSA } \\
\text { IPSR } \\
\text { IPU } \\
\text { IPUB } \\
\text { IPUBA } \\
\text { IRA } \\
\text { IR192 } \\
\text { ISCP } \\
\text { ISPEC } \\
\text { ISR } \\
\text { ITH } \\
\text { ITPAC } \\
\text { IU } \\
\text { IUPA } \\
\text { IUPU } \\
\text { K 40 } 40 \\
\text { LEPD } \\
\text { MFP } \\
\text { MN } 54 \\
\text { NA } 24\end{array}$ & 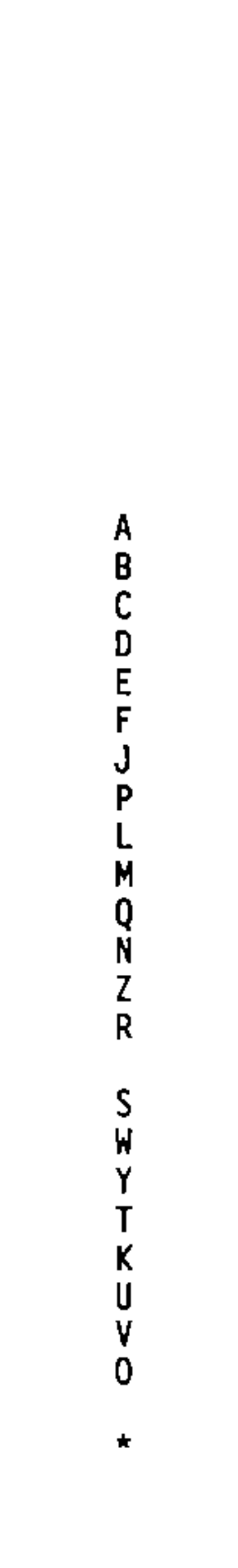 & $\begin{array}{l}\text { NP237 } \\
\text { PB210 } \\
\text { PM147 } \\
\text { P0210 } \\
\text { PU } \\
\text { PU238 } \\
\text { PU239 } \\
\text { PU240 } \\
\text { PU241 } \\
\text { PU242 } \\
\text { QUS } \\
\text { RA224 } \\
\text { RA226 } \\
\text { RA228 } \\
\text { RU106 } \\
\text { SR } \\
\text { S } 35 \\
\end{array}$ & H \\
\hline
\end{tabular}


TABLE B.15. Codes for In Vivo Schedule Type

Code Type of Measurement

$\begin{array}{ll}\text { WB } & \text { Whole body count } \\ \text { C } & \text { Chest count } \\ \text { C2 } & \text { Extended chest count } \\ \text { T } & \text { Thyroid }\end{array}$


IABLE B.16. In Vivo No-Result Codes

Code

Explanation of Code

C External contamination other than radon detected on the subject. Measurement invalid; no results obtained.

F Failure of equipment or faulty setup of equipment. Measurement invalid; no results obtained.

I Interference from localized activity in another part of the subject's body. Measurement invalid; no results obtained.

L Location of internal or external activity was qualitatively determined by mapping, masking, or collimating. May include one or more measurement counts. These measurements are qualitative for identifying location of activity and do not yield quantifiable estimates of activity.

M Medically administered radioactivity interfered with measurement. Measurement invalid; no results obtained.

$R \quad$ Radon interference from subject's clothing, hair, or skin. Measurement invalid; no results obtained.

$S$ The subject's actions interrupted completion of the count. Measurement invalid; no results obtained.

$X \quad$ Measurement invalid; no results obtained. 0ther noresult codes do not apply. See comment field for a brief description.

Notes

1) For invalid results, the ORE database shows "XX000" in the nuclide field and "00000" in the amount and detection level fields. A zero for detection level is presented as " $\angle M D A>$ ".

2) The comnent field may have a brief explanation in addition to the codes listed above. 


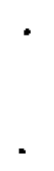




\section{APPENDIX C}

\section{ANALYTICAL PROCEDURES}


APPENDIX C

ANALYTICAL PROCEDURES

This appendix contains summaries of the procedures used by the Analytical Services Laboratory (Lab) to analyze indirect bioassay samples and the Whole Body Counter (WBC) Facility for performing direct bioassay measurements.

\section{C.1 INDIRECT BIOASSAY SAMPLES}

All indirect bioassay samples are analyzed to determine their content of various radionuclides according to detailed, written procedures, which are described briefly for each radionuclide as follows.

\section{C.1.1 Tritium in Urine}

One milliliter of the sample is mixed with scintillator solution and counted directly in a liquid scintillation spectrometer.

\section{C.1.2 Urine--Rapid and Expedite Processing}

Totol Rodiostrontium Up to $100 \mathrm{ml}$ of the sample is precipitated as a carbonate, dissolved and reprecipitated as a nitrate, scavenged with barium chromate, converted to carbonate, and counted in a low-background gas-flow proportional counter.

Plutonium

Americium and Curium
Plutonium is converted to (+IV) valence state using sodium nitrite and adsorbed on an anion exchange column. Iron and thorium are removed by nitric and hydrochloric acid. The plutonium is desorbed from the column, using ammonium iodide, and electrodeposited on a planchet. Alpha-emitting isotopes are counted using alpha spectrometry. Plutonium-24l activity is determined by dissolving the material from the planchet with nitric and hydrochioric acid and by counting the beta emissions in a liquid scintillation spectrometer.

The sample is wet-ashed using nitric acid and mixed with anion exchange resin to remove plutonium and other heavy metals. The residual solution is coprecipitated with calcium oxalate and redissolved with nitric acid. The americium and curium are concentrated with bidentate organophosphorus solvent (DDCP), electrodeposited on a planchet, and counted using alpha spectrometry. 


\section{C.1.2 Urine--Rapid and Expedite Processing (contd) \\ Uranium \\ One hundred microliters of sample are fused with a sodium fluoride-lithium fluoride flux. The mass of uraniun in the resulting solution is determined by measuring the yellow-green fluorescence using a fluorophotometer.}

\section{C.1.3 Feces--Rapid and Expedite Processing}

Total Radiostrontium The sample is wet-and dry-ashed. Strontium is precipitated as the nitrate, scavenged with barium chromate, converted to carbonate, and counted in a low-background gas-flow proportional counter.

Plutonium The sample is wet- and dry-ashed. Then the procedure is the same as that for urine (see Section C.1.2).

Americium and Curium The procedure is the same as that for urine (see Section C.1.2).

Uranium

The sample is wet-ashed only. Then the procedure is the same as that for urine (see Section C.1.2).

\section{C.1.4 Urine and Feces--Priority and Normal Processing}

For all analyses except tritium, the samples are first wet- and dry-ashed. Entire samples are used except for the low-sensitivity uranium analysis. Additional wetand dry-ashing, sometimes using perchloric and hydrofluoric acids, may be needed on fecal samples.

Tritium analysis and the low-sensitivity uranium analysis are not available for fecal samples.

Strontium-90

Strontium is precipitated as the carbonate and then as the sulfate. The redissolved material is scavenged with hydroxide followed by two barium chromate precipatations. This is followed by carbonate, nitrate, and a final carbonate precipatation. The carbonate is mounted on a planchet and counted with a low-background gas-flow proportional counter. If this count is less than $1 \mathrm{dpm}$, the procedure is terminated. If the first count is greater than $1 \mathrm{dpm}, 90 \mathrm{Y}$ is allowed to grow into equilibrium with the $90 \mathrm{Sr}$, then it is separated by hydroxide and oxalate precipitations, ignited to yttrium oxide, and the beta emissions are counted. The first count gives the total strontium activity, and the second (yttrium) count gives the $90 \mathrm{Sr}$ activity.

Plutonium

The procedure is essentially the same as that for rapid and expedite processing, except for the increased counting time. 


\section{C.1.4 Urine and Feces--Priority and Normal Processing (contd)}

Americium and Curium

Uranium

\section{C.1.5 Combinations}

The ash is dissolved in nitric acid and sodium nitrite and mixed with anion exchange resin to remove plutonium and other heavy metals. Anericium and curium in the residual solution are precipitated with calcium oxalate, redissolved with nitric acid, reprecipitated with oxalate, dissolved again with nitric, and precipitated with fuming nitric. The americium and curium are then concentrated with bidentate organophyosphorus (DDCP), stripped with hydrochloric acid, and adsorbed on a cation exchange column using ammonium thiocyanate as a complexing agent to remove iron and thorium. The americium and curium are removed from the column, electrodeposited on a planchet, and counted by alpha spectrometry.

To process uranium, two methods are used, depending on the sensitivity desired.

With the more sensitive method, the entire sample is used. The sample is wet-ashed with hydrochloric acid and adsorbed onto an anion exchange resin. The uranium is then desorbed from the column and extracted with hexone. The uranium is back-extracted into water by evaporating the hexone. The sample is then fused with a sodium fluoride-lithium fluoride flux, and the mass is determined using fluorophotometry.

With the less sensitive method, only $100 \mathrm{ml}$ of the sample is used, and the anion exchange step is skipped.

Analyses for other radionuclides are available as indicated in Tables 6.2 through 6.6 .

Usually more than one procedure can be performed on one sample. For instance, $1 \mathrm{ml}$ of a urine sample can be extracted for tritium analysis before proceeding with any of the other analyses. Other possible combinations are plutonium and strontium, plutonium and americium/ curium, plutonium and uranium, and plutonium, strontium, and americium/curium.

\section{C.2 DIRECT BIOASSAY MEASUREMENTS}

Details concerning procedures, equipment, and data processing for direct bioassay measurements are provided in the Whole Body Counting Manual (Palmer et al. 1987). Pertinent information is provided as follows. 


\section{C.2.1 Whole Body Counts}

Initial whole body counts are performed using the preview counter, which is a standup counter using five NaI detectors. The count time is typically 200 seconds. Roughly, radioactivity can be spatially identified as emanating from the head, chest, abdomen, and legs. Most radionuclides with gamma-ray energies from about 200 to $3000 \mathrm{keV}$ can be quantified, e.g., $137 \mathrm{Cs}, 60 \mathrm{Co}$.

If a radionuclide other than $40 \mathrm{~K}$ is detected, the person is asked to shower, change into clean coveralls, and is counted using a shadow-shield, moving-bed counter with two intrinsic germanium detectors. The germanium detectors have much better photopeak resolution, which generally eliminates interferences from several radionuclides.

If skin contamination is detected, Field Dosimetry is contacted.

The detection of some radionuclides trigger additional counts. For example, detection of 137 Cs usually triggers a chest count to check on the presence of ${ }^{144} \mathrm{Ce}$.

\section{C.2.2 Chest Counts}

The presence of high-energy gamma-emitting radionuclides in the chest is determined by whole body counting. The presence in the chest of gamma- or x-ray-emitting radionuclides with energies in the range of a few tens of keV to $200 \mathrm{keV}$ is determined by chest counting. The chest counter is typically used for counting $241 \mathrm{Am}, 235 \mathrm{U}, 234 \mathrm{Th}$ (as an indicator of $238 \mathrm{U}$ ) $144 \mathrm{Ce}, 154 \mathrm{Eu}, 155 \mathrm{Eu}, 232 \mathrm{Th}$, and to a lesser extent $238 \mathrm{Pu}$ and $239 \mathrm{Pu}$.

The chest counter is an array of six germanium planar detectors placed three on each side of the lung. The person being counted is seated in a chair in a slightly reclined position. Typical counts are 1000 seconds long. but counts up to 4000 seconds can be arranged if desired.

If material is detected in the chest, then an u1trasound measurement of the thickness of the chest wall is made, and the calculated activity in the lung is corrected for the absorption of the low-energy rays in the chest wall.

When activity such as $241_{A m}$ can exist in both the lung and bone, a head count is also performed, and the apparent activity from the chest count is corrected for the contribution from the bones in the chest region. The corrected activity represents the activity actually in the lung. 


\section{C.2.3 Head Counts}

Head counts are performed to quantify the skeletal activity of low-energy $x$ - or gamma-ray-enitting radionuclides, such as $241_{\mathrm{Am}}$. The head counter consists of two germanium planar detectors placed high on the forehead. The typical count time is 3000 seconds. The results of the head count are converted to activity in the total skeleton based on the distribution of $241_{A m}$ observed in the skeleton of a total body donation to the U.S. Transuranium Registry.

\section{C.2.4 Thyroid Counts}

Thyroid counts are performed using a single 3-in. $\times 3-i n$. $\mathrm{MaI}(\mathrm{T} 1)$ detector for $131 \mathrm{I}$ and two germanium planar detectors for 1251 or $129_{1}$. The typical count time is 2000 seconds.

\section{C.2.5 Liver Counts}

Liver counts are performed using an array of three germanium planar detectors. The typical count time is 2000 seconds. This count is calibrated for $241 \mathrm{Am}$ only. The result is corrected for skeletal interference, but it is not corrected for thickness of overlying tissue.

\section{C.2.6 Wound Counts}

Wound counts may be performed at either the EDF or at the 747-A Building depending on the circumstances. For low-energy $x$ or gamma rays, a single gemanium detector is used. For contamination emitting higher-energy gamma rays, the count is usually performed at the 747-A Building with a large-volume germanium detector. The typical count time is 10 minutes. The activity of isotopes of plutonium should be considered approximate, unless the depth of the activity in the tissue is known. 


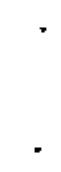




\section{APPENDIX D}

\section{SAMPLE KIT INSTRUCTIONS}




\section{SAMPLE KIT INSTRUCTIONS}

The Analytical Services Laboratory's user instructions for each of their nine sampling $k i t s$ are reproduced here in Exhibits 0.1 through 0.9 . Each of the instruction cards is printed on a different color of card stock for easy visual discrimination. The color is noted parenthetically under the exhibit title. 
Exhibit 0.1

Instructions for Kit Code 1

(Blue)

\section{INSTRUCTIONS \\ FOR ROUTINE BIOASSAY AT-HOME SAMPLING}

\section{PLEASE READ AND FOLLOW CAREFULLY}

- Check the kit for your correct name, address, and payroll number 8EFORE collecting a sampie. DO NOT USE this kit if it is not addressed to you. Please notify U.S. Testing. Blazssay Section, of any errors by phoning (509) 375-3131, ext. 39, collect; between 7:30 A.M. and 5:00 P.M.

- Please collect ALL urine during the periods one-half hour betore retiring and onehalf hour after rising for two consecutlve days. (Simulated $\mathbf{2 4}$ hour home sample.)

\begin{tabular}{|c|c|c|c|c|c|}
\hline $\begin{array}{l}\text { If XIt was } \\
\text { delivered on: } \\
\text { Monday } \\
\text { Tuesday } \\
\text { Wednesday } \\
\text { Thursday } \\
\text { Friday }\end{array}$ & 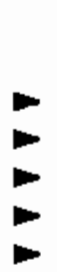 & $\begin{array}{l}\quad \text { Start } \\
\text { colligctlon on: } \\
\text { Monday } \\
\text { Tuesday } \\
\text { Wednesday } \\
\text { Saturday } \\
\text { Saturday }\end{array}$ & 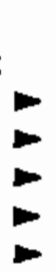 & $\begin{array}{l}\text { End collection or } \\
\text { morning of: } \\
\text { Wednesday } \\
\text { Thursday } \\
\text { Friday } \\
\text { Monday } \\
\text { Monday }\end{array}$ & $\begin{array}{l}\text { Kit will be } \\
\text { picked up } \\
\text { Wednesday } \\
\text { Thursday } \\
\text { Friday } \\
\text { Monday } \\
\text { Monday }\end{array}$ \\
\hline
\end{tabular}

- Urine passed only during the specified periods should be collected.

- Keep the bottles capped when not in use.

- Four bottles are provided in the xit. Begin with any bottle and use as many as necessary. Each bottle may be filled until approximately $1 / 4$ full.

- After flnal sampting has been completed. tighten each cap, replaca the bottles in the cardboard box and return the kit to the same place you received it.

- The bioassay sampling kit will be picked up at the same place it was dropped off on the pickup date indicated above.

U.S. TESTING CO., INC. BIOASSAY SECTION

2800 George Washington Way Alehtand. Washington 99352 
Exhibit 0.2

Instructions for Kit Code 2

(White)

\section{INSTRUCTIONS FOR TERMINATION BIOASSAY SAMPLING}

\section{PLEASE READ AND FOLLDW CAREFULLY}

- Check the klt for your correct name, address, and payroll number BefORE collecting a sample. DO NOT USE this kit if it is not addressed to you. Please notify U.S. Testlng. Bioassay Section, of any ertors by phoning (509) 375-3131, ext. 39. collect, between 7:30 A.M. and 5:00 P.M.

- Your employer has requested a final urine specimen from you to complete your individual radiation exposure history record. This is part of your employer's termination procedure.

- Please collect ALL urine passed within one-half hour of retiring on the above sample date and within one-half hour of rising.

- Keep the bottles capped when not in use.

- Four botties are provided In the kit. Begin with any bottle and use as many as necessary. Each bottle may be filled until approximately $* 4$ full.

- After final sampling has been completed, Ilghten each cap, replace the botties in the cardboard box and return the kit to the same place you received it.

- The bioassay sampling kit will be picked up at the same place it was dropped off on the pickup date indicated above. 


\section{Exhibit 0.3}

Instructions for Kit Code 3

Home Fraction

(Red)

\section{INSTRUCTIONS \\ FOR 24 HOUR TOTAL URINE SAMPLING HOME FRACTION}

\section{PLEASE READ AND FOLLOW CAREFULLY}

- Check the xit for your correct name, address, and payroll number BeforE collecting a sample. DO NOT USE this kit if it is not addressed to you. Please notily U.S. Testing, Bloassay Section, of any errors by phoning (509) 375-3131, ext. 39, collect, between 7:30 A.M. and 5:00 P.M.

- Please collect ALL urine passed from MIDNiGHT TO MIONIGHT on the above sample date. This kit is provided for home collection. A second kit may be provided for your use while at work.

- Keep the bottles capped when not in use.

- Four bottles are provided in the ktt. Begin with any bottle and use as many as

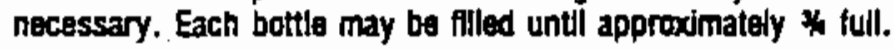

- After final sampling has been completed, tighten each cap, replace the bottles in the cardboard box and retum the kit to the same place you received $\mathrm{tt}$.

- The bioassay sampling kit will be picked up at the same place it was dropped off on the pickup date indleated above.

U.S. TESTING CO., IMC. BIOASSAY SECTION 2800 George Wasnington Way Rlohland, Wasinington 99352 
Exhibit D.3 (contd)

Instructions for Kit Code 3

Work Fraction

(Red)

\section{INSTRUCTIONS \\ FOR 24 HOUR TOTAL URINE SAMPLING WORK FRACTION}

\section{PLEASE READ AND FOLLOW CAREFULIY}

- Check the klt for your correct name, address, and payroll number BEFOAE collecting a sample. DO NOT USE this ktt if it is not addressed to you. Please notily U.S. Testling. Bloassay Section, of any errors by phoning (509) 375-3131, ext. 39, collect, between 7:30 A.M. and 5:00 P.M.

- Please collect ALL urine passed during wORKJNe hOURS on the above sample date. This kit is provided for work collection. A second kit may be provided for your use while at home.

- Keep the bottles capped when not In use.

- Four bottles are provided In the kit. Begin with any bottle and use as many as necessary. Each bottle may be filled until approximately $y_{\text {f }}$ full.

- After final sampling has been compieted, Hghten each cap, replace the bottles In the cardboard box and retum the kit to the same place you received it.

- The bioassay sampling kft wll be picked up at the same place it was dropped off on the pickup date indicated above.

U.S. TESTINE CO., INC. BIOASSAY SECTION 


\section{Exhibit D.4 \\ Instructions for Kit Code 4 \\ (Goldenrod) \\ INSTRUCTIONS \\ FOR SINGLE-VOID URINE SAMPLING}

\section{PLEASE READ AND FOLLOW CAREFULLY}

- Check the kit for your correct name and payroll number BEFone collecting a sample. DO NOT USE this kit if it is not addressed to you. Please notify U.S. Testing, Bioassay Section, of any arrors by phoning (509) 375-3131, ext. 39, collect, between 7:30 A.M. and 5:00 P.M.

- Unless you have been Instructed otherwise, please collect a single MORMAL voiding of urine in one of the bottles provided.

- Cap the bottle tightly, replace the bottle in the kit, and retum the kft to the sane place you received it.

- The kit will be picked up at the same place it was dropped off either today or tomorrow.

U.S. TESTING CO., INC. BIOASSAY SECTION

2800 George Washington Way Rtchland. Washington 99352 


\section{Exhibit D.5 \\ Instructions for Kit Code 5 \\ Front of Card \\ (White)}

Sample Date

Delivery Date

Pickup Date

\section{INSTRUCTIONS FOR COLLECTING A FECAL SAMPLE}

\section{PLEASE READ AND FOLLOW CAREFULLY}

- Check the kit for your correct name, address, and payroll number BEFORE coilecting a sample. DO NOT USE this kit if it is not addressed to you. Please notity U.S. Testing, Bloassay Section, of any problems or discrepancies in the information on the label. Phone fichland (509) 375-3131, ext. 39, collect, between 7:30 A.M. and 5:00 P.M.

- Please collect a stool specimen (fecal sample) on the above date.

- Place the equipment on your porch after sampling has been completed.

- Equipment will be recovered on the pickup date indicated above.

U.S. TESTING CO., INC. BIOASSAY SECTION 2800 George Wastington Way Rlchtand, Wastington 99352

AOOITIONAL INSTRUCTIONS ON BACK OF CARO 


\section{Exhibit D.5 (contd) \\ Instructions for Kit Code 5 \\ Back of Card \\ (White)}

\section{Directlons for use:}

1. Remove container and holder from sample kit, and rernove lid.

2. Pull up toiiet seat, place unit on bowl in center toward rear of bowl.

3. Put toilet seat on frame to hold unit in place. CAUTION: Stoot specimen must not contain urine.

4. After stool specimen has been coilected, remove plastic bag from rim of the container and foid over the stool sample. Replace cover and return to sample box. 


\section{Exhibit 0.6 \\ Instructions for kit Code 6 \\ (Yellow) \\ INSTRUCTIONS \\ FOR SPECIAL URINE SAMPLING}

\section{PLEASE READ AND fOLLOW CAREFULLY}

- Check the kit for your correct name, address, and payroil number BEFORE collecting a sample. DO NOT USE this kit if it is not addressed to you. Please notify U.S. Testing, Bioassay Section, of any errors by phoning (509) 375-3131, ext. 39, collect, between 7:30 A.M. and 5:00 P.M.

- UNLESS YOU HAVE BEgY INSTAUCTED OTHERWISE, please collect All urine passed within one-half hour of retiring on the above sample date and within onehalf hour of rising.

- Keep the bottles capped when not in use.

- Four bottles are provided in the kit. Begin with any bottle and use as many as necessary. Each bottle may be filled until approximately \$/ $_{4}$ full.

- After final sampling has been completed, tighten each cap, replace the bottles in the cardboard box and retum the kit to the same place you received it.

- The bioassay sampling kit will be picked up at the same piace it was dropped off on the pickup date indicated above.

U.S. TESTING CO., INE. BIOASSAY SECTION

2800 George Washington Way PJehland, Wasningten 99352 


\section{INSTRUCTIONS FOR SOLUBLE URANIUM IN URINE SAMPLING .}

\section{PLEASE READ AND FOLLOW CAAEFULLY}

Routine collection and analysis of urine sampies is an important part of the radiation dosimetry program for indlviduals working with soluble uranium. Therefore, it is requested that you read and carefully follow the instructlons below.

- Check the kit for your correct name, address, and payroll number BEFORE collecting a sample. BO NOT USE this kit if it is not addressed to you. Please notthy U.S. Testing. Bioassay Section, of any errors by phoning (509) 375-3131, ext. 39. collect, between 7:30 A.M. and 5:00 P.M.

- Please collect ALL urine excreted within ono-half hour before retiring on Sunday evening and one-half hour after rising on Monday morning.

- Keep the bottles capped when not in use.

- Four bottles are provided in the kit. Begin with any bottle and use as many as

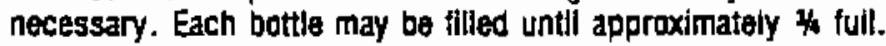

- After final sampling has been completed, please place all bottles, whether used or not, into the cardboard carrer and refold the handle to close the box.

- Your kit will be picked up on Monday morning from the same place where it was delivered. Be sure to leave your kit ostside where it an bo picked up on Monday morning.

\section{U.S. TESTING CO., INC. BIOASSAY SECTION 2800 George Washington Way Fichland. Washington 99352}


Exhibit 0.8

Instructions for Kit Code 8

Front of Card

(Peach)

\section{INSTRUCTIONS \\ FOR COLLECTING A FECAL SAMPLE}

\section{IMPORTANT: IF POSSIBLE, DO NOT USE UNTIL 24 HOURS AFTER LEAVING WORK PLACE.}

- Check the kit for your correct name, address, and payroll number BEFOAE collecting a sample. DO NOT USE this kit if it is not addressed to you. Please notity U.S. Testing, Bioassay Section, of any problems or discrepancies in the information on the container. Phone Richiand (509) 375-3:131, ext. 39, collect, between 7:30 A.M. and 5:00 P.M.

- Please collect specimen (fecal sample), foilowing the instructions given bélow.

- Place the equipment on your porch atter final sampling has been campleted.

- Equipment will be recovered on the pickup date.

Check time out of zone:

Less than 1 day

$1-3$ days

More than 3 days

\section{ADDITIONAL INSTRUCTIONS ON BACK OF CARD}




\section{Exhibit D.8 (contd) \\ Instructions for Kit Code 8 \\ Back of Card \\ (Peach)}

\section{Directions for usa:}

1. Remove container and holder from sample kit, and remove lid.

2. Pull up toilet seat, place unit on bowl in center toward rear of bowl.

3. Put toitet seat on frame to hold unit in place. Cauflon: Stool specimen must nof contain urine.

4. After stool specimen has been collected, remove plastic bag from rim of the container and fold over the stool sampie. Replace cover and return to sample box.

U.S. TESTING CO., INC. BIOASSAY SECTION

2800 George Washngton Way Ricnland, Washington 99352 
Exhibit 0.9

Instructions for Kit Code 9

(White)

INSTRUCTIONS FOR TERMINATION FOLLOW-UP SAMPLING

PLEASE READ AND FOLLOW CAREFULLY

1. Discard the outer box. Write the start date here:

2. Please collect ALL urine while at home until all bottles are used.

3. Three bottles are provided in the kit. Begin with any bottle and fill each bottle at least to the fill line but not higher than the bottle neck.

4. Keep the bottle capped when not in use.

5. After final sampling has been completed, recheck each cap for tightness. Replace the bottles in the cardboard box with the instruction care. Seal the box by moistening the gummed surface of the tape provided and centering over the box closure.

6. Return the package to U.S. Testing by calling Airborne Express at and requesting a package pickup with the changes to be paid by the receiver. Airborne can pickup the package at either your home or workplace. You may also go to a U.S. Post Office and ship the package COD. Third class.

7. If you have any questions please call U.S. Testing, Bioassay Section, at (509) 375-3131, ext. 39, collect, between 7:30 a.m. and 5:00 p.m.

U.S. TESTING CO., INC.: BIOASSAY SECTION 


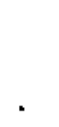


INDEX

$\checkmark$ 
INDEX

(Note: Referenced numbers refer to manual sections, not pages.)

analytical support lab

analytical and reporting requirements, Tables 6.1 through 6.6

services of, 6.1

summary of analytical procedures, Appendix $C .1$

bioassay

beginning and ending work, 5.1.6

capability, 5.1

criteria, 2.3, 5.1

long-term follow-up, 5.1 .5

offsite, 5.1 .7

plutonium, 5.3.4

reconmendations for, $3.2 .1,5.1$

uranium, 5.3.3

bioassay measurements

contractual detection level (CL), 6.1, 6.4.1, Tables 6.1 through 6.6 external contamination and, 7.6.1

follow-up levels, Appendix A

in vivo minimum detectable activities, Tables 6.7 and 6.8

reporting levels, 6.3.3, 6.3.5, 6.4.1, 6.4.2

results letters, 6.4.1, 6.4.2, Exhibits 6.3 through 6.5

scheduling indirect measurements, 6.3.2

scheduling in vivo measurements, 6.3.4

screening levels, 6.4.1, 6.4.2, Appendix A, Tables A.1 and A.2

bioassay program design

criteria for monitoring workers, 5.1

design goal, 2.3

example programs, Table 5.4

frequency of measurements, 5.3

selection of nuclides, 5.2

undetected dose for measurements, Table 5.3

biokinetic models, 3.3.6

chronic exposure, 5.1.1

computer codes, 3.3.7

confirmation of intake, 2.1.1

dose assessments

assumptions used for, 2.1.2, 3.3

criteria for performing, 2.1.1, 3.1.1, Table 3.1

documentation of, 2.1.3, 3.2.2, 4.1

investigation, 3.2.1,

methods, 3.3, 2.1.2, 3.1.2, 3.3.1

official record of, 4.1 
process of, Figure 3.1

reports, 2.2, 3.2.2, 3.2.3

revisions to, $2.1 .4,2.1 .4$

simplified, 3.3 .8

situations warranting, 3.1.4, Table 3.1

types of, 3.1.2

evaluation number, 3.2 .2

evaluations of internal exposure

- see dose assessments

exposure evaluator (EE)

how to contact, 7.4

services available, 7.2

when to contact, 7.3

incidents

bioassay measurements for, 7.5.2, Table 7.3, Table 7.4

final dose assessment, 7.5.3

need for dose assessment, 2.1.1, 7.0

preliminary dose assessment, 7.5.3

release of workers following, 7.6.4

therapy for dose reduction, 7.6.3

indicator radionuclides, $\mathbf{5 . 2}$

internal dose

annual report card, 4.3

database, 4.2

records, 4.1

reports, $4.1,4.3$

requests for, 4.4

INTERTRAC, 4.2

in vivo measurements

sumbary of procedures, Appendix C (C.2)

levels

contractual detection, 6.1, Tables 6.1 through 6.6

follow-up, Appendix A

in vivo minimum detectable activity, Tables 6.7 and 6.8 reporting, $6.3 .3,6.3 .5,6.4 .1,6.4 .2$

screening, 6.4.1, 6.4.2, Appendix $A$, Tables A.1 and A.2

multiple radionuclides, 5.1, 5.1.1, 5.1.3

Occupational Radiation Exposure (ORE) System

computer report screens and codes, Appendix B

request for internal dosimetry records, 4.4

potential intake fractions, 5.1.3, Table 5.2 
quality assurance, 8.0

analytical services laboratory, 8.1.1, 8.1.2 dose assessments, 8.2

IDP progran change records, 9.3.1

IDP records, 9.0, 9.1, 9.2, 9.3

in vivo measurements, 8.1 .3

reports to contractors, 2.2.1

reports to Radiological Records, 2.2 .2 

PNL -7001

UC -607

\section{DISTR1BUTION}

No. of

Copies

\section{OFFSITE}

2 DOE/Office of Scientific and Technical Information

S. C. Baker

Rocky Flats Plant

Rockwell International

P.0. Box 464

Golden, CO 80402-0464

J. S. Bogard

Oak Ridge National Laboratory

P.0. Box $X$

Building 4500-S, MS 105

0ak Ridge, TN 37831

R. J. Brake

Radiation Protection Group, $\mathrm{K}-483$

Los Alamos Nationa1 Laboratory

Los Alamos, NM 87545

J. Broadway

U.S. Environmental Protection Agency

Eastern Environmenta? Radiation Facility

P.0. Box 3009

Montgomery, AL 36109

L. L. Collins

Badcock and Hilcox

NNFRO-RL

P.0. Box 11165

Lynchburg, VA 24506

H. D. Fairman

Argonne National Laboratory

Building 200

9700 S. Cass Ave.

Argonne, IL 60439
No. of

Copies

R. B. Falk

Rocky Flats Plant

Rockwe 1$\}$ Internationa?

P.0. Box 464

Golden, CO 80402

D. Frazier

Martin Marietta Energy Systems

MS-7155

P.0. Box 2003

Oak Ridge, IN 37831-7155

R. L. Germain

Safety Representative

USEPA Region 8

g9g 18th St. Suite 500

Denver, CO 80202-2405

R. H. HaIl

Bldg. 735-A

Savannah River Plant

Aiken, SC 29801

R. W. Keys III

Fernald

Westinghouse Materials Company of Ohio

P.0. Box 398704

Cincinnati, $\mathrm{OH} 45239$

T. R. LaBone

Bldg 735-A

Savannah River Plant

Aiken, SC 29801

J. N. P. Lawrence

Los Alamos National Laboratory

HSE-1 MS-K483

Los Alamos, NM 87545 
No. of

Copies

E. T. Lessard

Safety and Environmental Protection Division

Building 535-A

Brookhaven National Laboratory

Upton, Long Island, NY 11973

G. Mansfield

Lawrence Livermore Laboratory

P.0. Box 5505

MS L-394

Livermore, CA 94550

D. R. Nelson EH 331.2

Radiological Controls

Division

Office of Nuclear Safety

U.S. Department of Energy

Washington, DC 20545

C. Pugh

Martin Marietta Energy Systems

B1dg. K1005, MS-7257

P.0. Box 2003

0ak Ridge, TN 37831-7257

T. Rucker

Science Applications International Corp. P.0. Box 2501

Oak Ridge, TN 37381

Prof. K. Skrable

Department of Physics

University of Lowe11

Lowe 11, MA 01854

C. Sun

Brookhaven National

Laboratory, Bldg. 703M

Upton, NY 11973
No. of

Copies

P. Szalinski

West Valley Nuclear Services Co.

P.0. Box 191

West Valley, NY 14171-0191

M. Thein

P.0. Box X. 4500S, MS105

Oak Ridge Mational Laboratory

Oak Ridge, TN 37831-6105

J. Tirpak

Bettis Atoric Power Laboratory Westinghouse Electgric Corp.

P.0. Box 79

West Mifflin, PA 15122

R. E. Toohey

Argonne National Laboratory

9700 S. Cass Avenue

Argonne, IL 60439

A. N. Tschaeche

Westinghouse Idaho

Nuclear Company

P.0. Box 4000

Idaho Falls, ID 84303

P. Webb

Lawrence Livermore National Laboratory

MS-L390

P.0. Box 808

Livermore, CA 94550

Chuan-Fu Wu

WIPP Project

Westinghouse Electric Corp.

P.0. Box 2078

Carlsbad, NM 88221-2078

ONSITE

Westinghouse Hanford Company
A. L. Aldridge R3-20 
No, of

Copies

51 Pacific Northwest Laboratory
D. E. Bihl
A3-60
E. H. Carbaugh (35) A3-60
S. K. Ennor
D. R. Fisher
A3-60
J. R. Johnson
$\mathrm{K} 3-57$
J. B. Martin
$\mathrm{K} 3-53$
P. C. Olsen
$\mathrm{K} 3-60$
J. D. Peters
K3 $3-60$
J. M. Selby
P7-01
M. L. Sula
K3-60
R. J. Traub
A3-60
Hanford Radiation Protection Historical Files
Health Physics Department Library
Technical Report Files (3)
Publishing Coordination 


.

. 